Sādhanā Vol. 39, Part 1, February 2014, pp. 221-266. (C) Indian Academy of Sciences

\title{
Effect of geological medium on seismic signals from underground nuclear explosion events - A case study for Baneberry site
}

\author{
R K SINGH*，S K SIKKA and ANIL KAKODKAR \\ Bhabha Atomic Research Centre, Trombay, Mumbai 400 085, India \\ email: rksingh@barc.gov.in; rksingh175@ rediffmail.com
}

MS received 7 June 2012; revised 1 August 2013; accepted 16 August 2013

\begin{abstract}
Seismic signals due to any underground nuclear explosion events are known to be influenced by the local geology of the test site and the yield level. In this paper, transient three-dimensional finite element code SHOCK-3D developed for the simulation of underground nuclear explosion events has been used to obtain synthetic acceleration signals for Baneberry site (Nevada) single and composite rock media. At this site an underground nuclear test of $10 \mathrm{kT}$ conducted on 18th December 1970 at source depth of $278 \mathrm{~m}$ resulted into venting as reported by Terhune et al with 2D simulation results and later by us through 3D simulation in Ranjan et al. First, the reasons of the venting for this event are summarized. After the successful validation of the 3D numerical model for Baneberry site rock media, parametric studies are carried out for 1 and $8 \mathrm{kT}$ yields at $100 \mathrm{~m}$ depth (Scaled Depths of Burst SDOB 100 and $50 \mathrm{~m} / \mathrm{kT}^{1 / 3}$, respectively) for homogeneous and composite Paleozoic and Tuff media of Baneberry site. It is demonstrated that the near source local geological formations and associated nonlinear effects significantly influence the seismic signals. With this study the seismic decoupling of the source by an order of magnitude has been illustrated. Finally, it is concluded that the seismic signals alone, in the absence of in-depth information of the local geology of the specific test site, are not appropriate measures of the source strength.
\end{abstract}

Keywords. Underground nuclear explosion; transient finite element; fluid-structure interaction; Baneberry event; nuclear yield estimation; nuclear event discrimination.

\section{Introduction}

Earlier numerical simulation of Pokharan-1, 1974 peaceful nuclear explosion (PNE) event was carried out to benchmark our in-house 3D finite element fluid-structure interaction SHOCK-3D code predictions as reported by Ranjan et al (2005). The capabilities of our code SHOCK-3D

*For correspondence 
for coupled gas cavity growth, chimney formation, cavity collapse, mound and crater transient and quasi-static simulation in rock media along with near field shock wave and far field seismic signal propagation has been illustrated. In addition, another validation example of Baneberry 1970 underground nuclear explosion test at Nevada site has also been investigated by us, in Ranjan et al (2006). This event is reported to have vented due to existing double fault system and hard Paleozoic layer beneath the source along with presence of clay-rich Tuff medium near the working point resulting into significant energy reflection towards ground zero and thus assisting the sliding along the pre-existing fault plane. Our 3D simulation results for Baneberry 1970 event have been benchmarked with published site observations and 2D computational results as reported by Terhune et al $(1977,1979)$. This has been the first successful 3D simulation of underground nuclear explosion event in a composite media with faults and complex geological strata and could explain the Baneberry venting mechanism due to sliding along the fault plane and also could confirm the crater size in the quasi-static simulation. Further studies carried out for Nevada test site uniform Paleozoic and Tuff media along with a number of composite media show that the near field ground signals and the far field seismic signals due to underground nuclear explosion events have large uncertainty. Despite claims of improved instrumentation and data collection from a large number of seismic stations, the nuclear events cannot be discriminated with respect to earthquake events and yield determination has still a larger uncertainty in absence of information on local geological media, the propagation path and the geological conditions at the monitoring stations.

For an underground nuclear explosion event, local geological factors such as constitutive mechanical and thermo-physical properties of local geological media, extent of inelastic crushed zones, cracking and resultant spallation of composite layers influence the seismic signals radiated from the source. In addition, the presence of composite layered media, existing geological faults, in situ stresses and tectonic strains, location of the free surface with respect to the source and the initial cavity size are also known to alter the seismic signals at the elastic radius that are further propagated and are sensed by the network of seismic stations. In addition, the teleseismic signals are also dependent on the anelastic properties of the earth media along its propagation path and finally on the local geology around the monitoring station. The effects of near source local geological factors that influence the seismic signals have been studied with threedimensional transient finite element code SHOCK-3D. In the present paper, a set of parametric studies for Paleozoic and Tuff rock uniform and composite media of Baneberry site are presented to highlight its influence on the seismic signals that are generated due to underground explosion events. Three-dimensional transient numerical simulation of the coupled gas cavity and geological media problem is complex due to the presence of large deformation and large strain of the media and the high strain rate dependence of the response. However, it is important to establish the effect of local inelastic and nonlinear behaviour of the geological media on the shock waves near the source and the seismic signals beyond the elastic radius. This study would help to estimate the limitations of seismic networks for detecting any event with requisite confidence. In addition, it may also be used to estimate the uncertainties that are present in the yield estimation in the absence of indepth information of the local geology of the test site.

Seismic decoupling and source region heterogeneities remain major limitations in verifying any underground nuclear explosion as described by Glenn (1984). Event identification and yield determination from the seismic signals alone have a number of uncertainties. This is due to very low fraction of seismic energy $(<0.01-2 \%$ of the source strength) that is propagated and is available for monitoring. This wide band of seismic energy is dependent on the coupling efficiency of the near source medium and is also a function of a number of variables described earlier. Besides, the site-specific geological formations and the local nonlinear processes also influence 
the seismic signals. Various theories regarding cavity decoupling have been proposed. Haskell (1961), Herbst et al (1961), Werth \& Herbst (1963), Latter et al (1961), Larsen (1979) and Patterson (1966) have significant contributions in this area. Haskell (1961) proposed a staticequilibrium theory applying Mohr-Coulomb yield condition for inelastic zone and obtained reasonable agreement with observations of Project Cowboy and Project Rainier of United States test programs. Latter et al (1961) studied the plastic response of the cavity wall on decoupling of the explosion using analytical equations in frequency domain.

Herbst et al (1961) used data from Project Cowboy to demonstrate decoupling for high chemical explosive events. Patterson (1966) used one-dimensional hydrodynamic numerical computer code using spherical symmetry to calculate Reduced Displacement Potential (RDP) and decoupling ratio to correlate the results with Project Dribble events viz., Salmon and Gnome. In this work, the results have been compared with site data from tamped and decoupled explosions. Further results to illustrate the potential use of large cavities and cavities of various shapes and sizes for decoupling and masking the effects of underground nuclear explosions have been given by Glenn (1984) and Glenn et al (1985). Seismologists have put forward various theories based on elasto-dynamic equations and integral representation theorems to illustrate the explosion phenomenology to define the seismic source functions. A number of models have been used to represent the source, taking into account the tectonic release due to explosion-induced cracking, and to generate the synthetics thereafter, employing analytical and numerical methods. Harkrider (1964), Mueller \& Murphy (1971) and Bache et al (1982) have proposed methods based on wave propagation theories to simulate the seismic effects related to underground explosions. Near source geology, resulting phenomena like tectonic release due to explosion-induced cracking and near free surface spall influence the spectral content of the seismic waves in the elastic region. Taylor \& Randall (1989) demonstrated the effects of spall on the regional signals using synthetic seismograms below $20 \mathrm{~Hz}$ frequency range. His results are based on regional spectral discrimination studies for Nevada Test Site (NTS) explosions and Western United States earthquakes. The frequency range and strength of the spall effect depend in a complicated manner upon yield, depth of burial, near source structure and material strength. As an example to describe the uncertainty in yield prediction, Bolt Bruce (1976) reports about the ambiguity associated with body wave magnitude $\mathrm{m}_{\mathrm{b}}$ value recorded at Eskdalemuir station in Scotland. For Bilby event of $235 \mathrm{kT}$ yield (Sep. 13, 1963, Nevada site) and Scaled Depth of Burst (SDOB) $115.8 \mathrm{~m} / \mathrm{kT}^{1 / 3}$ in Tuff medium with hard Paleozoic layer at $968 \mathrm{~m}$ depth the station recorded $\mathrm{m}_{\mathrm{b}}$ value of 5.5. The same station for Gasbuggy event of $29 \mathrm{kT}$ yield (Dec. 10, 1967, New Mexico) with SDOB $\sim 420.6 \mathrm{~m} / \mathrm{kT}^{1 / 3}$ in shale medium recorded comparable $\mathrm{m}_{\mathrm{b}}$ value of 5.3 though the respective yields had a ratio of 8.6.

The influence of inelastic processes; such as crushing and cracking of rock media, cavity growth and its collapse, tension-induced spalling of rock layers on the seismic signals has been described by Rodean (1980). He describes the forward problem starting with explosive detonation, propagation of shock waves in the inelastic medium, further propagation of elastic/anelastic waves to the monitoring location. It has been remarked that due to local geology the seismic signal amplitudes may change by an order of magnitude. Further, a large cavity causes decoupling of the source from the medium and the seismic amplitude may change by two orders of magnitude. This is due to rapid attenuation of the inelastic waves in air or weaker rock media with low shear strength that behaves almost like fluid. The forward problem is amenable to analysis and seismic signals can be predicted beyond the elastic radius with good accuracy. The factors that influence the signals at the elastic radius are the local geological formations, porosity, water content, in situ stresses and pre-existing tectonic strains. These must be included in the numerical model for the specific sites. The inverse problem of event identification, discrimination and yield 
determination is rather difficult even if the signals are available from a number of stations. With the knowledge of the local geology, the inverse problem can only be traced utmost to the elastic radius. Rodean (1980) has further described the forward problem of seismology that is amenable to a mathematical solution beginning with detonation at the source and ending with synthetic seismogram. The inverse problem can also be analyzed by inverting the recorded seismic data to obtain an equivalent elastic source, but it cannot extend backward in space and time into the nonlinear process of detonation. The inverse problem is thus ill-posed and any attempt to describe the source strength would have inherent limitation. Hence the RDP is only a description of an equivalent elastic source for the inverse problem and it does not contain definite information about the source strength.

The present paper highlights three-dimensional finite element numerical simulations of underground nuclear explosion events with code SHOCK-3D. Case studies in homogeneous and heterogeneous media are presented and synthetic seismic signals are generated beyond the elastic radius where the inelastic effects such as cracking, crushing or instability mechanisms are absent. Although the inelastic processes are localized around the cavity but the effect of these inelastic processes on the synthetic time signal amplitudes is significant. Seismic decoupling due to weak medium and composite layer pattern is demonstrated with above numerical examples. For all the test examples the Baneberry site rock media have been used.

The important inputs to analyze the problem are the source strength, rock dynamics properties describing the constitutive relations and Hugoniot equation of state for different rock layers. It is important to model the geological layers appropriately to pick up the shock wave reflections from the layer interfaces formed by different rock types and the free surface at ground zero. To analyze the problem for a longer duration Sommerfeld (1949) radiation boundary conditions are applied at the surfaces that are beyond the elastic radius from the source to avoid any spurious reflection from the numerical model boundary. In addition, the influence of gravity is included to simulate the free fall of the rising mound. This helps to estimate the impact or slap down effects of the spalled rock layers on the seismic signals. Further, a few parametric case studies are presented where it is demonstrated that the location of the source in soft or hard medium, composite pattern of the different geological layers strongly influence the seismic signals recorded beyond the elastic radius. These signals that are further propagated and sensed by seismic networks thus have inherent uncertainties due to local geological formations. The teleseismic signals are only a measure of some 'equivalent source strength' at the elastic radius and the inverse problem cannot be traced up to the source from the recorded signal data alone.

\section{SHOCK-3D - A transient coupled fluid-structure interaction finite element code for underground nuclear explosion events}

SHOCK-3D is an explicit, transient three-dimensional Lagrangian finite element code developed by us earlier for shock wave propagation problems. This three-dimensional code adopts the numerical models due to Cherry \& Petersen (1970), Schatz (1973) and Burton et al (1975) in an efficient 3D finite element formulation for underground explosion simulation. It couples strain rate dependent elasto-viscoplastic formulation for geological media with the hydrodynamic formulation to represent the gas cavity with an equation of state. The optimum computational efficiency and accuracy are achieved with tri-linear Gaussian integration rule for eight-noded isoparametric brick elements. In addition, appropriate viscous dissipation terms are used for both the domains to capture the shock front accurately. Detail theoretical description of this 
code is available in Ranjan et al $(2005,2006)$. For completeness a very brief description of the constitutive models for rock media and gas cavity is presented in this paper again.

\subsection{Constitutive models in code SHOCK-3D}

The fluid-structure interaction code SHOCK-3D with explicit transient formulation is finite element based, where in the two field problem of the rock media and explosion induced gas cavity are coupled to analyze the underground explosion problems. For the explosion-induced gas cavity non-viscous hydrodynamic formulation based fluid elements with limited overburden pressure are used to correlate the pressure $(\mathrm{p})$ with volumetric strain $\left(\varepsilon_{\mathrm{V}}\right)$ and specific energy $(\mathrm{E})$. The general form of this equation for the cavity gas is given as:

$$
\mathrm{p}=\mathrm{a}_{1}+\mathrm{a}_{2}\left(\varepsilon_{\mathrm{v}}\right)+\mathrm{a}_{3}\left(\varepsilon_{\mathrm{v}}\right)^{2}+\mathrm{a}_{4}\left(\varepsilon_{\mathrm{v}}\right)^{3}+\left[\mathrm{a}_{5}+\mathrm{a}_{6}\left(\varepsilon_{\mathrm{v}}\right)+\mathrm{a}_{7}\left(\varepsilon_{\mathrm{v}}\right)^{2}\right] \mathrm{E} .
$$

The above equation is used to obtain $\mathrm{p}$ as a polynomial function depending on the volumetric strain and hence the ideal gas model/iron gas model as given by Butkovich $(1967,1973)$ or any other suitable experimental model can be generated.

The constitutive model for the geological medium due to Hoek \& Brown (1998) for the different rock strata accounts for the confinement effect on the rock strength. Damage mechanics based failure models are used depending on the strain levels for quasi-brittle and ductile failures. The Hugoniot equation of state at high shock pressures and hydrostatic data for different rock media for reported simulation studies similar to Butkovich (1973) and Burton et al (1975) has been used in the present code. The loading and unloading bulk modulii in the different regimes such as the mean pressures corresponding to the maximum tensile and compressive stresses of the rock medium at zero confinement describing the Hugoniot elastic limits, hydrostatic pressure range and high pressure shock range are evaluated for different rock media. The equation of state for the rock media is represented as:

$$
\mathrm{p}=\mathrm{K}\left(\varepsilon_{\mathrm{v}}\right)+\Gamma\left(\varepsilon_{\mathrm{v}}\right) \mathrm{E}
$$

where $\mathrm{p}$ is the hydrodynamic pressure, the local bulk modulus, $\mathrm{K}\left(\varepsilon_{\mathrm{v}}\right)$, is obtained from Hugoniot equation of state depending on the loading or unloading condition, $\varepsilon_{\mathrm{V}}$ is the volumetric strain, $\mathrm{E}$ is the specific energy and $\Gamma$ is the Gruneisen parameter which allows dissipation of energy and is a function of volumetric strain.

The strain rate dependent model of the code SHOCK-3D has been formulated with the modified form of classical elasto-viscoplastic constitutive theory, which accounts for strain-rate sensitivity with allowance for progressive degradation of strength. In view of the limitations of the classical elasto-plastic and elasto-viscoplastic models to deal with rate and history dependent problems for transient shock and dynamic loadings the visco-plastic strain rate is defined as a function of elastic strain/stress rate. In addition, the damage due to the viscoplastic flow is monitored with the help of a variable strength limit surface. The yield surface defines the onset of viscoplastic flow and the strength limit surface defines the initiation of material degradation and these are represented with the help of first stress and second invariants of deviatoric stresses. A constant failure strain based criteria is used in this model irrespective of the strain rate. Thus, the present viscoplastic constitutive model of the code SHOCK-3D retains all the important features of rate dependent inelastic behaviour along with the equation of state which characterize the rock behaviour in the different regimes of shock loading, 
The overburden simulation is important for the accurate simulation of transient problem of underground explosion event since the rising mound is finally settled due to fall back induced by gravity forces. This feature is accounted with the simulation of the initial stress field due to the overburden.

The sets of transient semi-discrete set of simultaneous equations resulting from finite element discretization for rock media and gas cavity are solved with explicit time integration scheme, which are represented as:

$$
\mathbf{M a}^{\mathrm{t}}+\mathbf{C} \mathbf{v}^{\mathrm{t}}+\mathbf{S}^{\mathrm{t}}\left(\mathbf{d}^{\mathrm{t}}\right)=\mathbf{F}^{\mathrm{t}}
$$

Here $\mathbf{M}$ is the diagonal mass matrix, $\mathbf{C}$ is the damping matrix and $\mathbf{S}^{\mathrm{t}}\left(\mathbf{d}^{\mathrm{t}}\right)$ and $\mathbf{F}^{\mathrm{t}}$ are the internal and external force vectors, respectively. The vectors $\mathbf{a}^{\mathbf{t}}, \mathbf{v}^{\mathbf{t}}$ and $\mathbf{d}^{\mathrm{t}}$ denote the acceleration, velocity and displacement vectors, respectively, at time $t$ (denoted in the superscript). The central difference time marching scheme with time step $\Delta \mathrm{t}$ is used to integrate the above set of equations as shown in Eqs (4-6).

The acceleration field $\mathbf{a}^{\mathrm{t}+\Delta \mathrm{t}}$ is obtained as:

$$
\mathbf{a}^{\mathrm{t}+\Delta \mathrm{t}}=\mathbf{a}^{\mathrm{t}}=\mathbf{M}^{-1}\left[\mathbf{F}^{\mathrm{t}}-\mathbf{C} \mathbf{v}^{\mathrm{t}}-\mathbf{S}^{\mathrm{t}}\left(\mathbf{d}^{\mathrm{t}}\right)\right] .
$$

Further the velocity field $\mathbf{v}^{\mathrm{t}+\Delta t}$ is obtained as:

$$
\mathbf{v}^{\mathrm{t}+\Delta \mathrm{t}}=\mathbf{v}^{\mathrm{t}}+\mathbf{a}^{\mathrm{t}+\Delta \mathrm{t}} \Delta \mathrm{t}
$$

Finally, the displacement field $\mathbf{d}^{\mathrm{t}+\Delta \mathrm{t}}$ is updated as

$$
d^{t+\Delta t}=d^{t}+\mathbf{v}^{t+\Delta t} \Delta t
$$

The displacement and velocity fields updated by Eqs (5-6) are used to obtain the strains and strain rates at the numerical integration gauss points. The internal stress field is incremented at each time step depending on the stress rate. It is correlated with the Jaumann stress rate, which in turn is strain rate dependent. The internal force vector $\mathbf{S}^{t+\Delta t}\left(\mathbf{d}^{\mathrm{t}+\Delta t}\right)$ is updated from the internal stress field $\sigma^{\mathrm{t}+\Delta \mathrm{t}}$ over the model domain $\Omega$ for subsequent time step computations as:

$$
\mathbf{S}^{\mathrm{t}+\Delta \mathrm{t}}\left(\mathbf{d}^{\mathrm{t}+\Delta \mathrm{t}}\right)=\int_{\Omega} \mathbf{B}^{\mathrm{T}} \sigma^{\mathrm{t}+\Delta \mathrm{t}} \mathrm{d}^{\prime} \Omega .
$$

The damping matrix $\mathbf{C}$ is generated with Sommerfeld (1949) radiation condition to simulate a non-reflecting boundary as described in Zienkiewicz et al (1977) and Zienkiewicz \& Taylor (1991) to avoid any spurious reflection from the model boundary with normal and tangential directions as $\mathrm{n}$ and $\mathrm{t}$, respectively as follows:

$$
\begin{gathered}
\sigma_{\mathrm{n}}=\rho \mathrm{c}_{\mathrm{b}} \mathrm{v}_{\mathrm{n}}, \\
\sigma_{\mathrm{t}}=\rho \mathrm{c}_{\mathrm{s}} \mathrm{v}_{\mathrm{t}} .
\end{gathered}
$$

Here $\sigma_{\mathrm{n}}$ and $\sigma_{\mathrm{t}}$ are normal and tangential stresses, $\mathrm{v}_{\mathrm{n}}$ and $\mathrm{v}_{\mathrm{t}}$ are the normal and tangential components of the particle velocity at the mesh boundary, $\rho$ is the medium density and $\mathrm{c}_{\mathrm{b}}$ and $\mathrm{c}_{\mathrm{s}}$ are the body wave and shear wave velocities for the medium. These conditions are applied sufficiently away from the source where plane elastic wave conditions exist, in which case the wave speeds are constant. 


\subsection{SHOCK-3D benchmarking for Baneberry event (1970)}

The Baneberry event of 18th December 1970 conducted at Nevada test site with shot depth of $278 \mathrm{~m}$ and yield of $10 \mathrm{kT}$ (SDOB $\sim 129.3 \mathrm{~m} / \mathrm{kT}^{1 / 3}$ ) vented as reported by Terhune et al (1977, 1979). At such a large SDOB, in normal circumstances it should have been a fully contained explosion. However, it vented due to the establishment of a fracture path owing to the presence of Baneberry fault, dipping 59-68 within $\sim 45 \mathrm{~m}$ from the source, in a layered system of Paleozoic, Tuff and Alluvium rock strata as shown in figure 1a. This hard Paleozoic rock beneath a partially

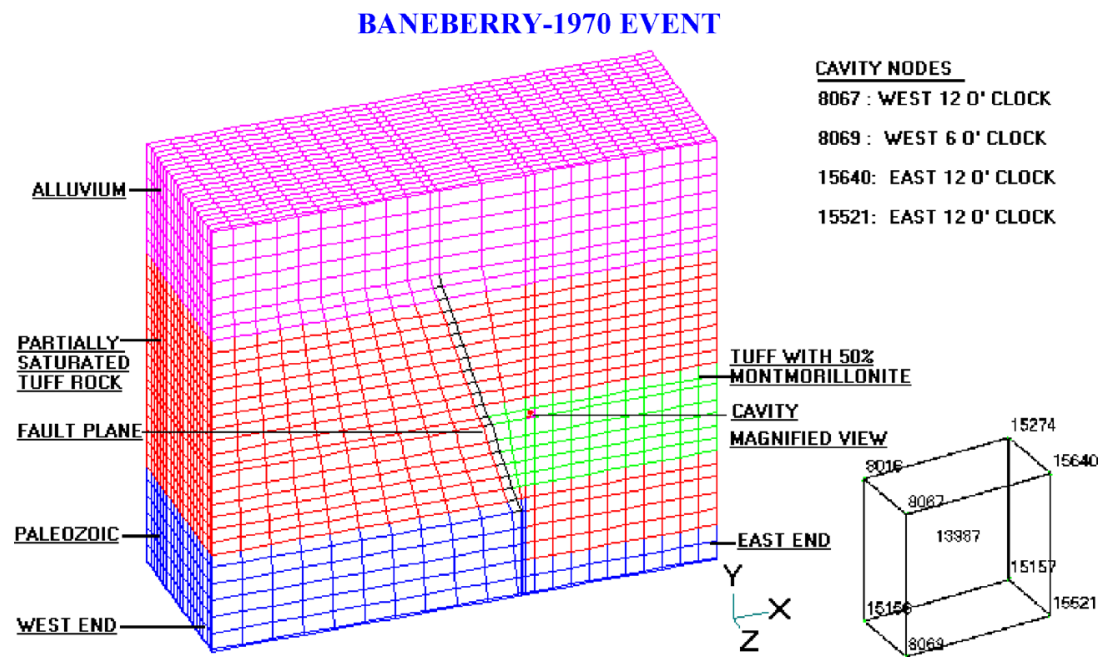

(a)

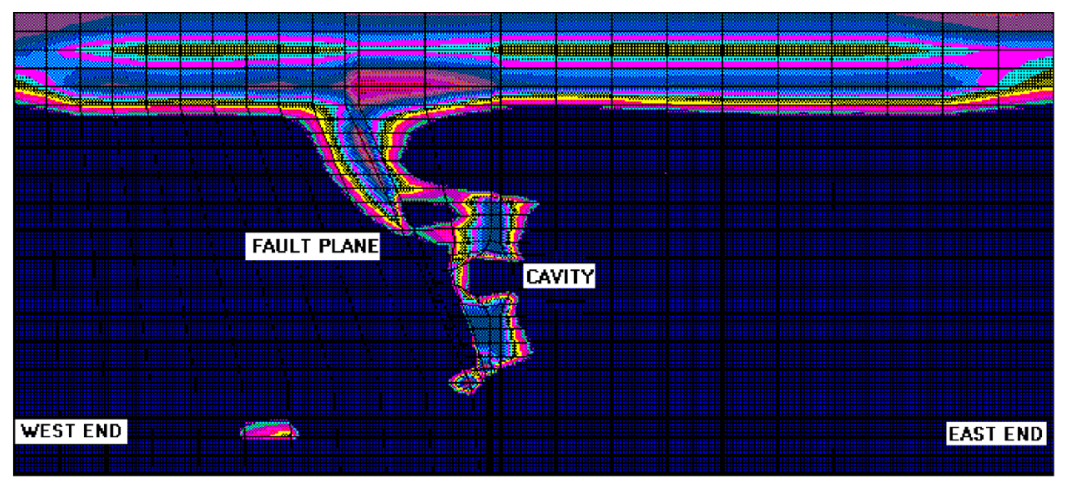

MAXINUM PRINCIPAL STRESS (Pa) CONTOURS AT 0.1 SEC

4000000. 2110000. 220000. -1670000 . -3560000 . -5450000 . -7340000 .

(b)

Figure 1. (a) 3D FEM half symmetry model (southern quadrant) with layered rock media, fault, location and nodal description of source fluid element (enlarged view) for $10 \mathrm{kT}$ Baneberry event. (b) Maximum principal stress $\left(\mathrm{N} / \mathrm{m}^{2}\right)$ at $0.1 \mathrm{~s}$ for $10 \mathrm{kT}$ Baneberry event. 
saturated Tuff medium on the west side was located closer to the source (within 80-90 m) due to tectonic displacement induced in the past by the pre-existing fault system. The emplacement of the source in the weaker tuffaceous medium (50\% montmorillonite) with the main Baneberry fault and top alluvial cover and strong reflections from the near source Paleozoic medium on the west side resulted in sliding and rupturing up to the free surface leading to venting. The field and post shot observations as well as evaluation of the cavity growth, mound formation, cratering and other aspects of the close in ground motion for this event along with an axi-symmetric numerical analysis has been reported earlier by Terhune et al $(1977,1979)$. We have successfully simulated and reported this event in Ranjan et al (2006) within a three-dimensional framework to benchmark our code SHOCK-3D.

In this study, a complete three-dimensional finite element analysis was taken up for the Baneberry event by accounting for the semi-infinite layered media on the east and west sides of the source in an integrated 3D half-symmetrical model. The important features of inter-layer and free surface interactions and more importantly, the explosion-induced rupture and sliding along the fault plane, were precisely simulated with code SHOCK-3D. The sliding along the fault plane and the resulting vent path was shown to be resulting from the formation of a dip-slip mechanism due to relatively stronger Tuff medium overlying a high impedance closer-to-the source Paleozoic strata on the west end and weaker clay-rich medium on a relatively distant (from the source) Paleozoic layer on the east end. In addition to the prediction of short and long time transient phenomena of the event, the predicted crater depth with a quasi-static analysis was found to be in close agreement with the field observations. The influence of gravity was accounted to estimate the mound fall back induced impact commonly known as slap down effects of the spalled rock layers. It has been possible to simulate all the features observed during the Baneberry event and explain more explicitly the sequence of the events that led to venting. Figure $1 \mathrm{~b}$ shows the vent path created due to interaction of the cavity with the fault and tension-induced rupture of the fault resulting into a sliding mechanism on account of reflected wave from the hard Paleozoic rock medium beneath the source. More details of this simulation are available in our paper Ranjan et al (2006).

\subsection{Finite element model for rock and emplacement cavity}

In the present numerical studies for synthetic signal generation in single and composite rock media of Baneberry site (Nevada), a three-dimensional model (figure 2) is used where the source cavity of ionized gas media is modelled with three-dimensional eight node fluid element and the surrounding rock media is modelled with three-dimensional eight node solid elements. Homogeneous and composite geological layer patterns with emplacement source as fluid medium can be used in this model for studying the coupled behaviour of the gas cavity and the surrounding rock media for underground nuclear explosion events. Cubical fluid cavity with each side of $6.36 \mathrm{~m}$ (volume $257.3 \mathrm{~m}^{3}$ ) has been used to study the decoupling behaviour in different rock media. The total number of elements in a cubical domain of $200 \mathrm{~m}$ sides is 13,750 with 15,548 numbers of nodes. The top surface is free which allows reflection of shock waves and seismic waves. Quarter symmetry is used on $x-y$ and $y-z$ planes near the source (figure 2) and Sommerfeld (1949) radiation boundary condition is used on the other remaining faces to simulate non-reflecting boundary conditions. This helps to obtain seismic signals in the elastic zone of the model and the analysis is possible for a longer duration to simulate the cavity growth, spall and surface mound growth and fallback. The stresses due to gravity have been accounted in the simulation studies. The code is run up to $2 \mathrm{~s}$ transient duration for the cases identified in 

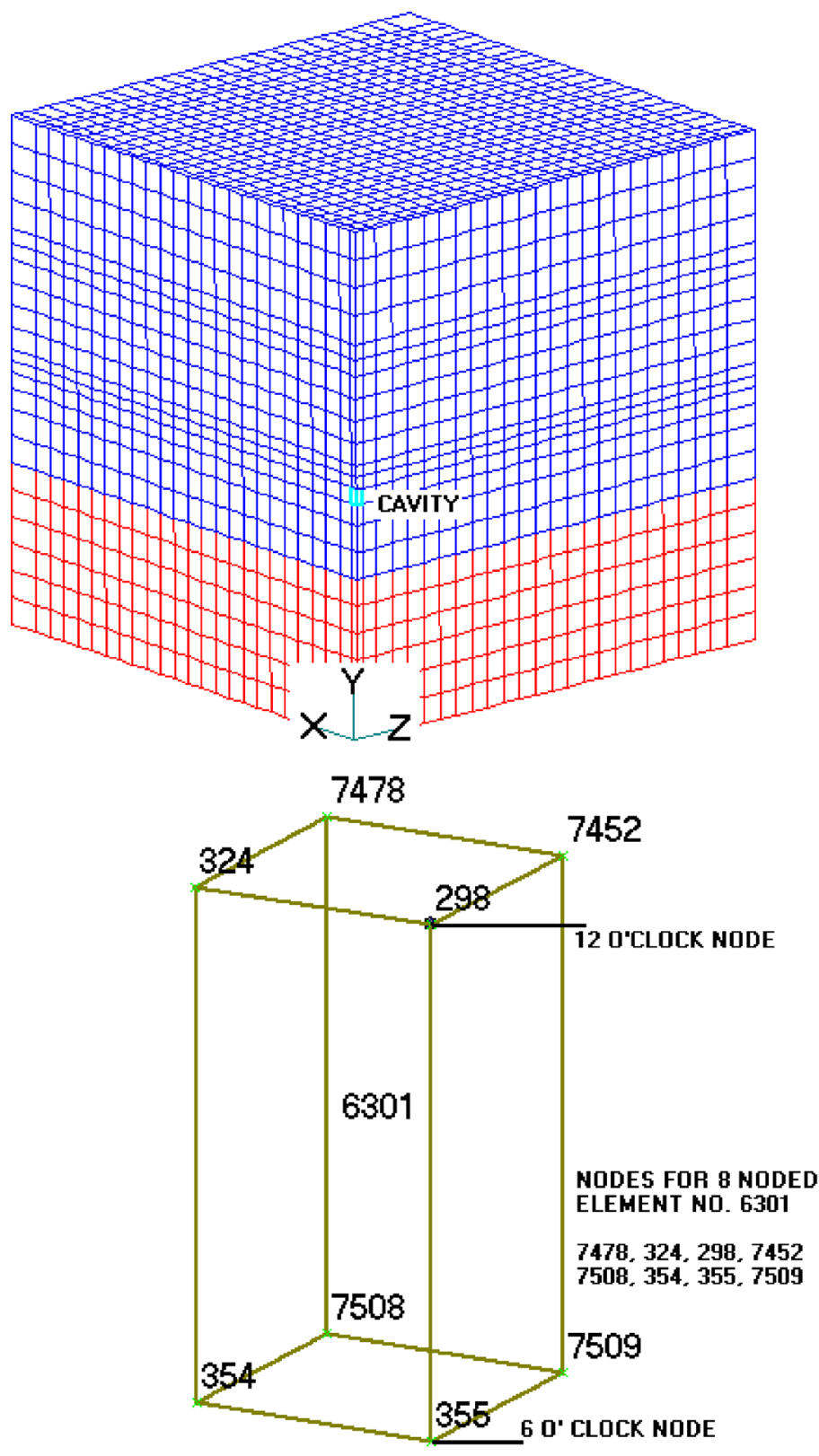

FLUID ELEMENT FOR EMPLACEHENT

Figure 2. 3D FEM model of layered geological media with fluid element as emplacement cavity (shown enlarged below the model). 
the next section with gravity option to simulate the free fall of the rising mound and spalled rock layers.

\section{Case studies for Baneberry rock strata}

After validation of Baneberry event, case studies were taken up for Baneberry rock uniform and composite strata. The results are obtained from the finite element code SHOCK-3D for the following parametric underground nuclear explosion simulation cases listed in table 1:

(a) Paleozoic rock medium for 1 and $8 \mathrm{kT}$ yields at the depth of $100 \mathrm{~m}$ that correspond to SDOB of 100 and $50 \mathrm{~m} / \mathrm{kT}^{1 / 3}$, respectively.

(b) Tuff rock medium for 1 and $8 \mathrm{kT}$ yields at the depth of $100 \mathrm{~m}$ that correspond to SDOB of 100 and $50 \mathrm{~m} / \mathrm{kT}^{1 / 3}$, respectively.

(c) Paleozoic-Tuff composite medium (PLTF) with emplacement in Paleozoic rock for 1 and $8 \mathrm{kT}$ yields at the depth of $100 \mathrm{~m}$ that correspond to SDOB of 100 and $50 \mathrm{~m} / \mathrm{kT}^{1 / 3}$, respectively. The upper Tuff layer is $66 \mathrm{~m}$ thick and distance of Paleozoic-Tuff interface from the emplacement is $36 \mathrm{~m}$.

(d) Tuff-Paleozoic composite medium (TFPL) with emplacement in Tuff rock for 1 and $8 \mathrm{kT}$ yields at the depth of $100 \mathrm{~m}$ that correspond to SDOB of 100 and $50 \mathrm{~m} / \mathrm{kT}^{1 / 3}$, respectively. The upper Tuff layer is $148.5 \mathrm{~m}$ thick and the Tuff-Paleozoic interface is $46.5 \mathrm{~m}$ below the emplacement in this case.

The above two cases of SDOBs have been selected to study cavity and mound growth and give reasonable explanation for spalling and cratering phenomena. The SDOB of 100 and $50 \mathrm{~m} / \mathrm{kT}^{1 / 3}$ have been selected to investigate the decoupling behaviour for the yields in the range of a few kilotons and these results can also be used to understand the behaviour in the sub-kiloton range often conducted at larger depths in clandestine manner that are known to give very weak signals and are beyond recognition with the existing seismic net works.

Homogeneous, intact and isotropic rock media has been considered to study the effects of inelastic behaviour due to local geological formations on the near source seismic signals beyond the elastic radius. The physical and engineering properties of different rock types are listed in table 2 and are similar to that used in our earlier paper by Ranjan et al (2006) on threedimensional finite element simulation of the Baneberry event. Rankine Hugoniot's equation of

Table 1. Cases for simulation studies.

\begin{tabular}{lcc}
\hline Medium & $\begin{array}{c}\text { Explosion } \\
\text { yield }(\mathrm{kT})\end{array}$ & $\begin{array}{c}\text { Scaled depth of burst } \\
(\mathrm{SDOB})\left(\mathrm{m} / \mathrm{kT}^{1 / 3}\right)\end{array}$ \\
\hline Paleozoic & 1 and 8 & 100 and 50 \\
Tuff & 1 and 8 & 100 and 50 \\
Paleozoic-Tuff composite PLTF & 1 and 8 & 100 and 50 \\
$\quad$ (WP in Paleozoic) & & \\
$\begin{array}{l}\text { Tuff-Paleozoic composite TFPL } \\
\text { (WP in Tuff) }\end{array}$ & 1 and 8 & 100 and 50 \\
\hline
\end{tabular}


Table 2. Engineering properties of Baneberry rock media.

\begin{tabular}{lcc}
\hline Properties & Paleozoic & Tuff \\
\hline Bulk density $\left(\mathrm{kg} / \mathrm{m}^{3}\right)$ & 2700 & 2140 \\
Grain density $\left(\mathrm{kg} / \mathrm{m}^{3}\right)$ & 2800 & 2650 \\
Poisson's ratio & 0.45 & 0.25 \\
P-wave velocity $(\mathrm{m} / \mathrm{s})$ & 6000 & 1834 \\
Uniaxial compressive strength $(\mathrm{MPa})$ & 60.0 & 7.0 \\
Shear strength $(\mathrm{MPa})$ & 75.0 & 4.2 \\
\hline
\end{tabular}

state (EOS) curves and shear strength failure curves for Paleozoic and Tuff media are representative of Baneberry site data Terhune et al (1977, 1979). The influence of various inelastic phenomena has been identified with the help of synthetic time signals and corresponding Fourier transforms. The vertical and horizontal acceleration signals have been recorded just diagonally opposite to the emplacement at a radial distance of $282 \mathrm{~m}$ for all the above cases. This ensures that the synthetic signals for various media are compared in the elastic zone at the emplacement depth of $100 \mathrm{~m}$. These signals constitute the seismic source function that is traced back with the help of the seismic signals recorded by regional and global networks for yield estimation. The influence of nonlinear effects would thus be propagated and yield estimation with consequent seismic recording alone without the accurate characterization of local geology remains uncertain. In the present study the original signals and filtered signals (DC to $15 \mathrm{~Hz}$ ) along with its Fourier transform are presented to highlight the uncertainty that is present in the yield estimation with seismograms in the above frequency band of interest.

\subsection{Influence of explosion yield in different geologic media}

In the present study, the effects on different geological media such as Paleozoic, Tuff, PLTF and TFPL composites for $1 \mathrm{kT}\left(\mathrm{SDOB} \sim 100 \mathrm{~m} / \mathrm{kT}^{1 / 3}\right)$ and $8 \mathrm{kT}\left(\mathrm{SDOB} \sim 50 \mathrm{~m} / \mathrm{kT}^{1 / 3}\right)$ yields have been studied. The results obtained for all the cases are described below.

\subsection{Paleozoic medium of Baneberry site}

Table 3 gives the summary of deformation pattern around the cavity and ground zero up to $2 \mathrm{~s}$. The average stable cavity radii after $2 \mathrm{~s}$ are 22.5 and $34.9 \mathrm{~m}$ for 1 and $8 \mathrm{kT}$ yields, respectively as can be seen in figures $3(\mathrm{a}-\mathrm{b})$ and $4(\mathrm{a}-\mathrm{b})$. In time versus vertical displacement plots, cavity oblonging effect (higher vertical displacement at 12 o'clock position compared to 6 o' clock position) can be observed at both the yields during the initial transient phase below $1 \mathrm{~s}$. However, for $8 \mathrm{kT}$ yield, the oblonging effect is more prominent with the maximum vertical displacement of $48.3 \mathrm{~m}$ at 12 o'clock position at $\sim 0.5 \mathrm{~s}$ which is expected at SDOB $\sim 50 \mathrm{~m} / \mathrm{kT}^{1 / 3}$. For $1 \mathrm{kT}$ yield ( $\mathrm{SDOB} \sim 100 \mathrm{~m} / \mathrm{kT}^{1 / 3}$ ) the stable cavity growth is established by this time. Figures $5(\mathrm{a}-\mathrm{b})$ show the azimuth plot of the vertical displacement history along the free surface from ground zero (GZ) and a sub-layer $11 \mathrm{~m}$ below GZ for SDOB $\sim 100 \mathrm{~m} / \mathrm{kT}^{1 / 3}$. The maximum mound uplifts of 1.4 and $19.6 \mathrm{~m}$ are observed at GZ at 0.1 and $2 \mathrm{~s}$, respectively. The vertical displacement profile along the sub-layer indicates that the peak value of $3.2 \mathrm{~m}$ is achieved at $0.5 \mathrm{~s}$ after which the rock strata at this sub-layer shows spall-induced separation with a peak value of $1.9 \mathrm{~m}$ at $2 \mathrm{~s}$, 
Table 3. Computational results for Paleozoic medium: 1 and $8 \mathrm{kT}$ cavity displacement (m) up to $2.0 \mathrm{~s}$.

\begin{tabular}{lrcrrr}
\hline \multirow{2}{*}{ Node/position } & \multicolumn{2}{c}{$1 \mathrm{kT}$} & & \multicolumn{2}{c}{$8 \mathrm{kT}$} \\
\cline { 2 - 3 } \cline { 5 - 6 } \cline { 5 - 6 } 298 12 o'clock west & 25.82 & 25.82 & & 29.95 & 29.95 \\
355 6 o'clock west & -19.15 & 19.15 & & -39.85 & 39.85 \\
\hline
\end{tabular}

Maximum total displacement (m) up to $2.0 \mathrm{~s}$ at $\mathrm{GZ}$

\begin{tabular}{lcc}
\hline & $1 \mathrm{kT}$ & $8 \mathrm{kT}$ \\
\cline { 2 - 3 } Time $(\mathrm{s})$ & Max. displacement & Max. displacement \\
\hline 0.1 & 1.37 & 3.466 \\
0.5 & 6.98 & 16.45 \\
1.0 & 12.6 & 30.34 \\
1.5 & 16.9 & 41.82 \\
2.0 & 19.56 & 51.21 \\
\hline
\end{tabular}

Maximum vertical displacement (m) up to $2.0 \mathrm{~s}$ at GZ

\begin{tabular}{lcc}
\hline & $1 \mathrm{kT}$ & $8 \mathrm{kT}$ \\
\cline { 2 - 3 } Time $(\mathrm{s})$ & Max. displacement & Max. displacement \\
\hline 0.1 & 1.37 & 3.466 \\
0.5 & 6.98 & 16.45 \\
1.0 & 12.6 & 30.34 \\
1.5 & 16.91 & 41.58 \\
2.0 & 19.56 & 51.68 \\
\hline
\end{tabular}

Maximum vertical velocity (m/s) up to $2.0 \mathrm{~s}$ at $\mathrm{GZ}$

\begin{tabular}{|c|c|c|}
\hline Time (s) & $\frac{1 \mathrm{kT}}{\text { Max. velocity }}$ & $\frac{8 \mathrm{kT}}{\text { Max. velocity }}$ \\
\hline 0.1 & 15.1 & 36.96 \\
\hline 0.5 & 11.6 & 30.76 \\
\hline 1.0 & 10.5 & 28.8 \\
\hline 1.5 & 6.71 & 22.47 \\
\hline 2.0 & 4.25 & 18.18 \\
\hline
\end{tabular}

Maximum vertical displacement $(\mathrm{m})$ up to $2.0 \mathrm{~s}$ for layer $11.0 \mathrm{~m}$ below GZ

\begin{tabular}{lcc}
\hline & $1 \mathrm{kT}$ & $8 \mathrm{kT}$ \\
\cline { 2 - 3 } Time $(\mathrm{s})$ & Max. displacement & Max. displacement \\
\hline 0.1 & 1.27 & 2.52 \\
0.5 & 3.2 & 12.35 \\
1.0 & 2.49 & 19.57 \\
1.5 & 2.1 & 23.46 \\
2.0 & 1.85 & 24.02 \\
\hline \multicolumn{2}{c}{ Maximum vertical velocity (m/s) up to 2.0 s for layer $11.0 \mathrm{~m}$ below $\mathrm{GZ}$} \\
\hline & $1 \mathrm{kT}$ & $8 \mathrm{kT}$ \\
\cline { 2 - 3 } Time (s) & Max. velocity & Max. velocity \\
\hline 0.1 & 12.11 & 27.72 \\
0.5 & -2.0 & 21.55 \\
1.0 & -3.0 & 13.74 \\
1.5 & 0.7 & 4.97 \\
2.0 & -0.4 & -6.65 \\
\hline
\end{tabular}



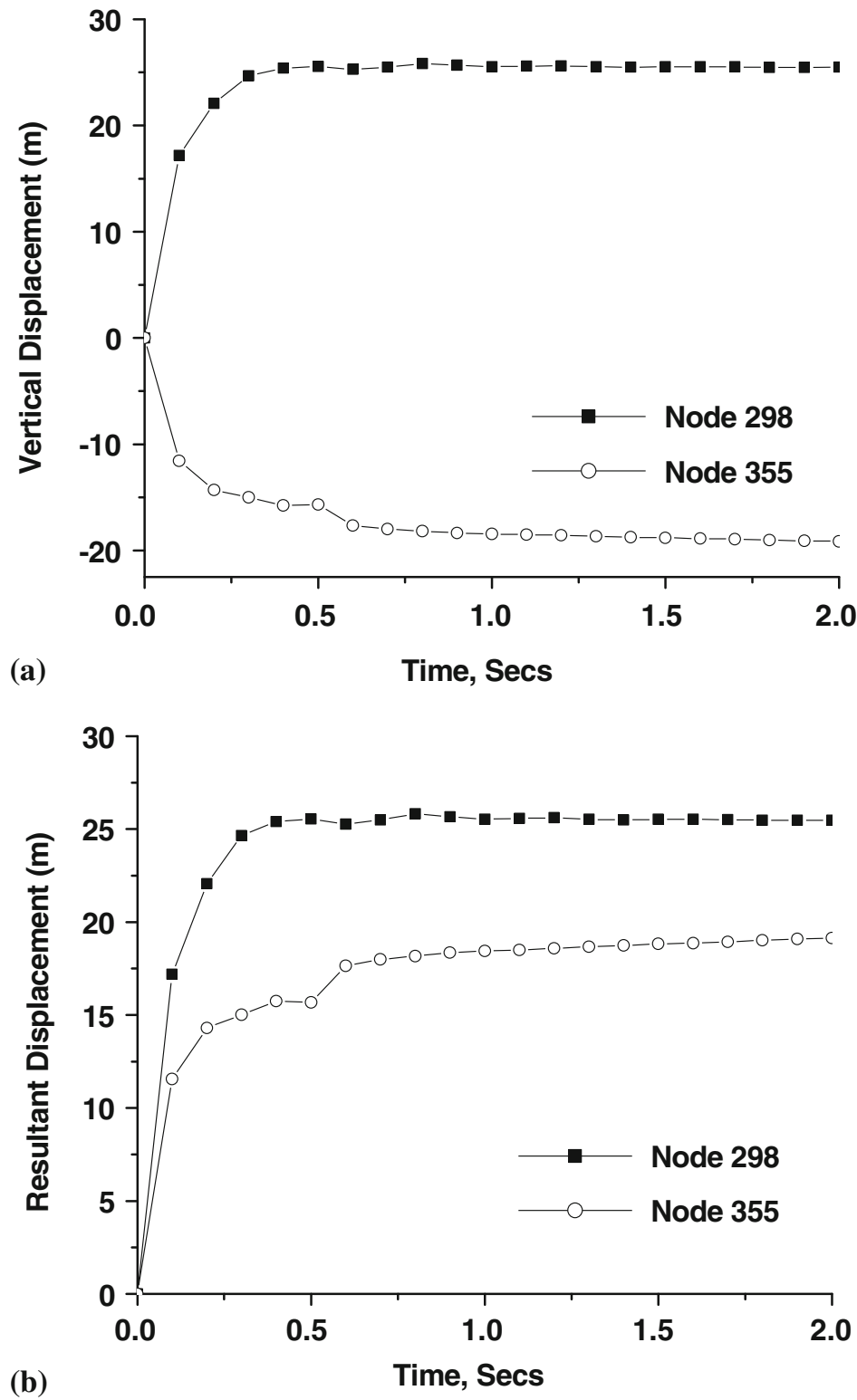

Figure 3. (a) Vertical displacement of cavity nodes 298 (12 o' clock) and 355 (6 o' clock) up to $2 \mathrm{~s}$ in Paleozoic medium for 1 kT. (b) Total displacement of cavity nodes 298 (12 o' clock) and 355 (6 o' clock) up to $2 \mathrm{~s}$ in Paleozoic medium for $1 \mathrm{kT}$.

thereby, indicating a monotonic deceleration of rock mass due to gravity. Behaviour consistent with the vertical displacement pattern mentioned above is observed in vertical velocity plots on these two layers as presented in figures $6(\mathrm{a}-\mathrm{b})$ for SDOB $\sim 100 \mathrm{~m} / \mathrm{kT}^{1 / 3}$. Along GZ the peak value of velocity $\sim 15 \mathrm{~m} / \mathrm{s}$ is reached at $0.1 \mathrm{~s}$ which reduces to $4.2 \mathrm{~m} / \mathrm{s}$ at $2 \mathrm{~s}$. The corresponding values at the sub-layer are 12 and $-0.4 \mathrm{~m} / \mathrm{s}$, thus indicating the layer separation. 

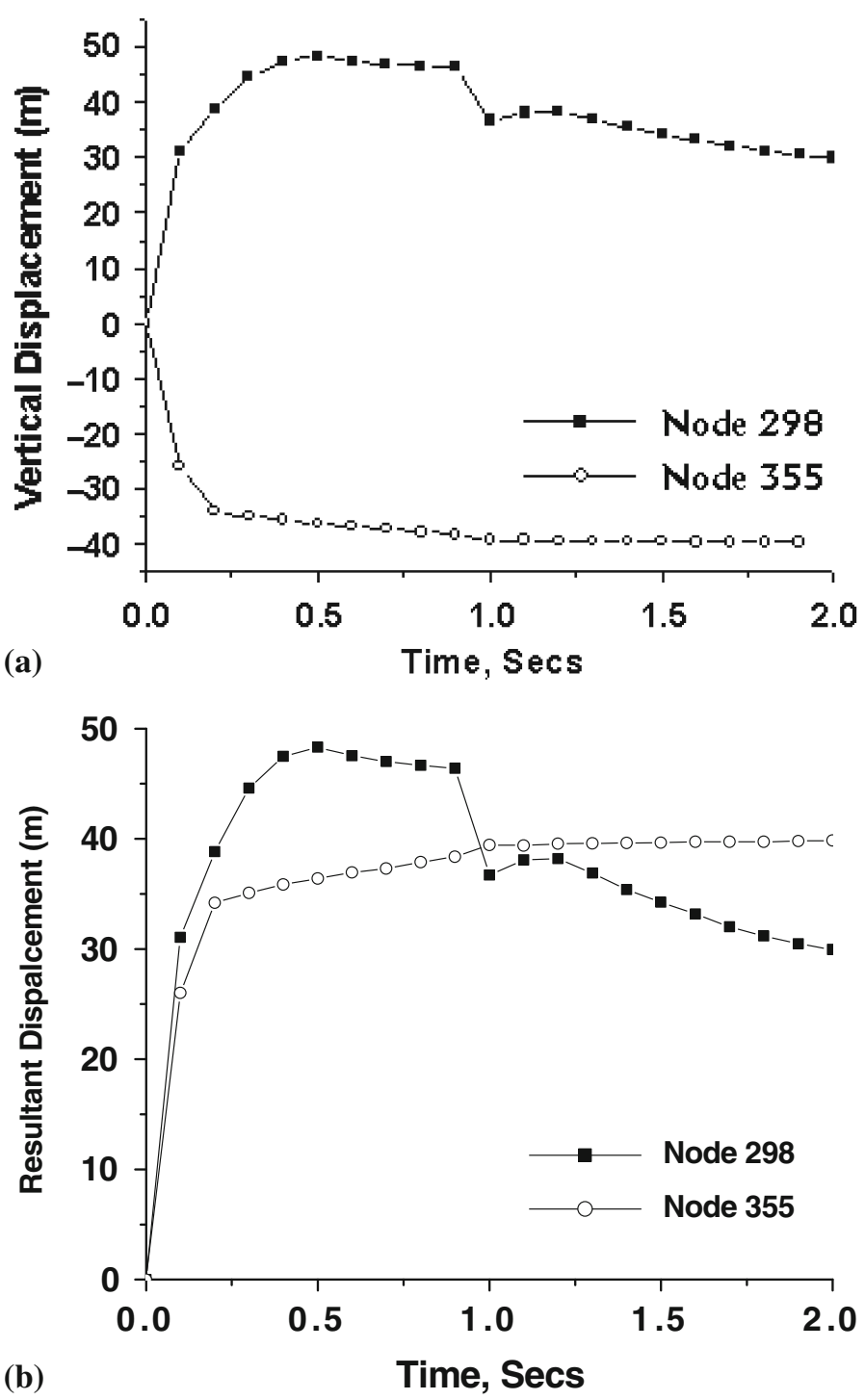

Figure 4. (a) Vertical displacement of cavity nodes 298 (12 o' clock) and 355 (6 o' clock) up to $2 \mathrm{~s}$ in Paleozoic medium for 8 kT. (b) Total displacement of cavity nodes 298 (12 o' clock) and 355 (6 o' clock) up to $2 \mathrm{~s}$ in Paleozoic medium for $8 \mathrm{kT}$.

Figures $7(\mathrm{a}-\mathrm{b})$ show the azimuth plot of the vertical displacement history along the free surface from GZ and a sub-layer $11 \mathrm{~m}$ below GZ for SDOB $\sim 50 \mathrm{~m} / \mathrm{kT}^{1 / 3}$. In this case, on both the surfaces monotonic increase in vertical displacement with time is observed. The maximum mound uplifts of 3.5 and $51.7 \mathrm{~m}$ are observed at GZ at 0.1 and $2 \mathrm{~s}$, respectively and at the sub-layer these values are 2.5 and $24 \mathrm{~m}$, respectively as normally expected at low SDOB of $50 \mathrm{~m} / \mathrm{kT}^{1 / 3}$. Along GZ the peak value of velocity $\sim 37 \mathrm{~m} / \mathrm{s}$ is reached at $0.1 \mathrm{~s}$ which reduces to 

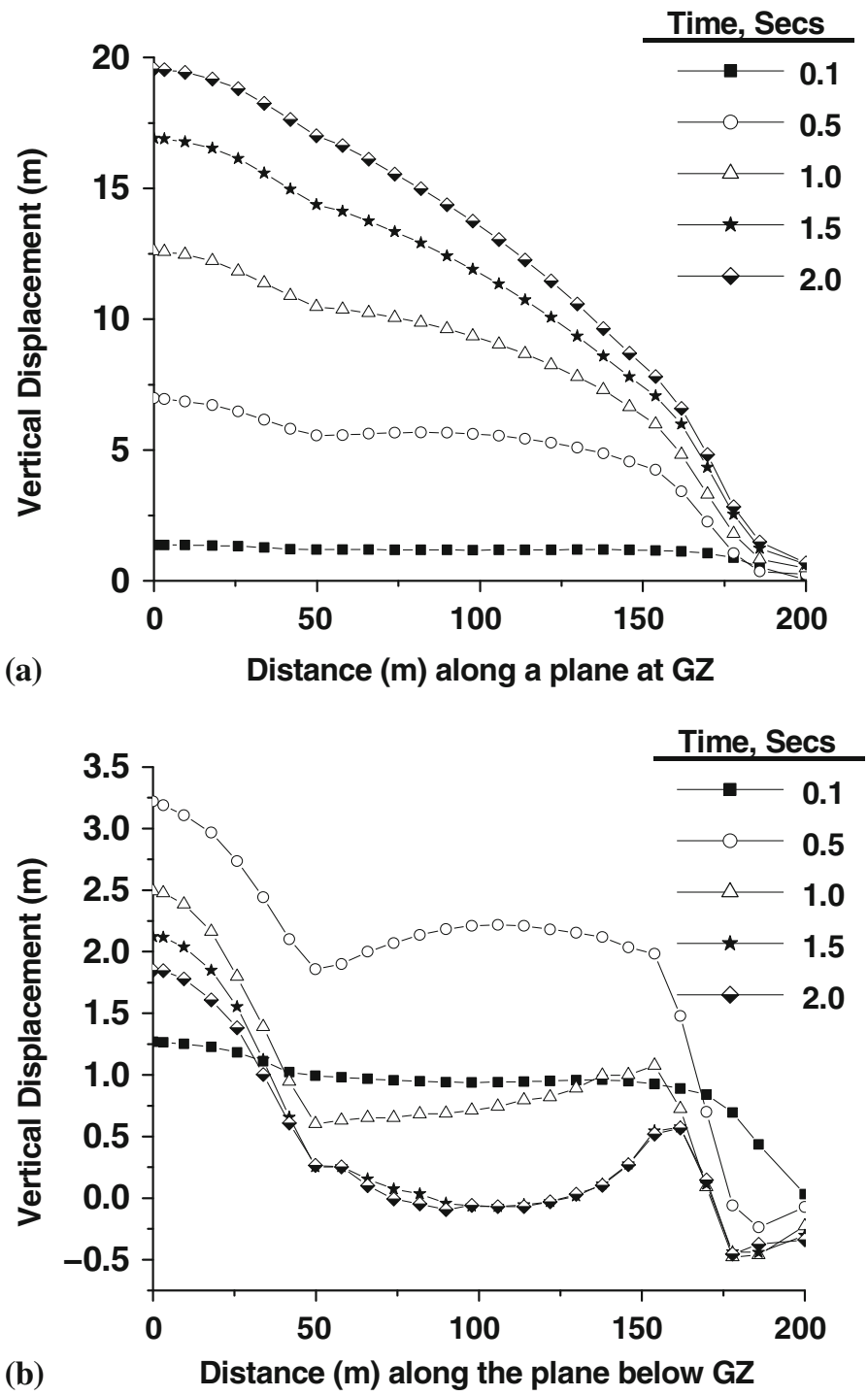

Figure 5. (a) Vertical nodal displacement $(\mathrm{m})$ at $0.1,0.5,1.0,1.5$ and $2 \mathrm{~s}$ on the horizontal layer along GZ (top surface) in Paleozoic medium for $1 \mathrm{kT}$. (b) Vertical nodal displacement (m) at 0.1, 0.5, 1.0, 1.5 and $2 \mathrm{~s}$ on the horizontal layer $11 \mathrm{~m}$ below GZ in Paleozoic medium for $1 \mathrm{kT}$.

$18.2 \mathrm{~m} / \mathrm{s}$ at $2 \mathrm{~s}$ as shown in figure $8 \mathrm{a}$. The corresponding values at the sub-layer (figure $8 \mathrm{~b}$ ) are 27.7 and $-6.7 \mathrm{~m} / \mathrm{s}$, thus indicating again the layer separation. Figures $7(\mathrm{a}-\mathrm{b})$ and $8(\mathrm{a}-\mathrm{b})$ indicate the tendency of crater formation for SDOB of $50 \mathrm{~m} / \mathrm{kT}^{1 / 3}$ with shift of $36 \mathrm{~m}$ in the peak mound displacement from GZ and dip in displacement and velocity profiles as evident from these curves. In case of SDOB of $100 \mathrm{~m} / \mathrm{kT}^{1 / 3}$, the peak value of displacement is always at GZ, thus, indicating a tendency of small mound formation after fallback as shown by $1.3 \mathrm{~m}$ peak vertical 


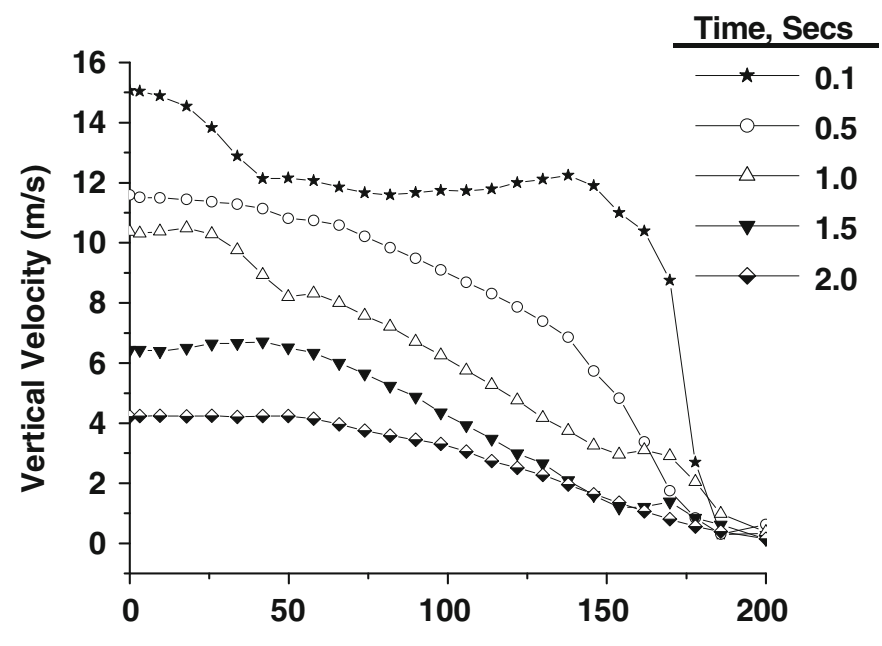

(a)

Distance (m) along a plane at GZ

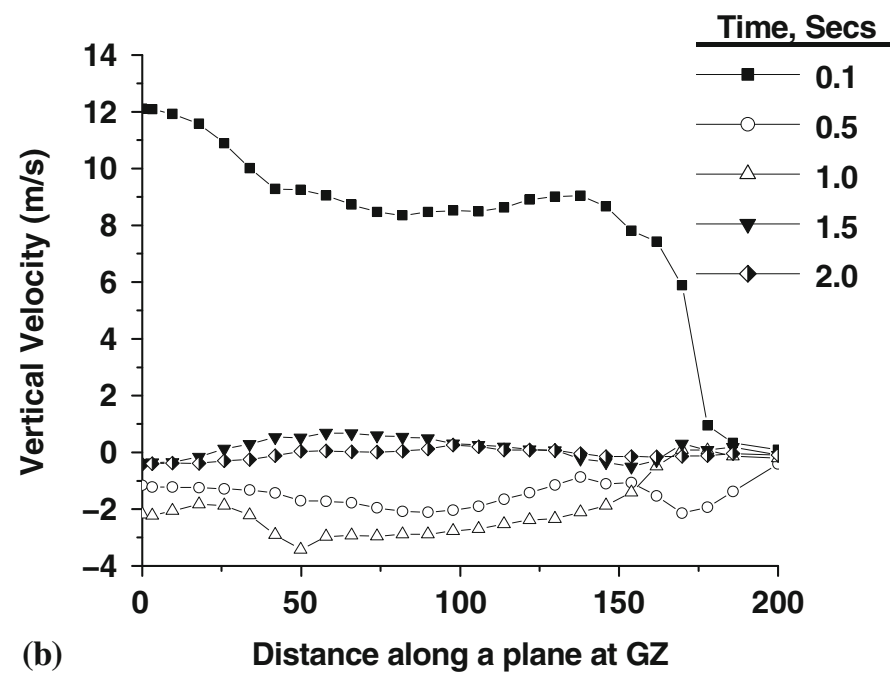

Figure 6. (a) Vertical nodal velocity $(\mathrm{m} / \mathrm{s})$ at $0.1,0.5,1.0,1.5$ and $2 \mathrm{~s}$ on the horizontal layer at GZ (top surface) in Paleozoic medium for $1 \mathrm{kT}$. (b) Vertical nodal velocity $(\mathrm{m} / \mathrm{s})$ at $0.1,0.5,1.0,1.5$ and $2 \mathrm{~s}$ on horizontal layer below GZ in Paleozoic medium for $1 \mathrm{kT}$.

displacement at the sub-layer after $2.0 \mathrm{~s}$ shown in figure 5a. Also a point worth highlighting is the influence of greater oblonging effect at SDOB of $50 \mathrm{~m} / \mathrm{kT}^{1 / 3}$ on the subsequent mound growth and cratering. At larger SDOB of $100 \mathrm{~m} / \mathrm{kT}^{1 / 3}$, the surface effects are the minimal due to stable cavity growth.

\subsection{Tuff medium of Baneberry site}

Table 4 gives the summary of deformation pattern around the cavity and ground zero up to $2 \mathrm{~s}$. The stable cavity radii after $2 \mathrm{~s}$ are 18.5 and $30.7 \mathrm{~m}$ for 1 and $8 \mathrm{kT}$ yields, respectively as can 

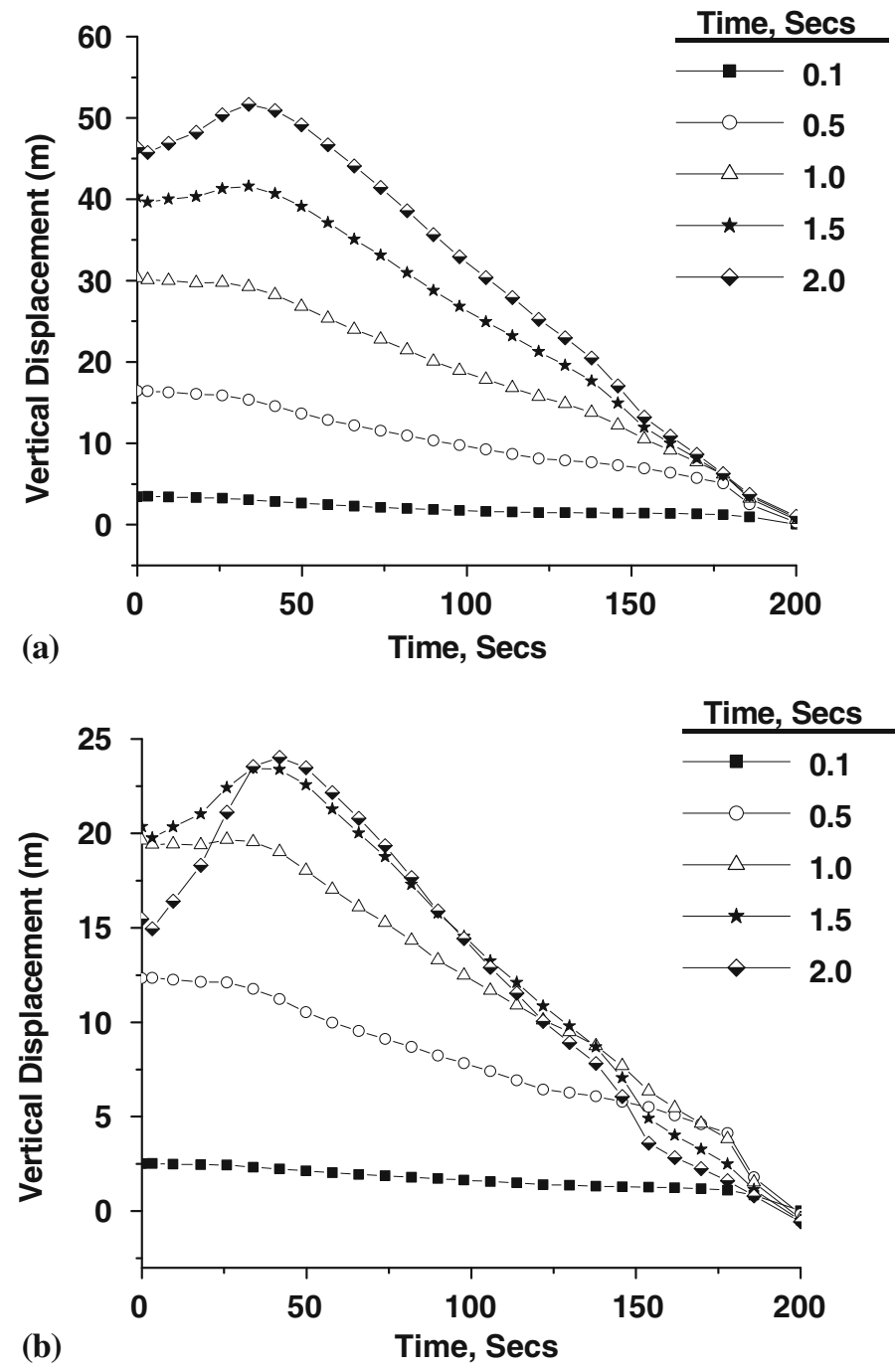

Figure 7. (a) Vertical nodal displacement $(\mathrm{m})$ at $0.1,0.5,1.0,1.5$ and $2 \mathrm{~s}$ on the horizontal layer along GZ (top surface) in Paleozoic medium for $8 \mathrm{kT}$. (b) Vertical nodal displacement (m) at 0.1, 0.5, 1.0, 1.5 and $2 \mathrm{~s}$ on the horizontal layer below GZ in Paleozoic medium for $8 \mathrm{kT}$.

be seen in figures $9(a-b)$ and $10(a-b)$. In time versus vertical displacement plots, cavity growth stabilizes after $0.7 \mathrm{~s}$. Due to lower impedance of Tuff medium compared to Paleozoic medium, the oblonging effect is less prominent in this case. Lower cavity radius in Tuff medium compared to Paleozoic is attributed to the larger impedance of the latter. The strong rarefaction wave for the Paleozoic medium after reflection from top surface produces significant oblonging effect on the cavity that masks the effect of its higher strength and higher overburden pressure. Without this influence, it would normally result in lower cavity radius for Paleozoic medium compared to Tuff medium as is normally obtained by empirical/semi-analytical simplified correlations. For 

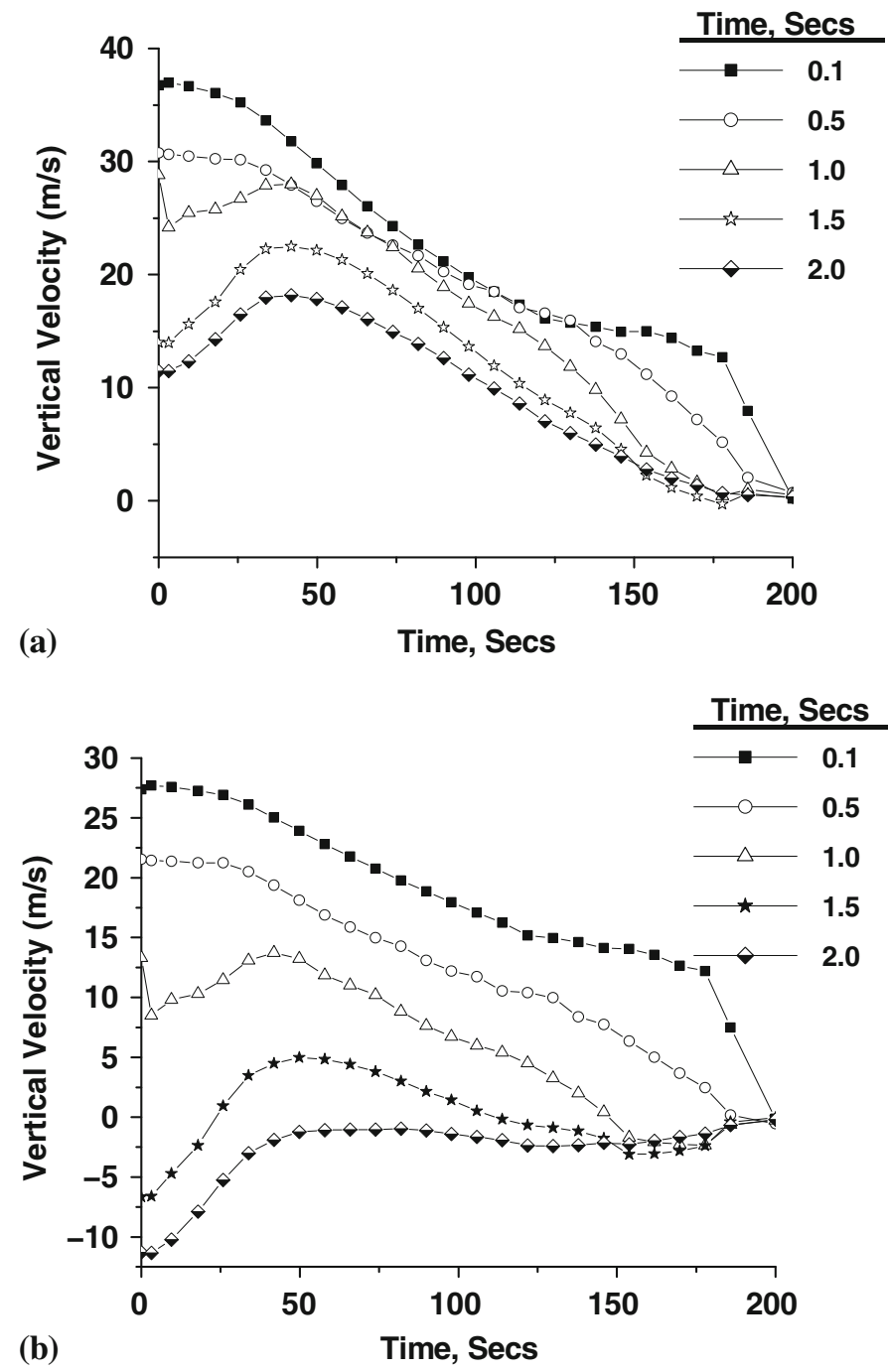

Figure 8. (a) Vertical nodal velocity $(\mathrm{m} / \mathrm{s})$ at $0.1,0.5,1.0,1.5$ and $2 \mathrm{~s}$ on the horizontal layer at GZ (top surface) in Paleozoic medium for $8 \mathrm{kT}$. (b) Vertical nodal velocity $(\mathrm{m} / \mathrm{s})$ at $0.1,0.5,1.0,1.5$ and $2 \mathrm{~s}$ on horizontal layer below GZ in Paleozoic medium for $8 \mathrm{kT}$.

composite media (PLTF and TFPL), the rarefaction from the Paleozoic-Tuff interface is weak which results in lower cavity growth for PLTF (source in Paleozoic) than TFPL (source in Tuff). This is discussed in detail in following sections.

Figures 11(a-b) show the azimuth plot of the vertical displacement history along the free surface from GZ and a sub-layer of $11 \mathrm{~m}$ below GZ for SDOB of $100 \mathrm{~m} / \mathrm{kT}^{1 / 3}$. The maximum mound uplifts of 1.0 and $19.5 \mathrm{~m}$ are observed at GZ at 0.1 and $2 \mathrm{~s}$, respectively wherein the peak values for the sub-layer are 0.9 and $7.0 \mathrm{~m}$. As shown in figure 12a along GZ the peak value of velocity $\sim 13.2 \mathrm{~m} / \mathrm{s}$ is reached at $0.5 \mathrm{~s}$ which reduces to $5.2 \mathrm{~m} / \mathrm{s}$ at $2 \mathrm{~s}$. The peak values for the 
Table 4. Computational results for Tuff medium: 1 and $8 \mathrm{kT}$ cavity displacement (m) up to $2.0 \mathrm{~s}$.

\begin{tabular}{|c|c|c|c|c|}
\hline \multirow[b]{2}{*}{ Node/position } & \multicolumn{2}{|c|}{$1 \mathrm{kT}$} & \multicolumn{2}{|r|}{$8 \mathrm{kT}$} \\
\hline & Y disp & Cavity radius & Y disp & Cavity radius \\
\hline 29812 o'clock west & 18.49 & 18.49 & 30.73 & 30.73 \\
\hline 3556 o'clock west & -15.06 & 15.06 & -28.86 & 29.08 \\
\hline \multicolumn{5}{|c|}{ Maximum total displacement $(\mathrm{m})$ up to $2.0 \mathrm{~s}$ at $\mathrm{GZ}$} \\
\hline \multirow[b]{2}{*}{ Time (s) } & \multicolumn{2}{|c|}{$1 \mathrm{kT}$} & \multicolumn{2}{|r|}{$8 \mathrm{kT}$} \\
\hline & \multicolumn{2}{|c|}{$\overline{\text { Max. displacement }}$} & \multicolumn{2}{|r|}{$\overline{\text { Max. displacemen }}$} \\
\hline$\overline{0.1}$ & \multicolumn{2}{|c|}{0.99} & \multicolumn{2}{|r|}{2.2} \\
\hline 0.5 & \multicolumn{2}{|c|}{5.84} & \multicolumn{2}{|r|}{15.7} \\
\hline 1.0 & \multicolumn{2}{|c|}{11.5} & \multicolumn{2}{|r|}{31.3} \\
\hline 1.5 & \multicolumn{2}{|c|}{16.4} & \multicolumn{2}{|r|}{46.4} \\
\hline 2.0 & \multicolumn{2}{|c|}{19.5} & \multicolumn{2}{|r|}{60.2} \\
\hline
\end{tabular}

Maximum vertical displacement (m) up to $2.0 \mathrm{~s}$ at GZ

\begin{tabular}{lcc}
\hline & $1 \mathrm{kT}$ & $8 \mathrm{kT}$ \\
\cline { 2 - 3 } Time $(\mathrm{s})$ & Max. displacement & Max. displacement \\
\hline 0.1 & 0.99 & 2.2 \\
0.5 & 5.84 & 15.7 \\
1.0 & 11.5 & 31.3 \\
1.5 & 16.4 & 46.3 \\
2.0 & 19.5 & 60.2 \\
\hline
\end{tabular}

Maximum vertical velocity (m/s) up to $2.0 \mathrm{~s}$ at $\mathrm{GZ}$

\begin{tabular}{lcc}
\hline & $1 \mathrm{kT}$ & $8 \mathrm{kT}$ \\
\cline { 2 - 3 } Time $(\mathrm{s})$ & Max. velocity & Max. velocity \\
\hline 0.1 & 12.1 & 36.2 \\
0.5 & 13.2 & 32.2 \\
1.0 & 10.9 & 29.4 \\
1.5 & 7.88 & 29.2 \\
2.0 & 5.2 & 26.0 \\
\hline
\end{tabular}

Maximum vertical displacement (m) up to $2.0 \mathrm{~s}$ for layer $11.0 \mathrm{~m}$ below GZ

\begin{tabular}{|c|c|c|}
\hline Time (s) & $\frac{1 \mathrm{kT}}{\text { Max. displacement }}$ & $\frac{8 \mathrm{kT}}{\text { Max. displacement }}$ \\
\hline 0.1 & 0.92 & 1.9 \\
\hline 0.5 & 5.01 & 12.9 \\
\hline 1.0 & 5.7 & 23.4 \\
\hline 1.5 & 6.9 & 30.3 \\
\hline 2.0 & 7.05 & 33.2 \\
\hline
\end{tabular}

Maximum vertical velocity (m/s) up to $2.0 \mathrm{~s}$ for layer $11.0 \mathrm{~m}$ below $\mathrm{GZ}$

\begin{tabular}{lcc}
\hline & $1 \mathrm{kT}$ & $8 \mathrm{kT}$ \\
\cline { 2 - 3 } Time $(\mathrm{s})$ & Max. velocity & Max. velocity \\
\hline 0.1 & 11.99 & 29.9 \\
0.5 & 8.3 & 24.5 \\
1.0 & 1.0 & 17.6 \\
1.5 & -2.4 & 9.7 \\
2.0 & -2.8 & 2.0 \\
\hline
\end{tabular}



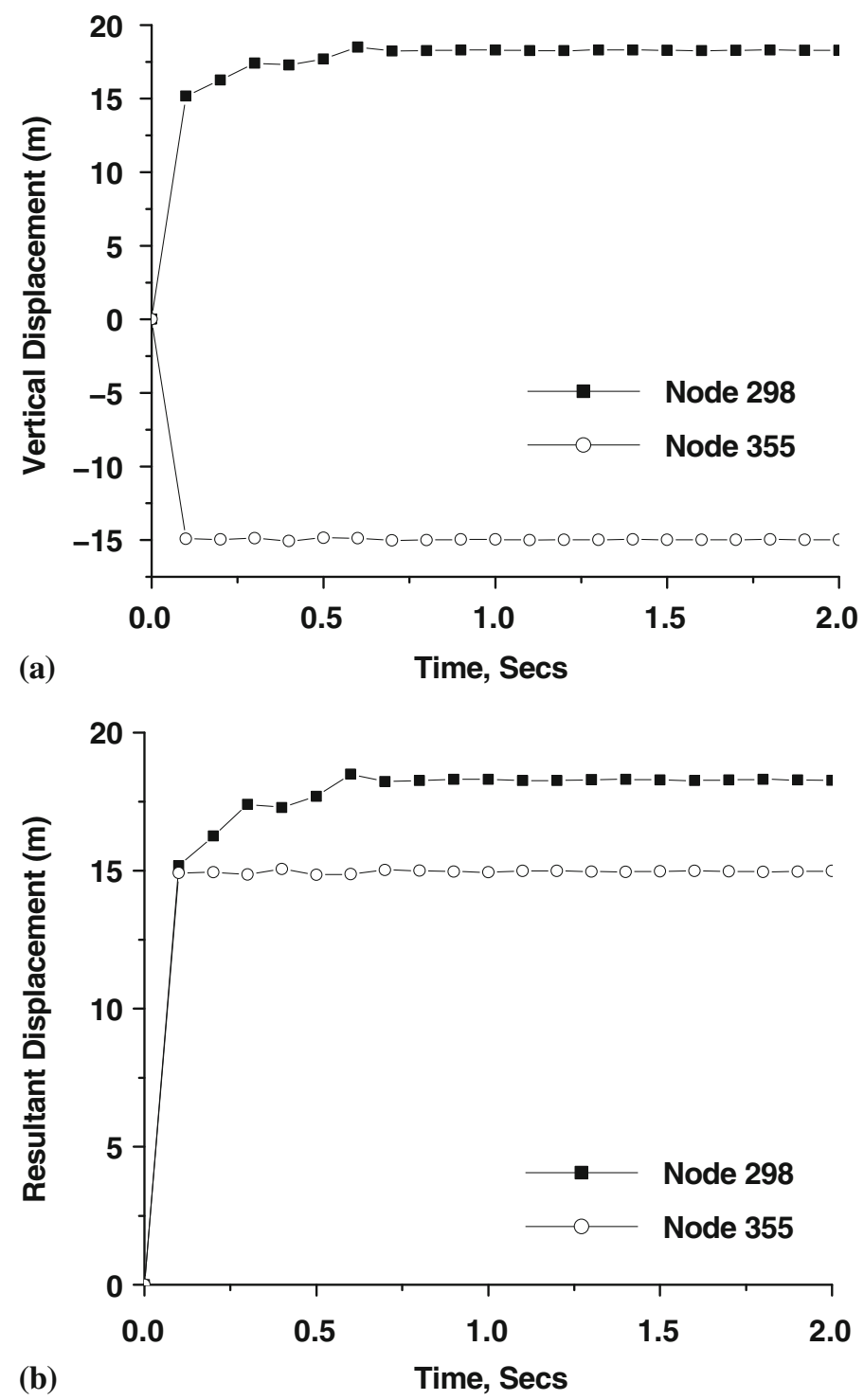

Figure 9. (a) Vertical displacement of cavity nodes 298 (12 o' clock) and 355 (6 o' clock) up to $2 \mathrm{~s}$ in Tuff medium for 1 kT. (b) Total displacement of cavity nodes 298 (12 o' clock) and 355 (6 o' clock) up to $2 \mathrm{~s}$ in Tuff medium for $1 \mathrm{kT}$.

sub-layer are $12 \mathrm{~m} / \mathrm{s}$ at $0.1 \mathrm{~s}$ and $-2.8 \mathrm{~m} / \mathrm{s}$ at $2 \mathrm{~s}$, as shown in figure $12 \mathrm{~b}$, which indicates the fallback and layer separation.

Figures 13(a-b) show the azimuth plot of the vertical displacement history along the free surface from GZ and a sub-layer $11 \mathrm{~m}$ below GZ for SDOB of $50 \mathrm{~m} / \mathrm{kT}^{1 / 3}$. In this case, on both the surfaces monotonic increase in vertical displacement with time is observed. The maximum 

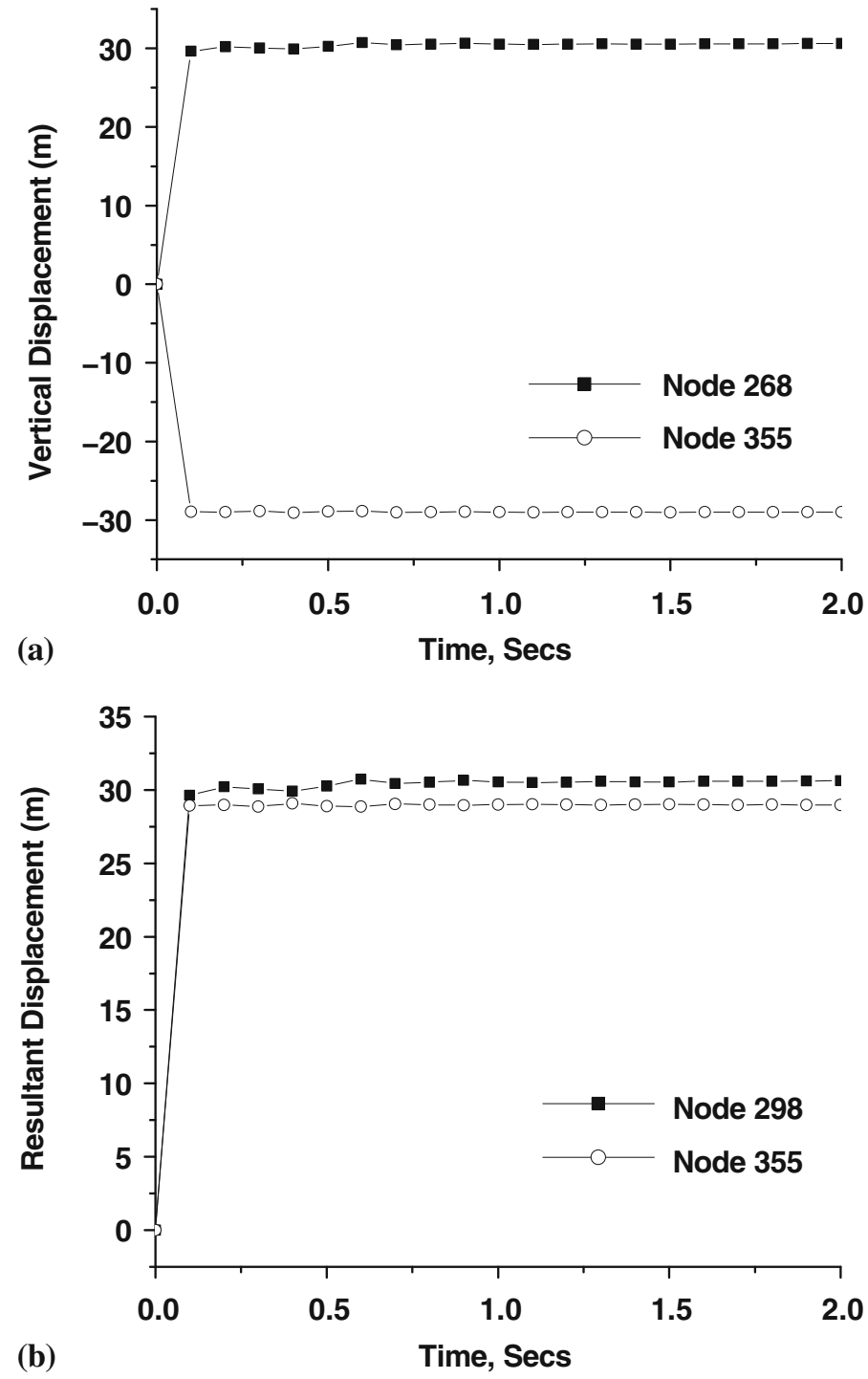

Figure 10. (a) Vertical displacement of cavity nodes 298 (12 o' clock) and 355 (6 o' clock) up to $2 \mathrm{~s}$ in Tuff medium for 8 kT. (b) Total displacement of cavity nodes 298 (12 o' clock) and 355 (6 o' clock) up to $2 \mathrm{~s}$ in Tuff medium for $8 \mathrm{kT}$.

mound uplifts of 2.2 and $60.2 \mathrm{~m}$ are observed at GZ at 0.1 and $2 \mathrm{~s}$, respectively and at the sublayer these values are 1.9 and $33.2 \mathrm{~m}$, respectively. Along GZ the peak value of velocity $\sim 36 \mathrm{~m} / \mathrm{s}$ is reached at $0.1 \mathrm{~s}$, which reduces to $26 \mathrm{~m} / \mathrm{s}$ at $2 \mathrm{~s}$ as shown in figure $14 \mathrm{a}$. The corresponding values at the sub-layer, as shown in figure $14 \mathrm{~b}$, are 30 and $2.0 \mathrm{~m} / \mathrm{s}$, thus indicating their separation. Hence, as compared to the case of SDOB of $100 \mathrm{~m} / \mathrm{kT}^{1 / 3}$, here we observe pronounced surface effects with a tendency of crater formation, which will be formed after a longer duration. 


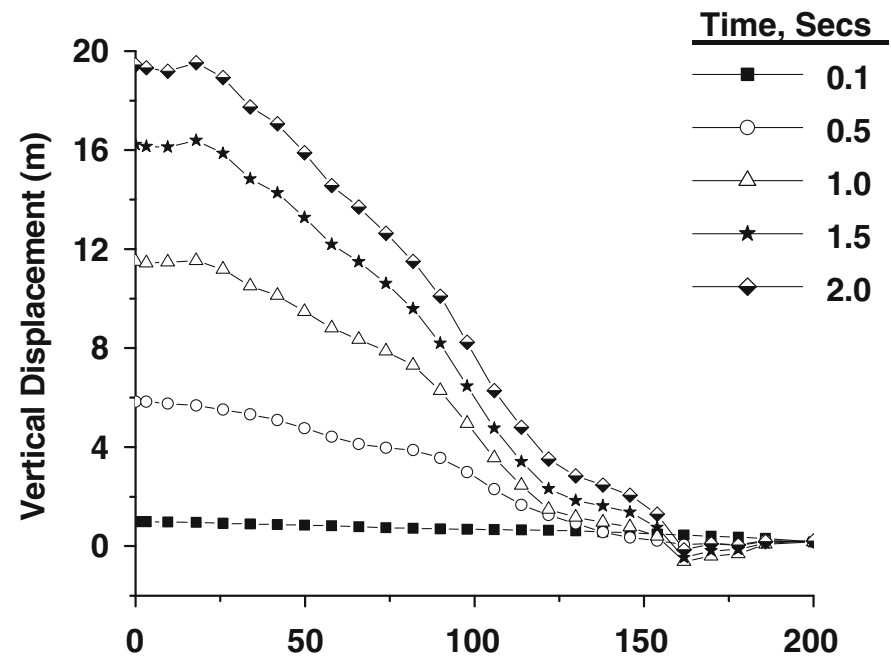

(a)

Distance $(\mathrm{m})$ along the plane at $\mathrm{GZ}$

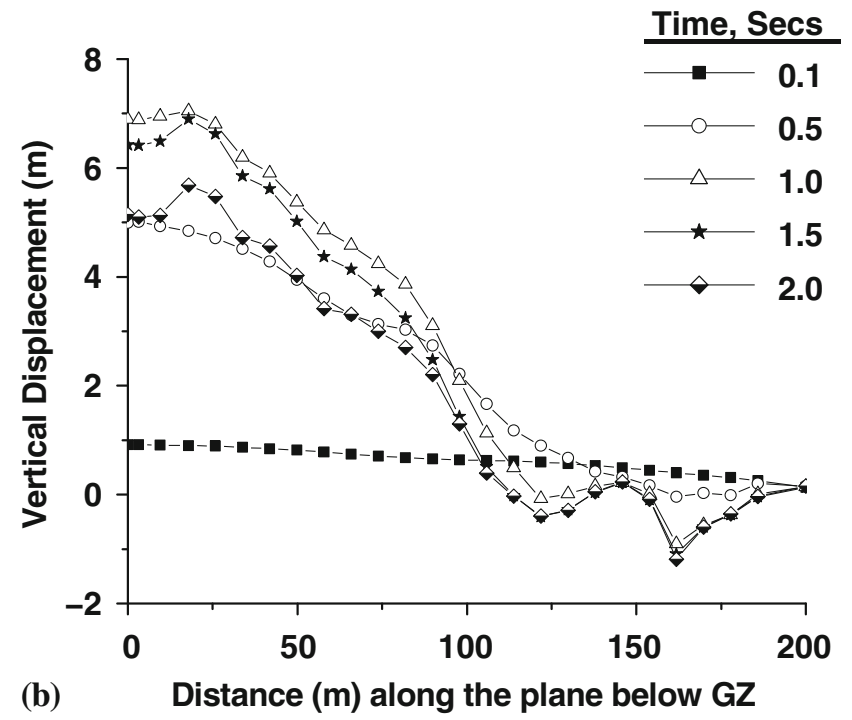

Figure 11. (a) Vertical nodal displacement (m) at $0.1,0.5,1.0,1.5$ and $2 \mathrm{~s}$ on the horizontal layer along GZ (top surface) in Tuff medium for $1 \mathrm{kT}$. (b) Vertical nodal displacement (m) at 0.1, 0.5, 1.0, 1.5 and $2 \mathrm{~s}$ on the horizontal layer $11 \mathrm{~m}$ below GZ in Tuff medium for $1 \mathrm{kT}$.

Here one can underscore the point that at SDOB of $50 \mathrm{~m} / \mathrm{kT}^{1 / 3}$, spall separation at $0.5 \mathrm{~s}$ in both the media is comparable ( $\sim 4.1 \mathrm{~m}$ for Paleozoic and $2.8 \mathrm{~m}$ for Tuff) whereas at higher SDOB of $100 \mathrm{~m} / \mathrm{kT}^{1 / 3}$, the layer separation in Tuff is about $0.8 \mathrm{~m}$ while in stronger Paleozoic rock this value is $3.8 \mathrm{~m}$. This indicates stronger rarefaction generation from the free surface in Paleozoic rock, which has higher impedance. In case of Tuff medium less energy is radiated to the free surface at SDOB of $100 \mathrm{~m} / \mathrm{kT}^{1 / 3}$. Thus the induced spall is very small. However this effect 


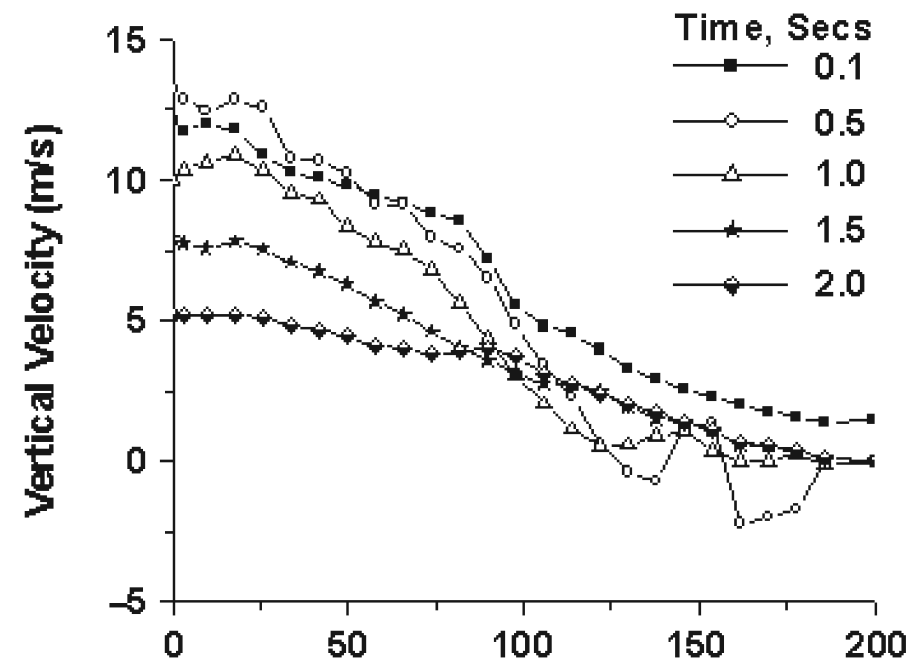

(a)

Distance $(\mathrm{m})$ along the plane at GZ

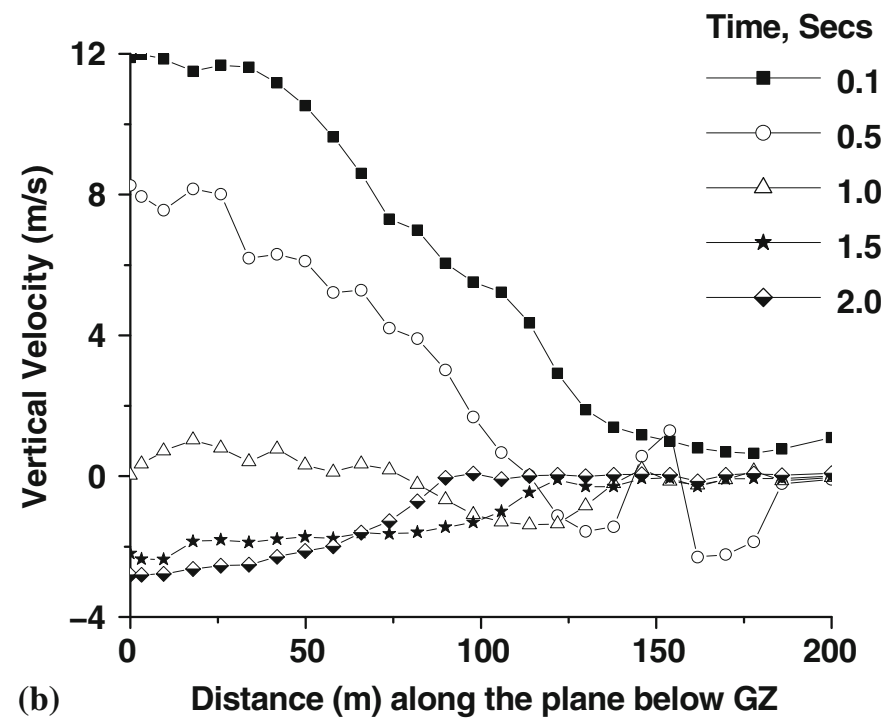

Figure 12. (a) Vertical nodal velocity $(\mathrm{m} / \mathrm{s})$ at $0.1,0.5,1.0,1.5$ and $2 \mathrm{~s}$ on the horizontal layer at GZ (top surface) in Tuff medium for $1 \mathrm{kT}$. (b) Vertical nodal velocity $(\mathrm{m} / \mathrm{s})$ at $0.1,0.5,1.0,1.5$ and $2 \mathrm{~s}$ on horizontal layer $11 \mathrm{~m}$ below GZ in Tuff medium for $1 \mathrm{kT}$.

is masked at SDOB of $50 \mathrm{~m} / \mathrm{kT}^{1 / 3}$ for both the media as is evident from conical deformation pattern at $0.5 \mathrm{~s}$ shown in figures $15(\mathrm{a}-\mathrm{b})$.

\subsection{Influence of stratification in geological media}

The effect of local geological strata in case of composite PLTF and composite TFPL media was further examined. Table 5 gives the summary of deformation pattern around the cavity and free surface at GZ up to $2 \mathrm{~s}$ for both composite media. 

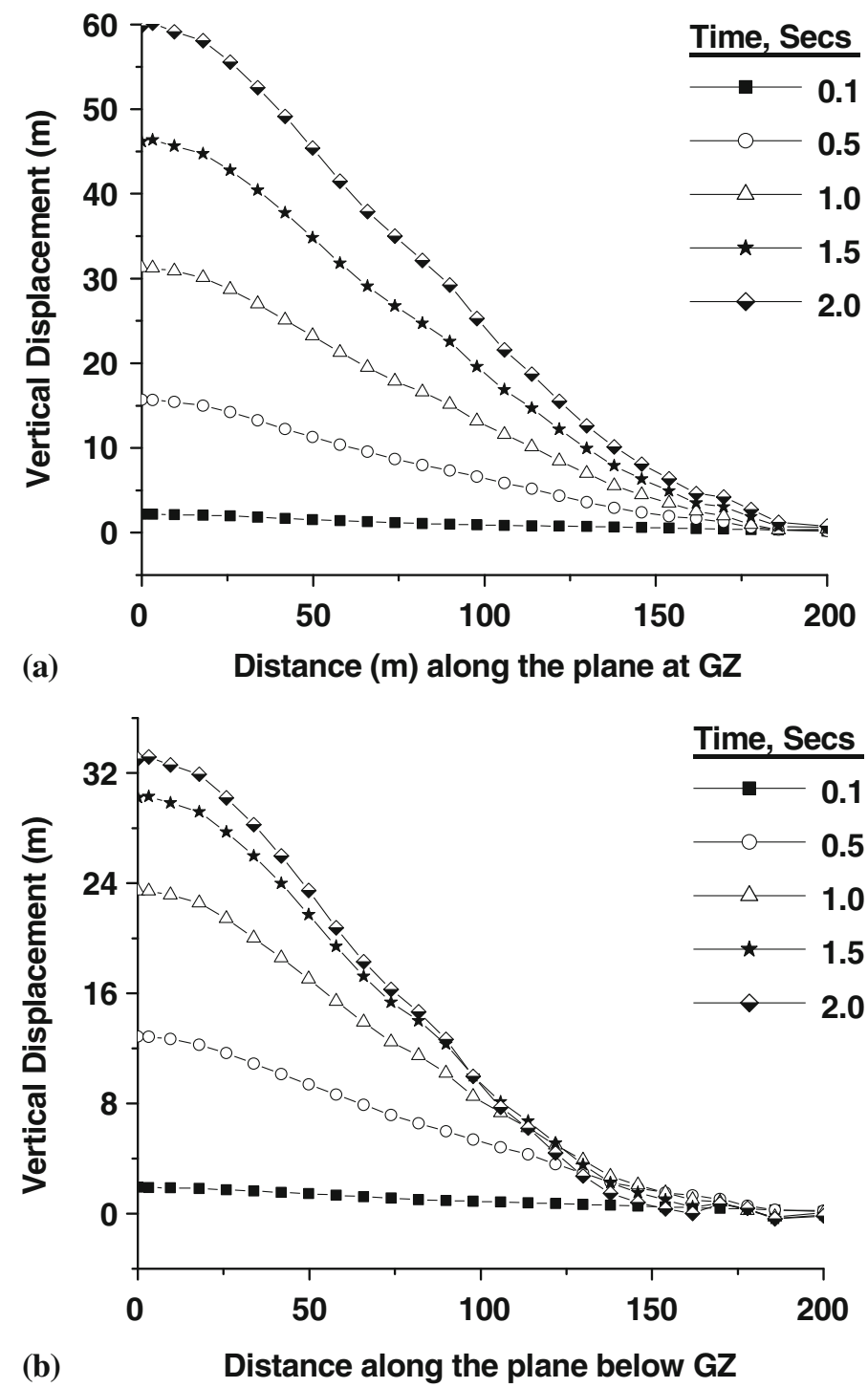

Figure 13. (a) Vertical nodal displacement (m) at $0.1,0.5,1.0,1.5$ and $2 \mathrm{~s}$ on the horizontal layer along GZ (top surface) in Tuff medium for $8 \mathrm{kT}$. (b) Vertical nodal displacement (m) at 0.1, 0.5, 1.0, 1.5 and $2 \mathrm{~s}$ on the horizontal layer $11 \mathrm{~m}$ below GZ in Tuff medium for $8 \mathrm{kT}$.

\subsection{Baneberry site composite PLTF medium}

The stable cavity radii in PLTF composite medium after $2 \mathrm{~s}$ are 15.6 and $25 \mathrm{~m}$ for 1 and $8 \mathrm{kT}$ yields, respectively as can be seen in figures $16(a-b)$ and $17(a-b)$. In time versus vertical displacement plots, cavity growth stabilizes after $0.5 \mathrm{~s}$. Cavity growth as well as cavity oblonging with time as compared to the case of homogeneous Paleozoic medium is thus reduced with the introduction of weaker Tuff layer at the top for both SDOBs. 

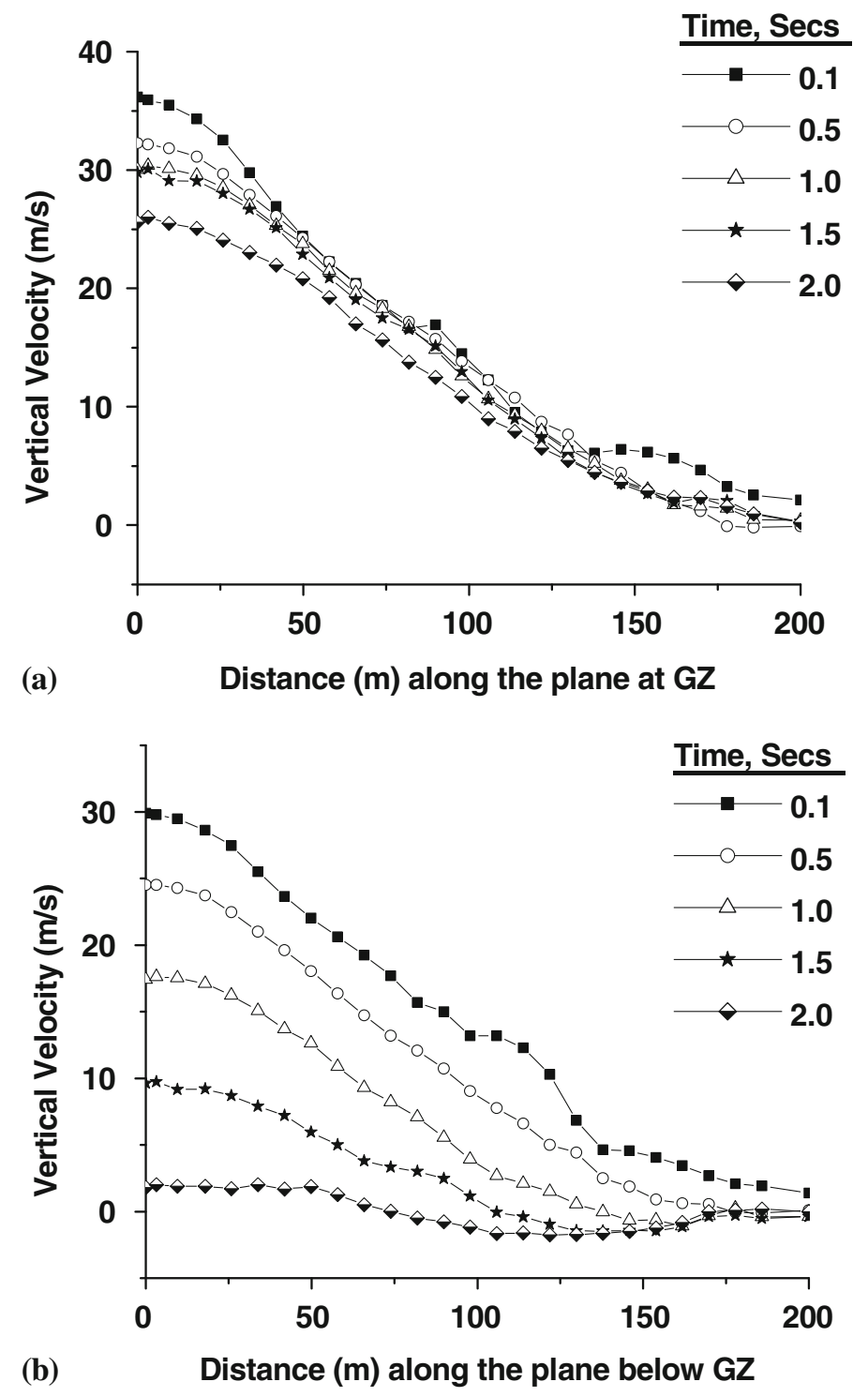

Figure 14. (a) Vertical nodal velocity $(\mathrm{m} / \mathrm{s})$ at $0.1,0.5,1.0,1.5$ and $2 \mathrm{~s}$ on the horizontal layer at GZ (top surface) in Tuff medium for $8 \mathrm{kT}$. (b) Vertical nodal velocity $(\mathrm{m} / \mathrm{s})$ at $0.1,0.5,1.0,1.5$ and $2 \mathrm{~s}$ on horizontal layer $11 \mathrm{~m}$ below GZ in Tuff medium for $8 \mathrm{kT}$.

Figures 18(a-b) show the azimuth plot of the vertical displacement history along the free surface from GZ and a sub-layer $11 \mathrm{~m}$ below GZ for SDOB of $100 \mathrm{~m} / \mathrm{kT}^{1 / 3}$. The maximum mound uplifts of 1.0 and $20.5 \mathrm{~m}$ are observed at GZ at 0.1 and $2 \mathrm{~s}$, respectively wherein the peak values for the sub-layer are 1 and $6 \mathrm{~m}$. As shown in figure 19a along GZ the peak value of velocity $\sim 11.3 \mathrm{~m} / \mathrm{s}$ is reached at $0.1 \mathrm{~s}$ which reduces to $8.1 \mathrm{~m} / \mathrm{s}$ at $2 \mathrm{~s}$. The peak values for the sub-layer are $11.2 \mathrm{~m} / \mathrm{s}$ at $0.1 \mathrm{~s}$ and $-2.9 \mathrm{~m} / \mathrm{s}$ at $2 \mathrm{~s}$, as shown in figure $19 \mathrm{~b}$, which indicates a fallback and layer separation. 


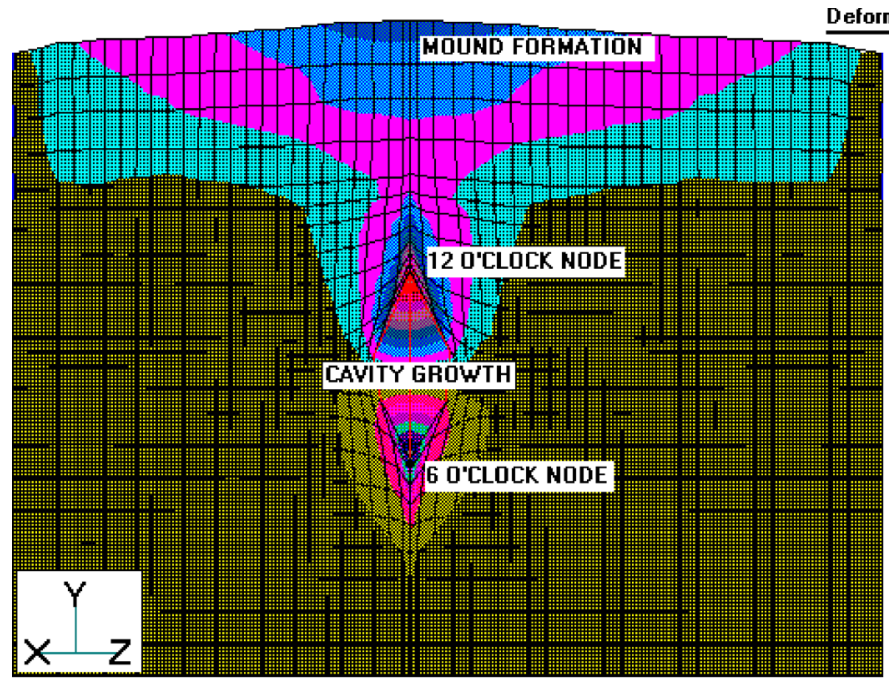

Deformation [m] Contour

(a)
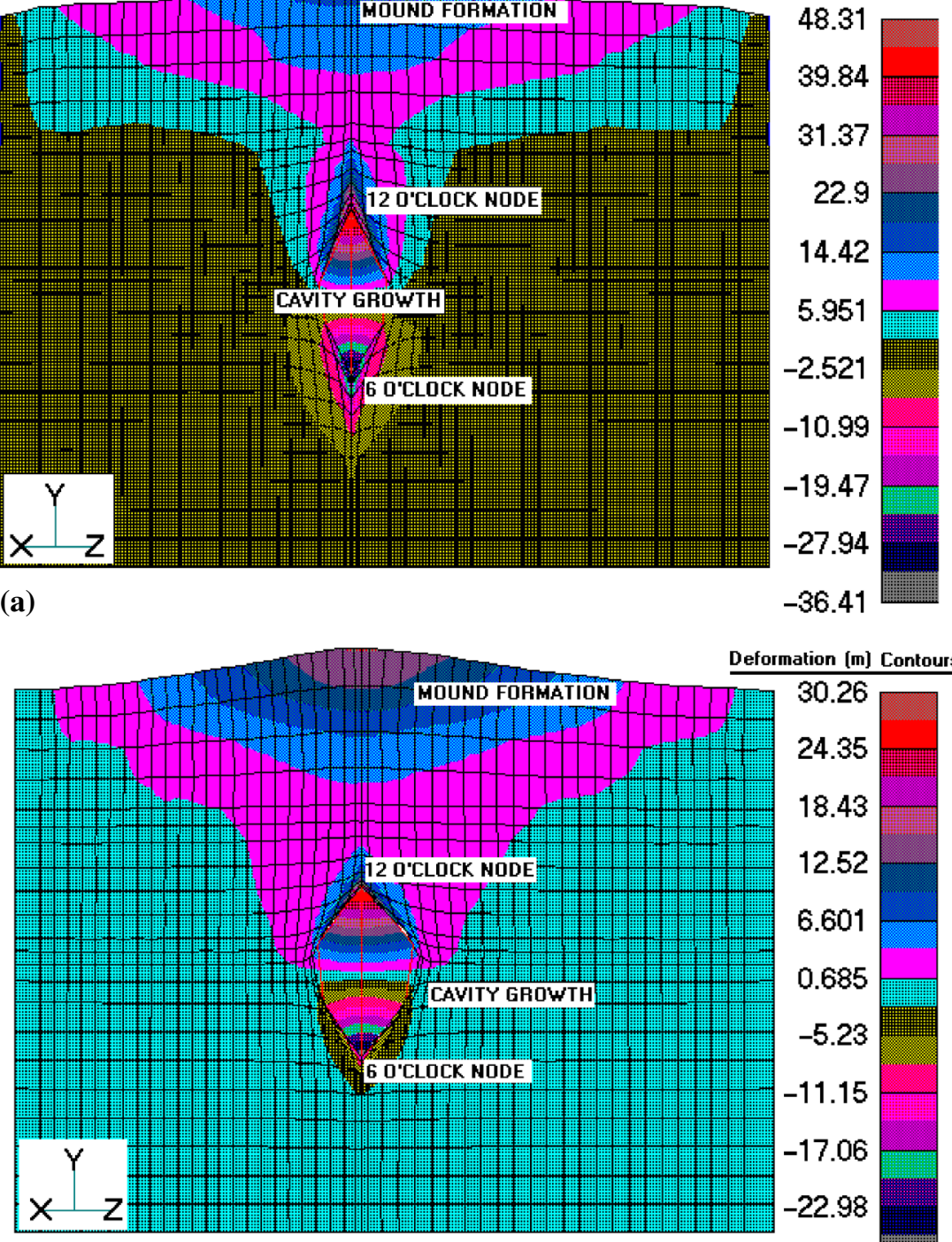

Deformation [m] Contours

(b)

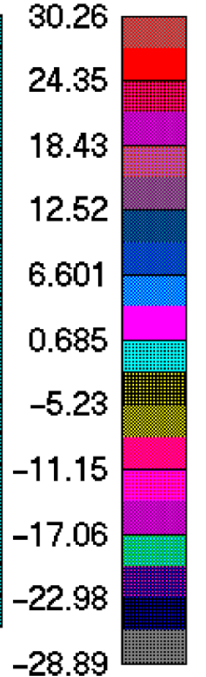

Figure 15. (a) Cavity growth (m) and mound formation (m) as $0.5 \mathrm{~s}$ in Paleozoic medium for $8 \mathrm{kT}$ yield (SDOB $50 \mathrm{~m} / \mathrm{kT}^{1 / 3}$ ). (b) Cavity growth $(\mathrm{m})$ and mound formation $(\mathrm{m})$ as $0.5 \mathrm{~s}$ in Tuff medium for $8 \mathrm{kT}$ Yield (SDOB $50 \mathrm{~m} / \mathrm{kT}^{1 / 3}$ ).

Figures 20(a-b) show the azimuth plot of the vertical displacement history along the free surface from GZ and a sub-layer $11 \mathrm{~m}$ below GZ for SDOB of $50 \mathrm{~m} / \mathrm{kT}^{1 / 3}$. In this case, on both the surfaces monotonic increase in vertical displacement with time is observed. The maximum mound uplifts of 2.1 and $47.9 \mathrm{~m}$ are noticed at GZ at 0.1 and $2 \mathrm{~s}$, respectively and at the sub-layer these values are 1.9 and $24.7 \mathrm{~m}$, respectively. Along GZ the peak value of velocity $\sim 29.2 \mathrm{~m} / \mathrm{s}$ is reached at $0.1 \mathrm{~s}$ which reduces to $21 \mathrm{~m} / \mathrm{s}$ at $2 \mathrm{~s}$ as shown in figure $21 \mathrm{a}$. The corresponding values 
Table 5. Computational results for Paleozoic-Tuff (PLTF) and Tuff-Paleozoic (TFPL) composite media.

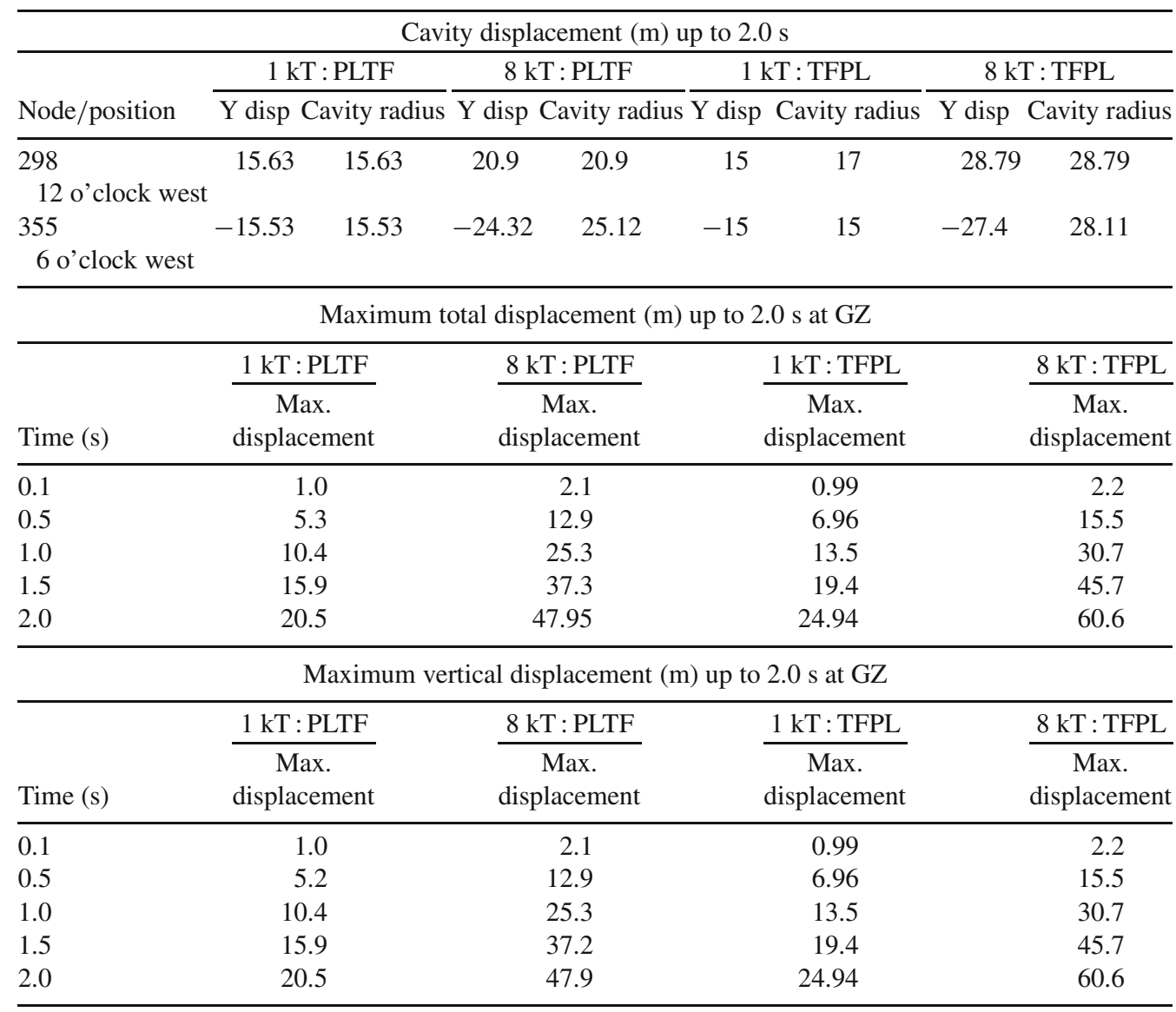

at the sub-layer, shown in figure $21 \mathrm{~b}$, are 27 and $-2.7 \mathrm{~m} / \mathrm{s}$, thus indicating layer separation. Hence, compared to the case of SDOB of $100 \mathrm{~m} / \mathrm{kT}^{1 / 3}$, in this case, we observe pronounced surface effects with a tendency of crater formation. With source in the Paleozoic medium, the free surface deformation behaviour and its magnitude are similar to homogeneous Paleozoic medium but at the sub-layer below GZ the deformations are slightly lower. This again shows the effect of weaker rarefaction from top Tuff layers as described earlier.

\subsection{Baneberry site composite TFPL medium}

The stable cavity radii in TFPL composite medium after $2 \mathrm{~s}$ are 17 and $28.8 \mathrm{~m}$ for 1 and $8 \mathrm{kT}$ yields, respectively as can be seen in figures $22(a-b)$ and $23(a-b)$. Thus, it is observed that with source in Tuff medium, the cavity growth is more compared to PLTF composite where the source was emplaced in Paleozoic medium. In both composite media, the effect of overburden on cavity growth is prominent compared to the influence of respective shear strengths and the rarefaction wave. In time vs. vertical displacement plots, cavity growth stabilizes after $0.5 \mathrm{~s}$ at both the 
Table 5. (contd.)

\begin{tabular}{|c|c|c|c|c|c|}
\hline \multicolumn{6}{|c|}{ Maximum vertical displacement $(\mathrm{m})$ up to $2.0 \mathrm{~s}$ for layer $11.0 \mathrm{~m}$ below GZ } \\
\hline & $1 \mathrm{kT}:$ PLTF & \multirow{2}{*}{ 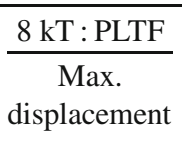 } & \multirow{2}{*}{$\frac{1 \mathrm{kT}: \mathrm{TFPL}}{\mathrm{Max} .}$} & \multicolumn{2}{|r|}{$8 \mathrm{kT}:$ TFPL } \\
\hline Time (s) & $\begin{array}{c}\text { Max. } \\
\text { displacement }\end{array}$ & & & \multicolumn{2}{|r|}{$\begin{array}{c}\text { Max. } \\
\text { displacement }\end{array}$} \\
\hline 0.1 & 1.0 & 1.9 & 0.93 & \multicolumn{2}{|r|}{1.9} \\
\hline 0.5 & 4.4 & 11.2 & 6.7 & \multicolumn{2}{|r|}{12.6} \\
\hline 1.0 & 4.6 & 19.5 & 11.4 & \multicolumn{2}{|r|}{23.4} \\
\hline 1.5 & 5.9 & 24.2 & 12.7 & \multicolumn{2}{|r|}{31.3} \\
\hline 2.0 & 6.1 & 24.7 & 13.0 & \multicolumn{2}{|r|}{35.8} \\
\hline \multicolumn{6}{|c|}{ Maximum vertical velocity (m/s) up to $2.0 \mathrm{~s}$ at $\mathrm{GZ}$} \\
\hline & $1 \mathrm{kT}:$ PLTF & \multicolumn{2}{|c|}{$8 \mathrm{kT}:$ PLTF } & $1 \mathrm{kT}: \mathrm{TFPL}$ & $8 \mathrm{kT}: \mathrm{TFPL}$ \\
\hline Time (s) & $\overline{\text { Max. velocity }}$ & \multicolumn{2}{|c|}{$\overline{\text { Max. velocity }}$} & Max. velocity & $\overline{\text { Max. velocity }}$ \\
\hline 0.1 & 11.3 & \multicolumn{2}{|c|}{29.2} & 14.8 & 36.2 \\
\hline 0.5 & 10.9 & \multicolumn{2}{|c|}{25.7} & 14.05 & 31.4 \\
\hline 1.0 & 11.14 & \multicolumn{2}{|c|}{24.3} & 12.84 & 30.0 \\
\hline 1.5 & 10.0 & \multicolumn{2}{|c|}{23.4} & 12.09 & 30.0 \\
\hline 2.0 & 8.1 & \multicolumn{2}{|c|}{21.0} & 11.5 & 28.6 \\
\hline \multicolumn{6}{|c|}{ Maximum vertical velocity (m/s) up to $2.0 \mathrm{~s}$ for layer $11.0 \mathrm{~m}$ below GZ } \\
\hline & $1 \mathrm{kT}:$ PLTF & \multicolumn{2}{|c|}{$8 \mathrm{kT}:$ PLTF } & $1 \mathrm{kT}:$ TFPL & $8 \mathrm{kT}: \mathrm{TFPL}$ \\
\hline Time (s) & $\overline{\text { Max. velocity }}$ & \multicolumn{2}{|c|}{ Max. velocity } & Max. velocity & $\overline{\text { Max. velocity }}$ \\
\hline 0.1 & 11.2 & \multicolumn{2}{|c|}{27.0} & 27.04 & 29.8 \\
\hline 0.5 & 6.2 & \multicolumn{2}{|c|}{20.3} & 20.3 & 24.4 \\
\hline 1.0 & -2.1 & \multicolumn{2}{|c|}{13.4} & 13.43 & 18.8 \\
\hline 1.5 & -2.4 & \multicolumn{2}{|c|}{7.6} & 7.6 & 12.7 \\
\hline 2.0 & -2.9 & \multicolumn{2}{|c|}{-2.7} & -2.7 & 4.9 \\
\hline
\end{tabular}

yield levels. Cavity growth as well as cavity oblonging with time as compared to the case of homogeneous medium is reduced. For SDOB of $100 \mathrm{~m} / \mathrm{kT}^{1 / 3}$, oblonging of $2 \mathrm{~m}$ is observed. Cavity growth for both the composite media is of the same order due to marginal difference ( $\sim 20 \%$ ) in overburden pressure although the shear strengths of the two media near emplacement have large variation. At SDOB of $50 \mathrm{~m} / \mathrm{kT}^{1 / 3}$, this difference is slightly more due to the fact that the influence of rarefaction wave from the top surface again becomes significant for the near surface events.

Figures 24(a-b) show the azimuth plot of the vertical displacement history along the free surface from GZ and a sub-layer $11 \mathrm{~m}$ below GZ for SDOB of $100 \mathrm{~m} / \mathrm{kT}^{1 / 3}$. The maximum mound uplifts of 1.0 and $25 \mathrm{~m}$ are observed at GZ at 0.1 and $2 \mathrm{~s}$, respectively wherein the corresponding peak values for the sub-layer are 0.9 and $13 \mathrm{~m}$. Unlike the PLTF medium in which a tendency to form a mound was observed with a focusing of compression waves around GZ, here the shock waves reflected from the underlying hard Paleozoic layer are focused away from GZ and there is a tendency to form a subsidence crater. As shown in figure 25a along GZ the peak value of velocity $\sim 14.8 \mathrm{~m} / \mathrm{s}$ is reached at $0.1 \mathrm{~s}$, which reduces to $11.5 \mathrm{~m} / \mathrm{s}$ at $2 \mathrm{~s}$. The peak 

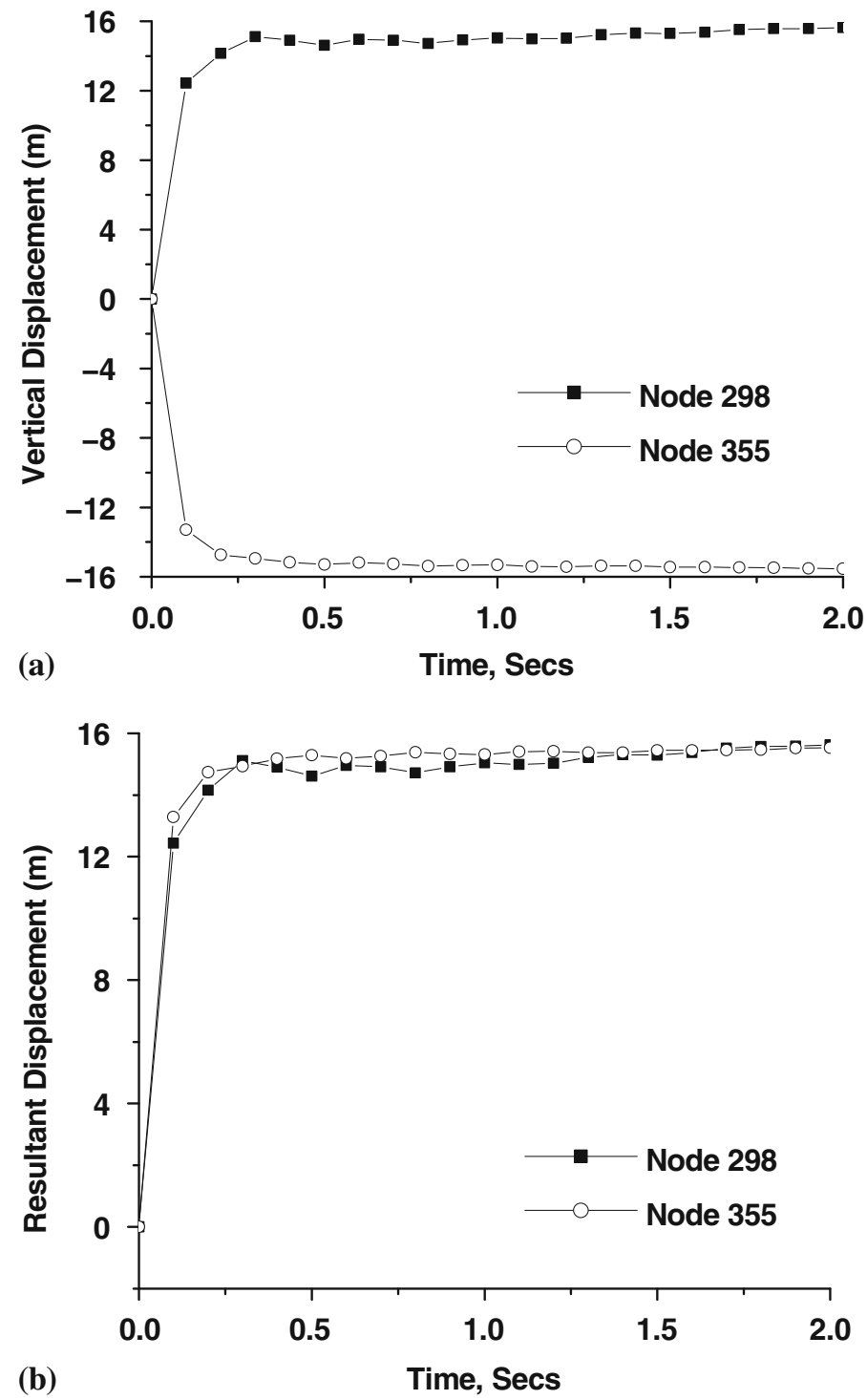

Figure 16. (a) Vertical displacement of cavity nodes 298 (12 o' clock) and 355 (6 o' clock) up to $2 \mathrm{~s}$ in PLTF composite medium for 1 kT. (b) Total displacement of cavity nodes 298 (12 o' clock) and 355 (6 o' clock) up to $2 \mathrm{~s}$ in PLTF composite medium for $1 \mathrm{kT}$.

values for the sub-layer are $27 \mathrm{~m} / \mathrm{s}$ at $0.1 \mathrm{~s}$ and $-2.7 \mathrm{~m} / \mathrm{s}$ at $2 \mathrm{~s}$, as shown in figure $25 \mathrm{~b}$, which indicates a fallback and layer separation. The shift in positions of velocity and deformation peaks is noticeable in figures 24 and 25 .

Figures 26(a-b) show the azimuth plot of the vertical displacement history along the free surface from GZ and a sub-layer $11 \mathrm{~m}$ below GZ for SDOB of $50 \mathrm{~m} / \mathrm{kT}^{1 / 3}$. In this case, on both the surfaces monotonic increase in vertical displacement with time is observed. The maximum 

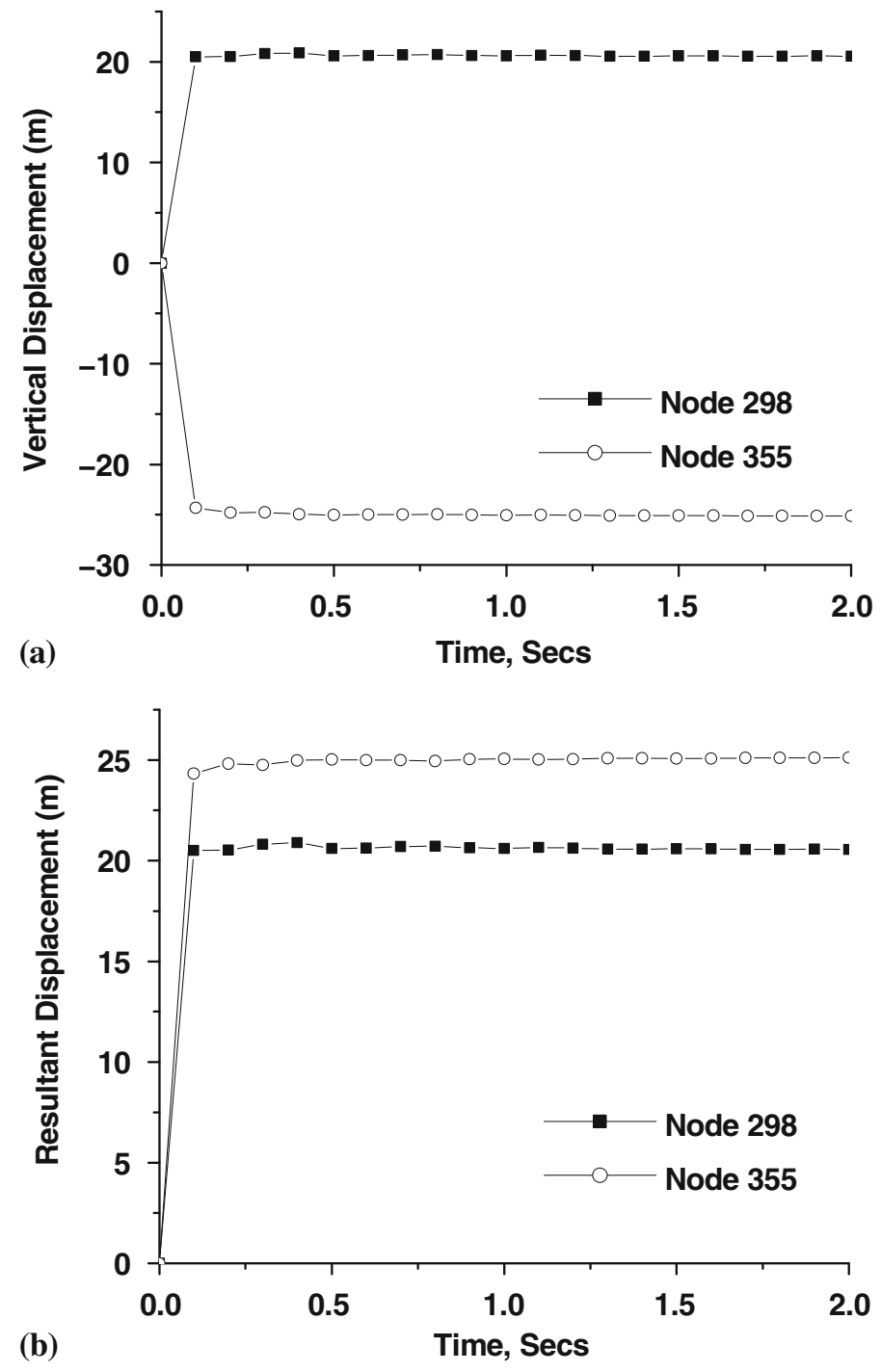

Figure 17. (a) Vertical displacement of cavity nodes 298 (12 o' clock) and 355 (6 o' clock) up to $2 \mathrm{~s}$ in PLTF composite medium for 8 kT. (b) Total displacement of cavity nodes 298 (12 o' clock) and 355 (6 o' clock) up to $2 \mathrm{~s}$ in PLTF composite medium for $8 \mathrm{kT}$.

mound uplifts of 2.2 and $60.6 \mathrm{~m}$ are observed at GZ at 0.1 and $2 \mathrm{~s}$, respectively and at the sublayer these values are 1.9 and $35.8 \mathrm{~m}$, respectively. Along GZ the peak value of velocity $\sim 36 \mathrm{~m} / \mathrm{s}$ is reached at $0.1 \mathrm{~s}$ which reduces to $28.6 \mathrm{~m} / \mathrm{s}$ at $2 \mathrm{~s}$ as shown in figure $27 \mathrm{a}$. The corresponding values at the sub-layer, as shown in figure $27 \mathrm{~b}$, are 29.8 and $4.9 \mathrm{~m} / \mathrm{s}$, thus indicating their separation. Thus compared to the case of SDOB of $100 \mathrm{~m} / \mathrm{kT}^{1 / 3}$, in this case, we observe pronounced surface effects with higher mound uplift due to lower SDOB. The effect of focusing due to medium impedance difference, which is observed for SDOB of $100 \mathrm{~m} / \mathrm{kT}^{1 / 3}$ in TFPL, is offset due to lower SDOB of $50 \mathrm{~m} / \mathrm{kT}^{1 / 3}$. 


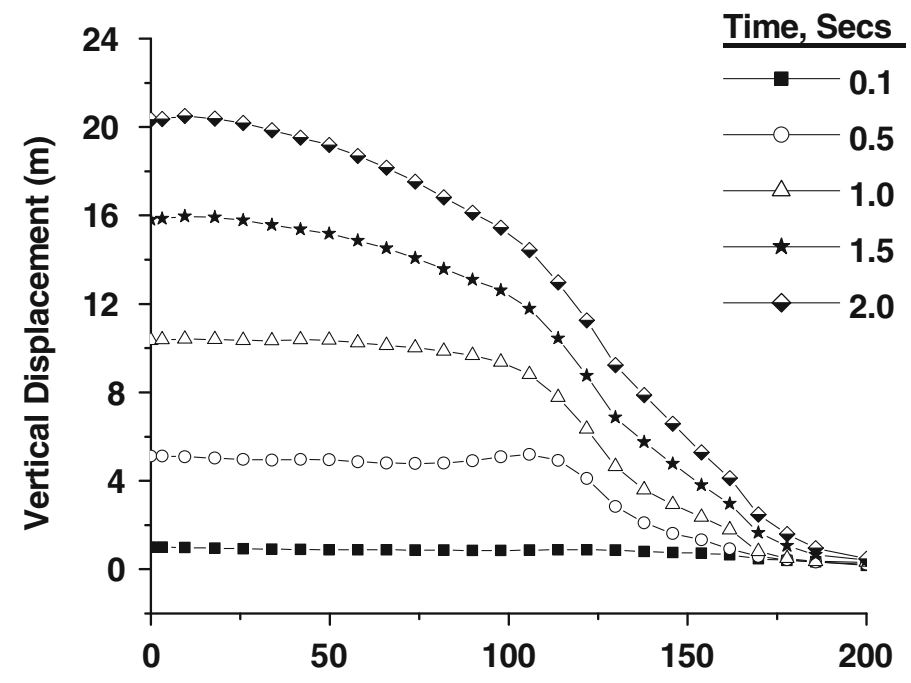

(a)

Distance $(\mathrm{m})$ along the plane at $\mathrm{GZ}$

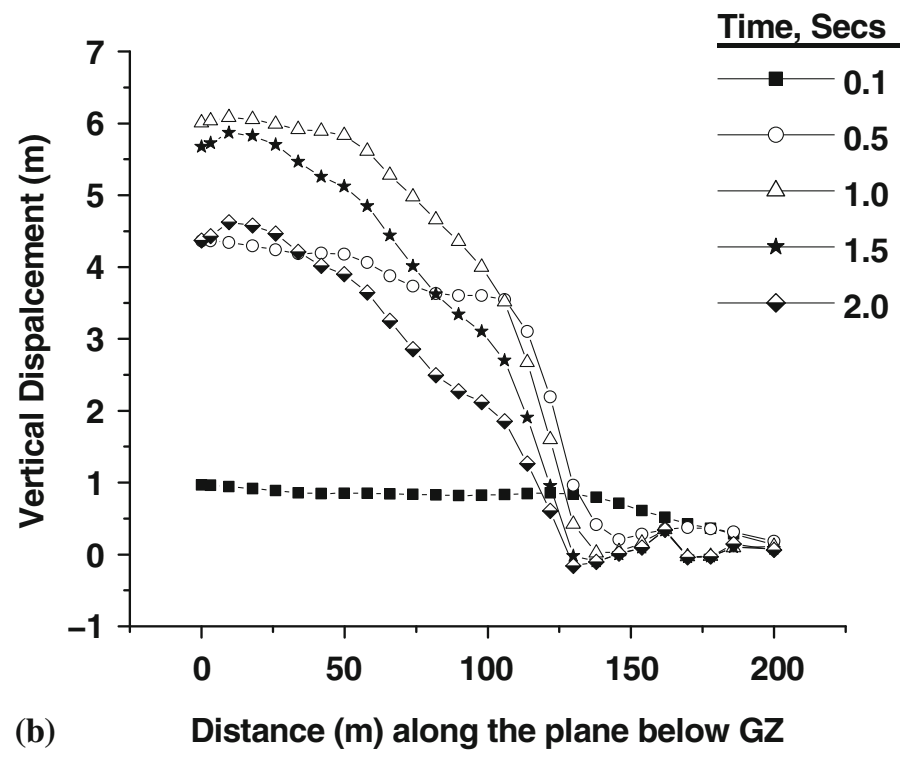

Figure 18. (a) Vertical nodal displacement (m) at $0.1,0.5,1.0,1.5$ and $2 \mathrm{~s}$ on the horizontal layer along GZ (top surface) in PLTF composite medium for $1 \mathrm{kT}$. (b) Vertical nodal displacement (m) at 0.1, 0.5, 1.0, 1.5 and $2 \mathrm{~s}$ on the horizontal layer below GZ in PLTF composite medium for $1 \mathrm{kT}$.

Compared to PLTF composite media, in TFPL composite layer pattern, uniformity in deformation pattern at lower SDOB of $50 \mathrm{~m} / \mathrm{kT}^{1 / 3}$ is observed with a difference of around $13 \mathrm{~m}$ in maximum mound uplift at $2 \mathrm{~s}$. This can be attributed to large fraction of energy reflected from the underlying Paleozoic layer. Hence, in both the cases, crater formation due to mound fallback could be expected after a longer duration. 

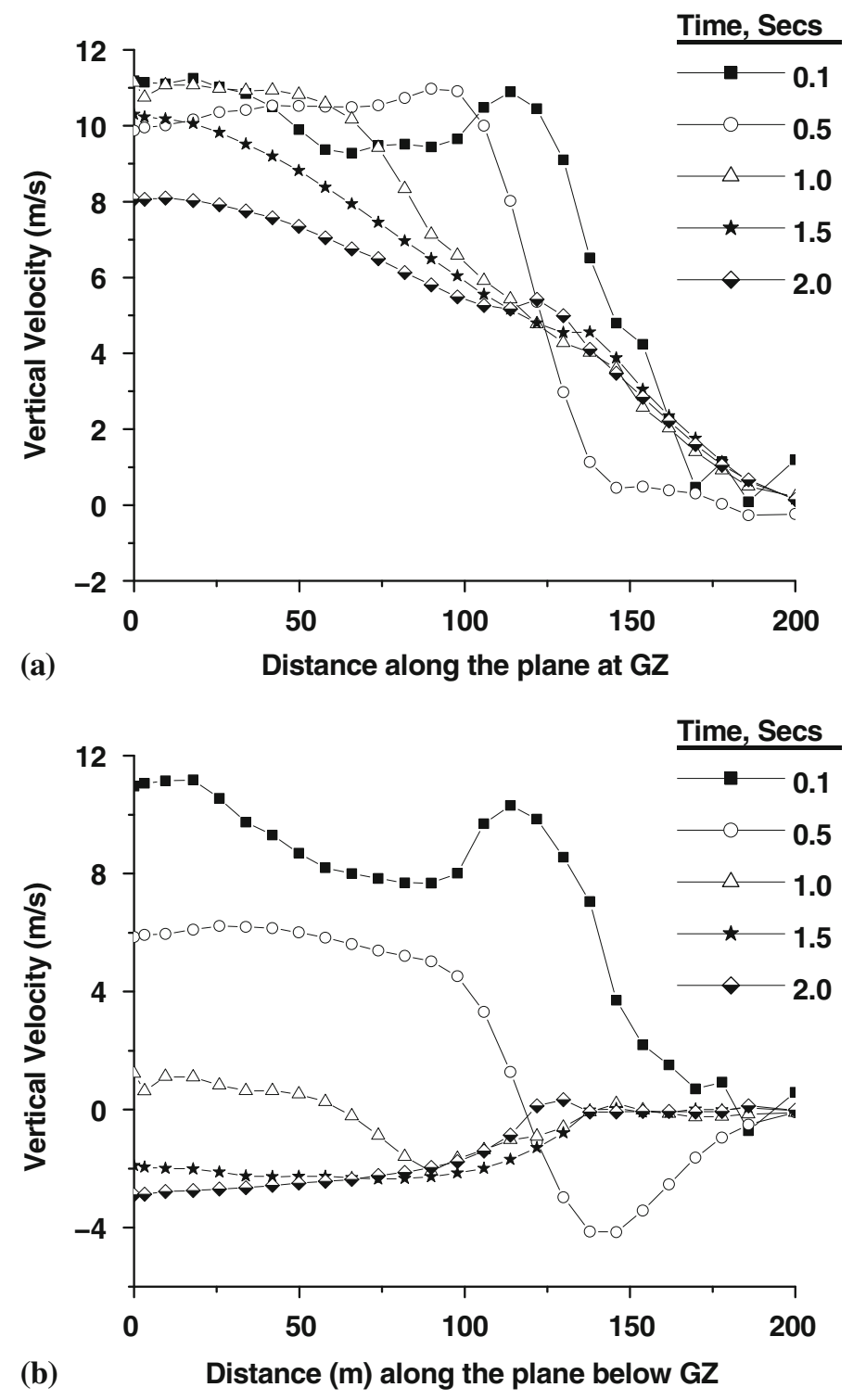

Figure 19. (a) Vertical nodal velocity $(\mathrm{m} / \mathrm{s})$ at $0.1,0.5,1.0,1.5$ and $2 \mathrm{~s}$ on the horizontal layer at GZ (top surface) in PLTF composite medium for $1 \mathrm{kT}$. (b) Vertical nodal velocity $(\mathrm{m} / \mathrm{s})$ at $0.1,0.5,1.0,1.5$ and $2 \mathrm{~s}$ on the horizontal layer below GZ in PLTF composite medium for $1 \mathrm{kT}$.

\subsection{Comparison of near source synthetic acceleration signals}

For all the cases identified above, the vertical and horizontal accelerations were sensed at the source depth with a radial distance of $282 \mathrm{~m}$, diagonally opposite the source. The original signals were filtered for the frequency band above $15 \mathrm{~Hz}$ to study the spectral amplitude of the synthetic signals in the frequency band of interest (DC to $15 \mathrm{~Hz}$ ). The seismic energy is propagated in this frequency band while the signals above this band are attenuated and are not significant for the 

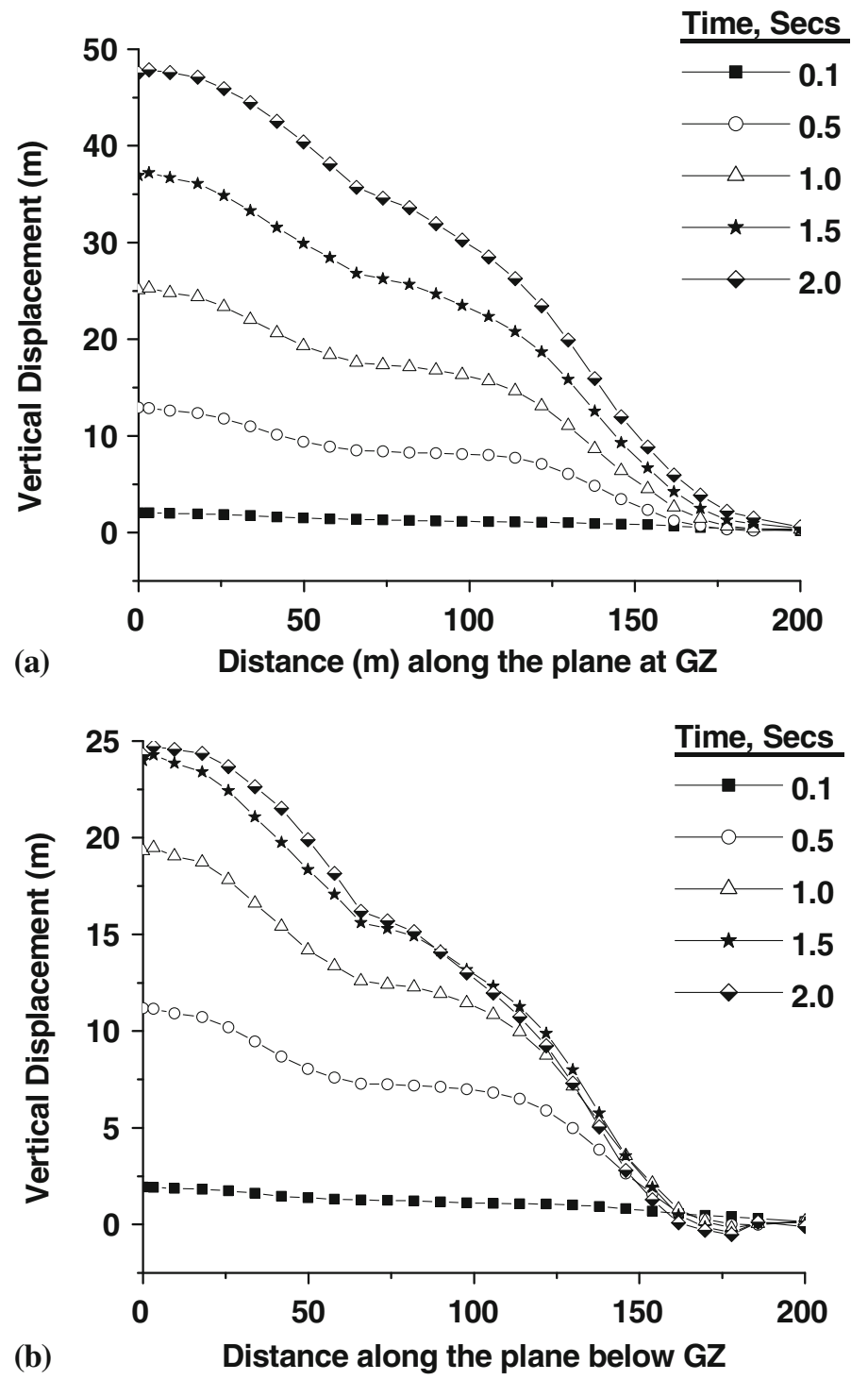

Figure 20. (a) Vertical nodal displacement (m) at $0.1,0.5,1.0,1.5$ and $2 \mathrm{~s}$ on the horizontal layer along GZ (top surface) in PLTF composite medium for $8 \mathrm{kT}$. (b) Vertical nodal displacement (m) at 0.1, 0.5, 1.0, 1.5 and $2 \mathrm{~s}$ on the horizontal layer below GZ in PLTF composite medium for $8 \mathrm{kT}$.

present study. The propagated seismic energy sensed by the regional centers and global networks in this band are used for the nuclear explosion event detection and discrimination and at times for approximate yield estimation. The acceleration signals for the individual Paleozoic and Tuff mediums and the two composite media PLTF and TFPL were filtered for both the SDOBs of 100 and $50 \mathrm{~m} / \mathrm{kT}^{1 / 3}$ and the peak acceleration values and the spectral values in the frequency band of DC to $15 \mathrm{HZ}$ were obtained. 

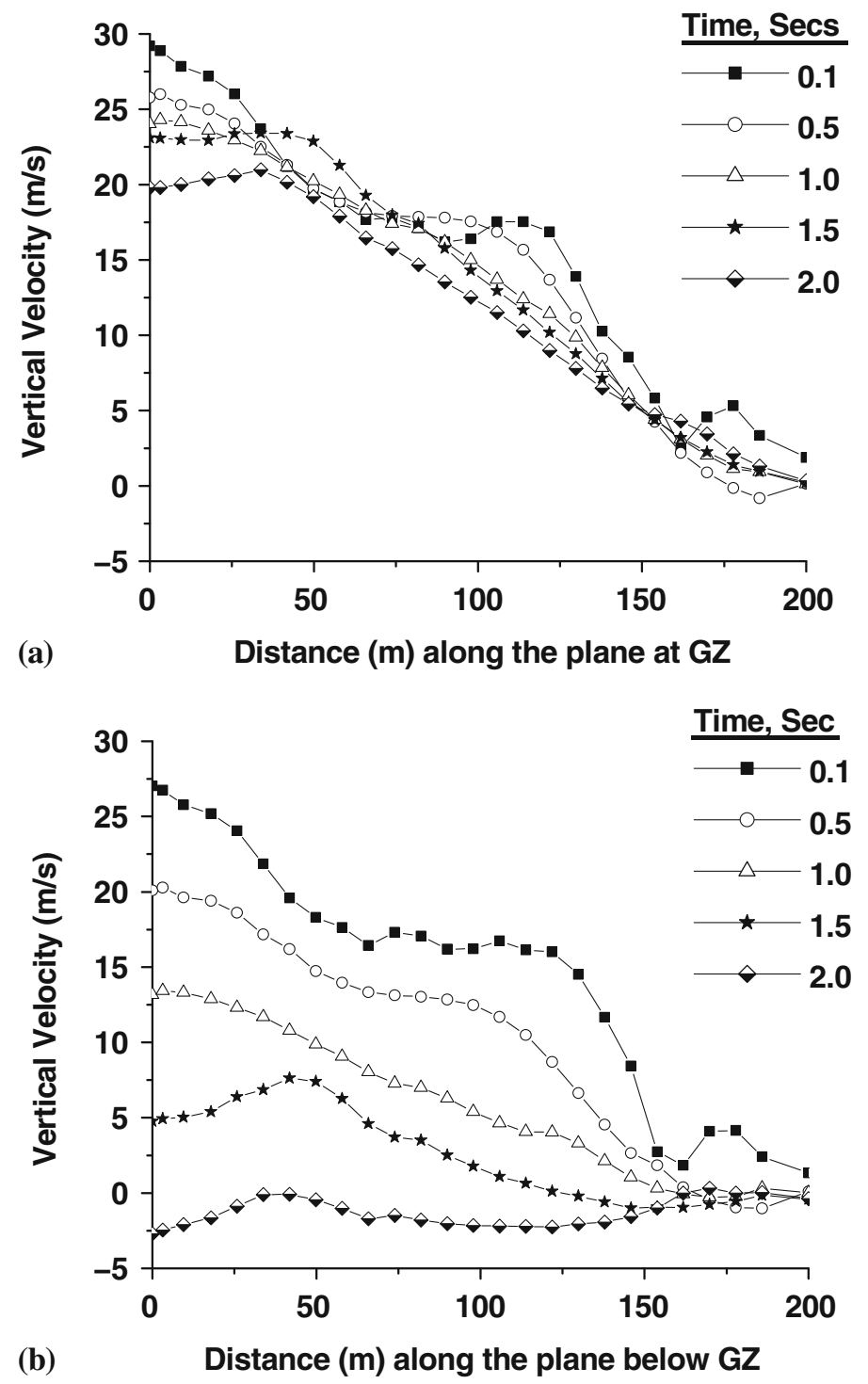

Figure 21. (a) Vertical nodal velocity $(\mathrm{m} / \mathrm{s})$ at $0.1,0.5,1.0,1.5$ and $2 \mathrm{~s}$ on the horizontal layer at GZ (top surface) in PLTF composite medium for $8 \mathrm{kT}$. (b) Vertical nodal velocity $(\mathrm{m} / \mathrm{s})$ at $0.1,0.5,1.0,1.5$ and $2 \mathrm{~s}$ on the horizontal layer $11 \mathrm{~m}$ below GZ in PLTF composite medium for $8 \mathrm{kT}$.

Tables 6-8 gives the computed peak horizontal and vertical acceleration ( $A_{X}$ and $\left.A_{Y}\right)$ signals along with their maximum Fourier amplitudes (Fax and Fay), recorded up to $15 \mathrm{~Hz}$. In this table the peak values of spectral accelerations are recorded within a frequency interval of $1 \mathrm{~Hz}$. Thus it is possible to compare the coupling behaviour of different media at both the SDOBs of 100 and $50 \mathrm{~m} / \mathrm{kT}^{1 / 3}$. 

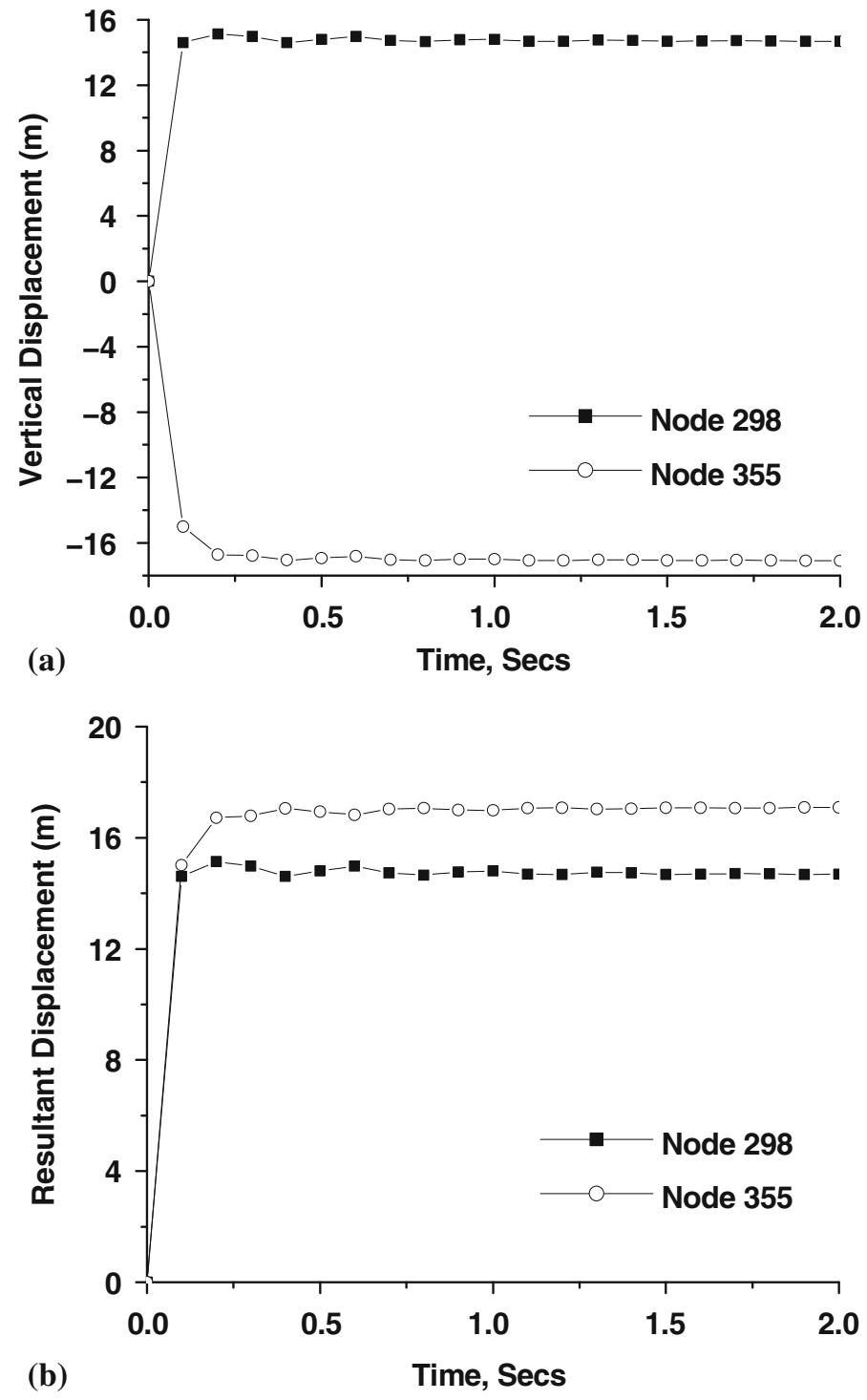

Figure 22. (a) Vertical displacement of cavity nodes 298 (top node) and 355 (bottom) up to $2 \mathrm{~s}$ in TFPL composite medium for $1 \mathrm{kT}$. (b) Total displacement of cavity nodes 298 (top node) and 355 (bottom) up to $2 \mathrm{~s}$ in TFPL composite medium for $1 \mathrm{kT}$.

\subsection{Time domain acceleration signal amplitudes}

It is noted that the horizontal accelerations are weaker compared to the vertical accelerations in a homogeneous medium which is normally the observation in near source signals. For the case of homogeneous medium, the ratio of $\mathrm{A}_{\mathrm{Y}}$ in Paleozoic medium to that in Tuff medium for SDOB of $100 \mathrm{~m} / \mathrm{kT}^{1 / 3}$ are 4.18 , a decrease from 46 to $11 \mathrm{~m} / \mathrm{s}^{2}$. However, the horizontal signals are very weak for both the medium $(\sim 1 \mathrm{~g})$. For SDOB of $50 \mathrm{~m} / \mathrm{kT}^{1 / 3}$, the ratio of $\mathrm{A}_{\mathrm{Y}}$ in these two 

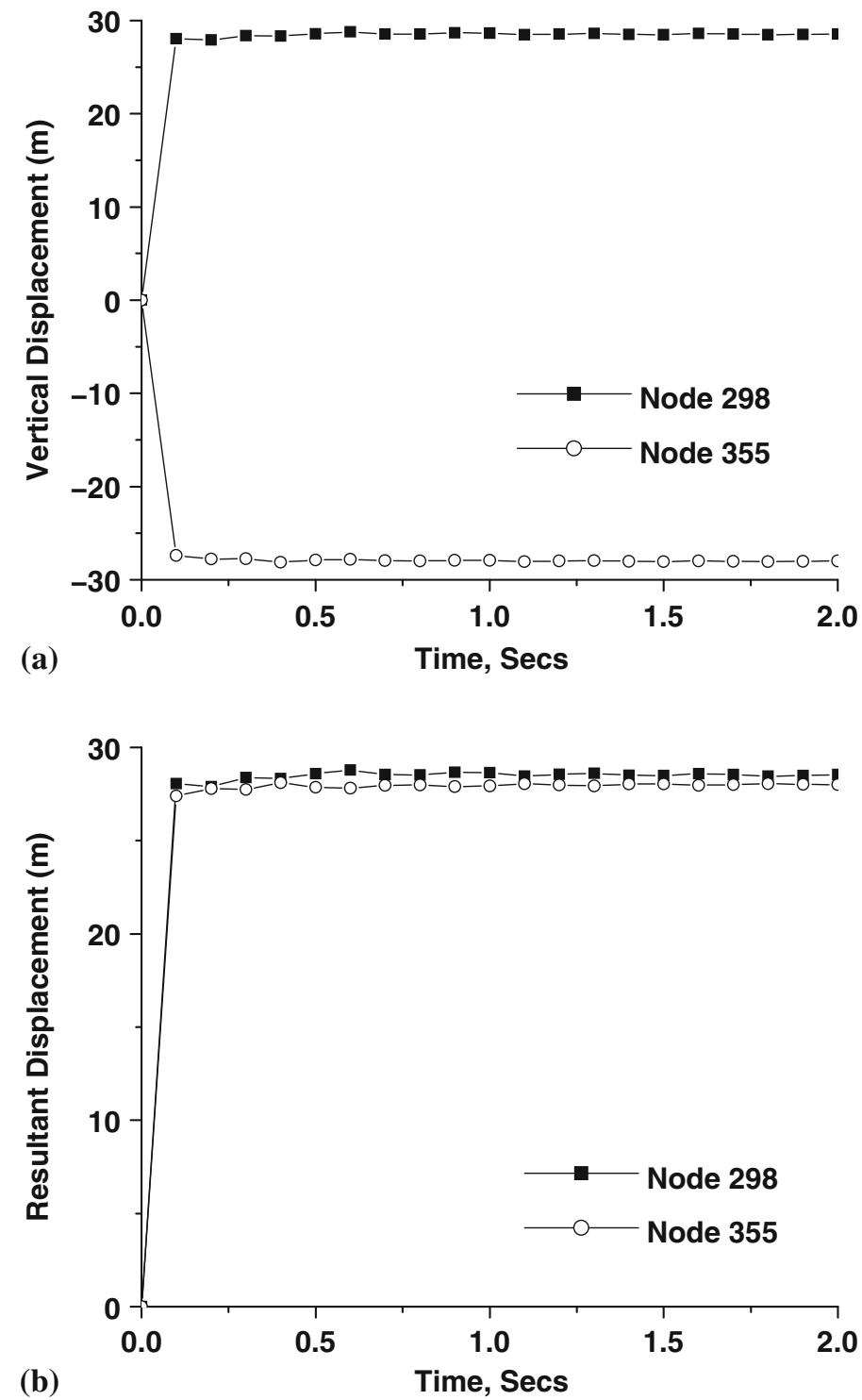

Figure 23. (a) Vertical displacement of cavity nodes 298 (top node) and 355 (bottom) up to $2 \mathrm{~s}$ in TFPL composite medium for $8 \mathrm{kT}$. (b) Total displacement of cavity nodes 298 (top node) and 355 (bottom) up to $2 \mathrm{~s}$ in TFPL composite medium for $8 \mathrm{kT}$.

mediums (Paleozoic and Tuff) is 2.16, a decrease from 69 to $32 \mathrm{~m} / \mathrm{s}^{2}$ and $A_{X}$ values are 23.5 and $20 \mathrm{~m} / \mathrm{s}^{2}$, which are comparable. This shows that Tuff medium masks the significant signals even at the lower SDOB of $50 \mathrm{~m} / \mathrm{kT}^{1 / 3}$. This is attributed to pronounced inelastic behaviour in Tuff medium compared to the Paleozoic medium, which results in higher decoupling.

Vertical component, $A_{Y}$ in Paleozoic medium for SDOB of $50 \mathrm{~m} / \mathrm{kT}^{1 / 3}\left(69 \mathrm{~m} / \mathrm{s}^{2}\right)$ is 1.5 times more than the value for SDOB of $100 \mathrm{~m} / \mathrm{kT}^{1 / 3}\left(46 \mathrm{~m} / \mathrm{s}^{2}\right)$. For this case, horizontal component, 

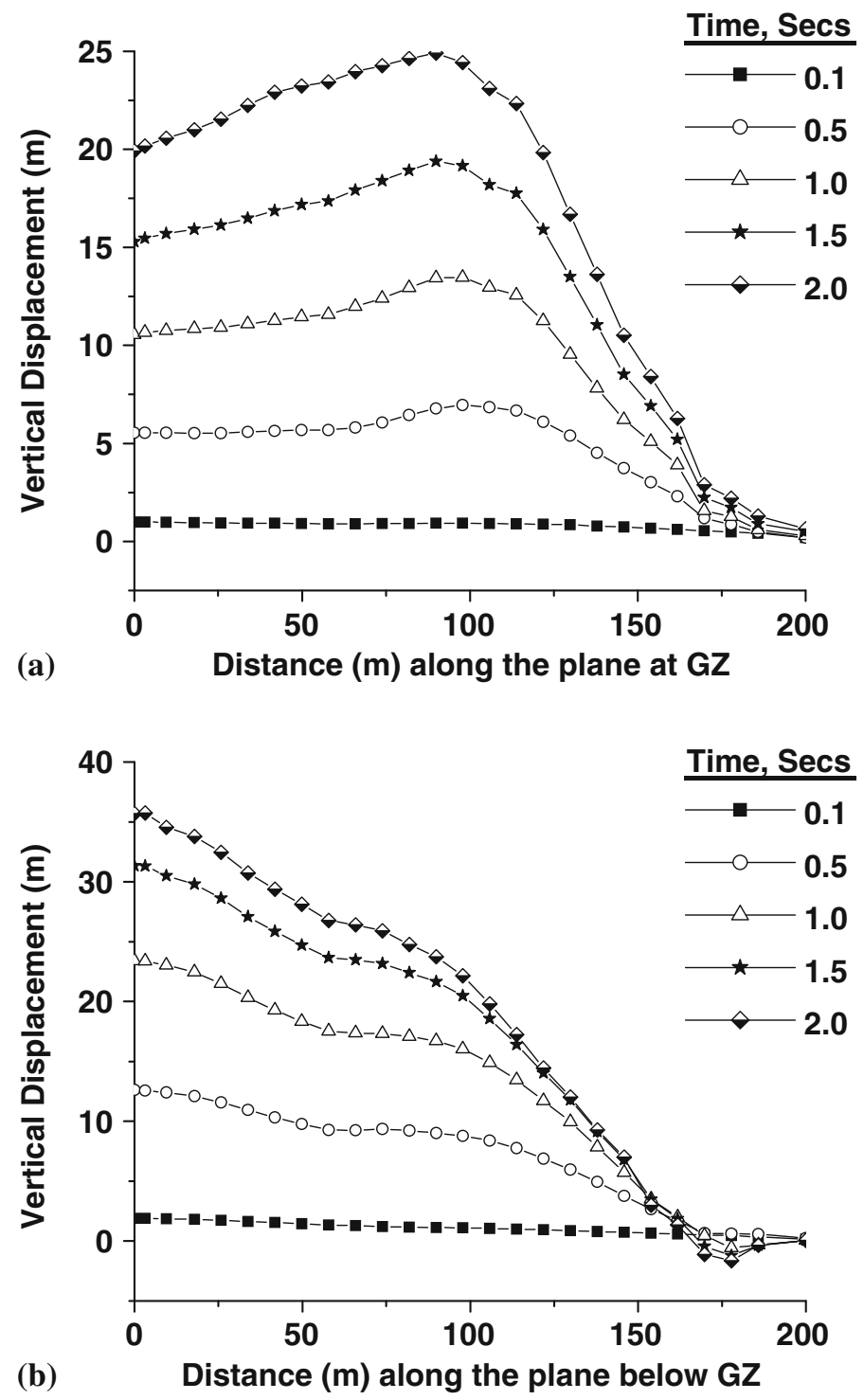

Figure 24. (a) Vertical nodal displacement (m) at $0.1,0.5,1.0,1.5$ and $2 \mathrm{~s}$ on the horizontal layer along GZ (top surface) in TFPL composite medium for $1 \mathrm{kT}$. (b) Vertical nodal displacement (m) at 0.1, 0.5, 1.0, 1.5 and $2 \mathrm{~s}$ on the horizontal layer $11 \mathrm{~m}$ below GZ in TFPL composite medium for $1 \mathrm{kT}$.

$\mathrm{A}_{\mathrm{X}}$ for $\mathrm{SDOB}$ of $50 \mathrm{~m} / \mathrm{kT}^{1 / 3}\left(23.5 \mathrm{~m} / \mathrm{s}^{2}\right)$ is three times more than the value for SDOB of $100 \mathrm{~m} / \mathrm{kT}^{1 / 3}\left(8.1 \mathrm{~m} / \mathrm{s}^{2}\right)$. But for the weaker Tuff medium, this increase is around 3 times for $A_{Y}\left(32 \mathrm{~m} / \mathrm{s}^{2}\right.$ compared to $\left.11 \mathrm{~m} / \mathrm{s}^{2}\right)$ and 2 times for $A_{X}\left(20 \mathrm{~m} / \mathrm{s}^{2}\right.$ compared to $\left.10 \mathrm{~m} / \mathrm{s}^{2}\right)$ as can be seen in table 6 .

In the composite media, the ratio of $A_{Y}$ in PLTF to that in TFPL for SDOB of $100 \mathrm{~m} / \mathrm{kT}^{1 / 3}$ is $4.55\left(50 \mathrm{~m} / \mathrm{s}^{2}\right.$ compared to $\left.11 \mathrm{~m} / \mathrm{s}^{2}\right)$. This value is $1.25\left(22.4 \mathrm{~m} / \mathrm{s}^{2}\right.$ compared to $\left.17.9 \mathrm{~m} / \mathrm{s}^{2}\right)$ for 

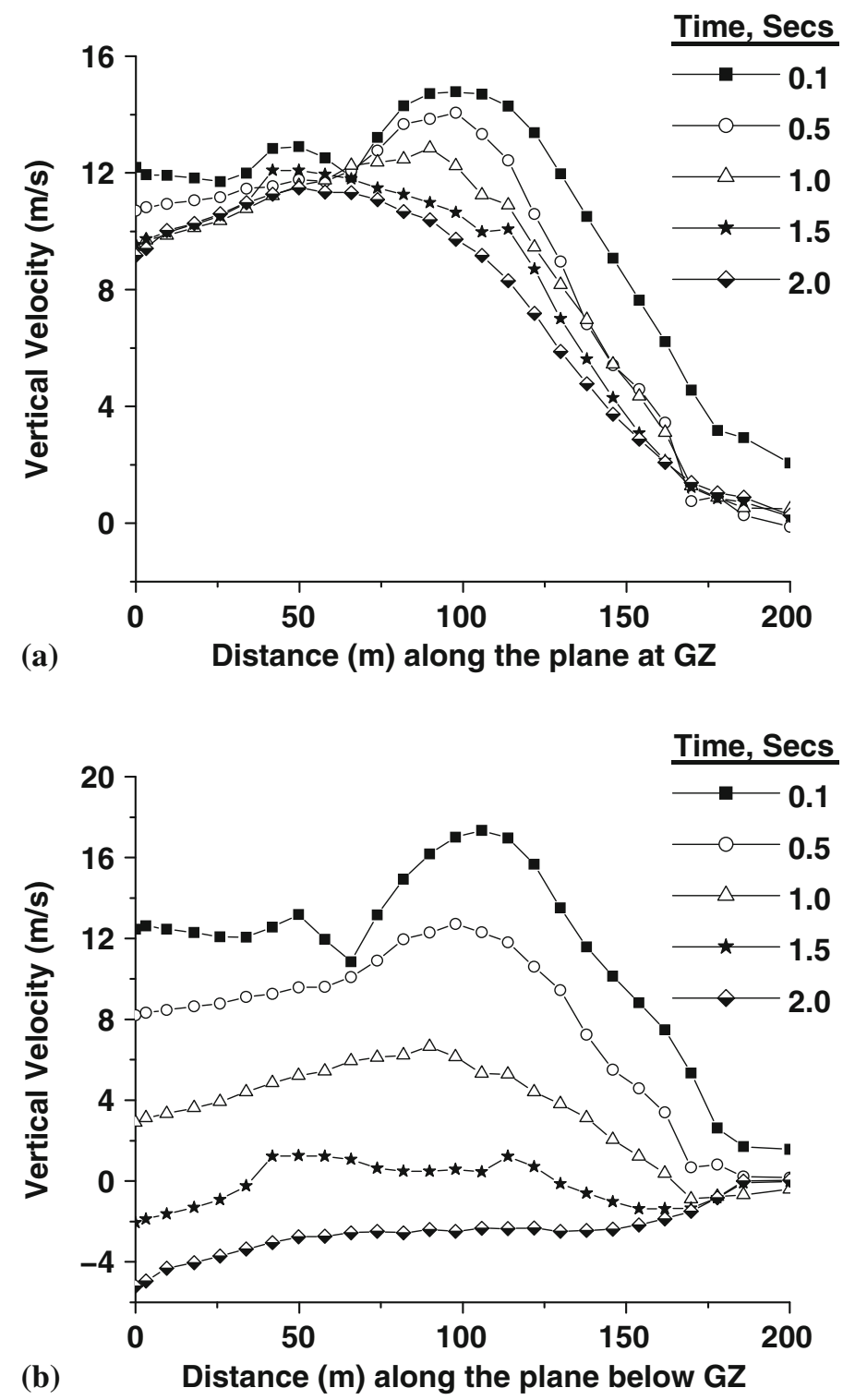

Figure 25. (a) Vertical nodal velocity $(\mathrm{m} / \mathrm{s})$ at $0.1,0.5,1.0,1.5$ and $2 \mathrm{~s}$ on the horizontal layer at GZ (top surface) in TFPL composite medium for $1 \mathrm{kT}$. (b) Vertical nodal velocity $(\mathrm{m} / \mathrm{s})$ at $0.1,0.5,1.0,1.5$ and $2 \mathrm{~s}$ on the horizontal layer $11 \mathrm{~m}$ below GZ in TFPL composite medium for $1 \mathrm{kT}$.

peak horizontal acceleration $\left(A_{X}\right)$. For SDOB of $50 \mathrm{~m} / \mathrm{kT}^{1 / 3}$, the ratio of $A_{Y}$ is $5.45\left(60 \mathrm{~m} / \mathrm{s}^{2}\right.$ compared to $11 \mathrm{~m} / \mathrm{s}^{2}$ ).

In the composite PLTF medium the value of $A_{Y}$ decreases by $1 \mathrm{~g}\left(50 \mathrm{~m} / \mathrm{s}^{2}\right.$ compared to $60 \mathrm{~m} / \mathrm{s}^{2}$ ) with decrease in SDOB from 100 to $50 \mathrm{~m} / \mathrm{kT}^{1 / 3}$. In composite TFPL medium, AY values are of the same order $(\sim 1.1 \mathrm{~g})$ for both the SDOBs but $\mathrm{A}_{\mathrm{X}}$ increases by a factor of $1.8\left(30 \mathrm{~m} / \mathrm{s}^{2}\right.$ compared to $\left.17.9 \mathrm{~m} / \mathrm{s}^{2}\right)$ with decrease of SDOB from 100 to $50 \mathrm{~m} / \mathrm{kT}^{1 / 3}$. This 

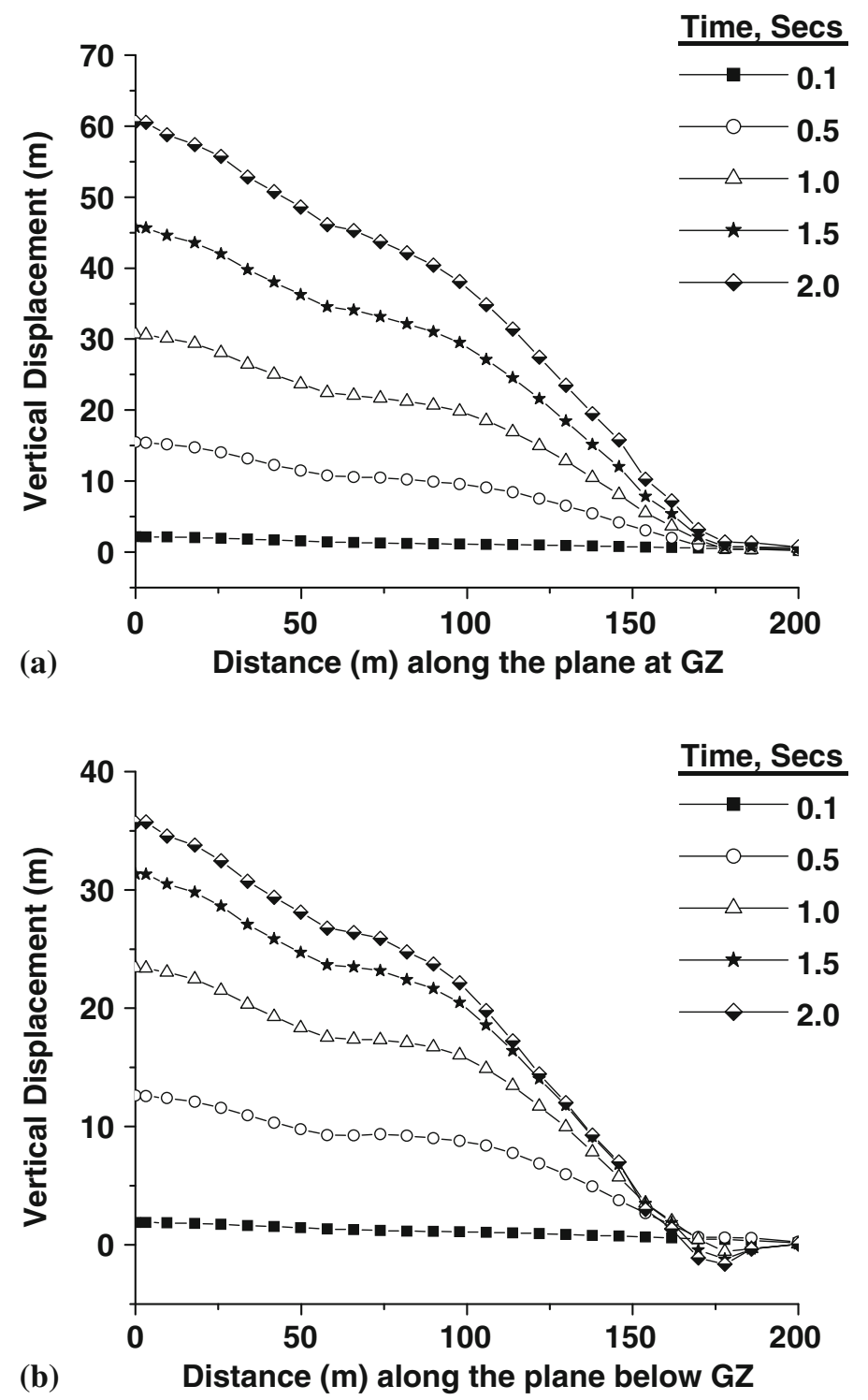

Figure 26. (a) Vertical nodal displacement (m) at $0.1,0.5,1.0,1.5$ and $2 \mathrm{~s}$ on the horizontal layer along GZ (top surface) in TFPL composite medium for $8 \mathrm{kT}$. (b) Vertical nodal displacement (m) at 0.1, 0.5, 1.0, 1.5 and $2 \mathrm{~s}$ on the horizontal layer $11 \mathrm{~m}$ below GZ in TFPL composite medium for $8 \mathrm{kT}$.

is because the waves reflected from underlying Paleozoic layer have major component in the horizontal direction, which become significant with lowering of the SDOB.

\subsection{Frequency domain spectral amplitudes}

In this section, a comparison has been made between spectral amplitudes of computed synthetic acceleration signals for media that are selected for the present study with varying impedance and 

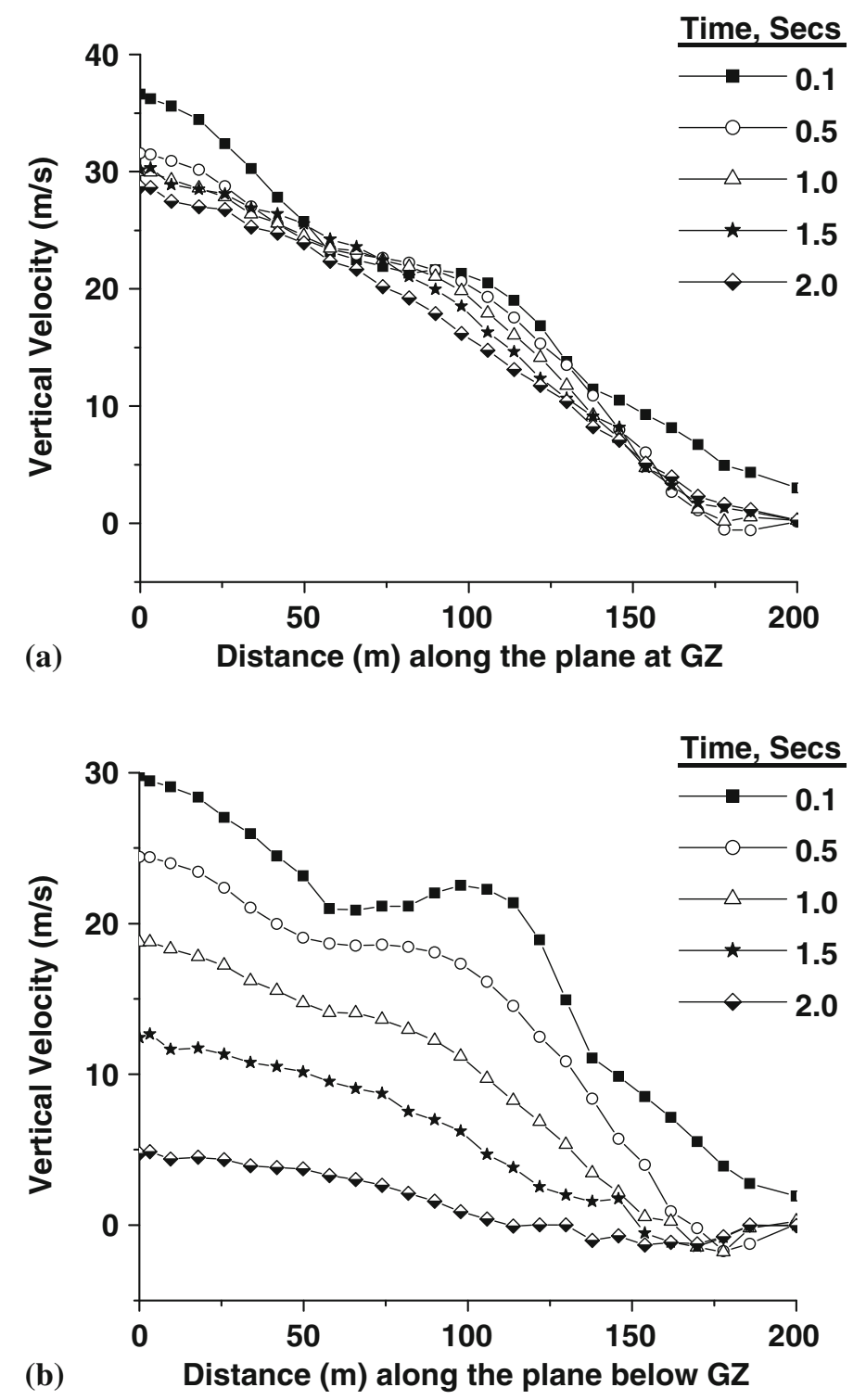

Figure 27. (a) Vertical nodal velocity $(\mathrm{m} / \mathrm{s})$ at $0.1,0.5,1.0,1.5$ and $2 \mathrm{~s}$ on the horizontal layer at GZ (top surface) in TFPL composite medium for $8 \mathrm{kT}$. (b) Vertical nodal velocity $(\mathrm{m} / \mathrm{s})$ at $0.1,0.5,1.0,1.5$ and $2 \mathrm{~s}$ on the horizontal layer $11 \mathrm{~m}$ below GZ in TFPL composite medium for $8 \mathrm{kT}$.

strength for the two SDOBs. For both the SDOBs, the ratio of spectral acceleration for Paleozoic and Tuff media and composites PLTF and TFPL are studied. These ratios have been calculated using the values given in tables 7 and 8 and are presented in tables 9 and 10 for the vertical and horizontal spectral acceleration amplitudes. It is noted that for SDOB of $50 \mathrm{~m} / \mathrm{kT}^{1 / 3}$ the spectral amplitudes are higher than for SDOB of $100 \mathrm{~m} / \mathrm{kT}^{1 / 3}$. 
Table 6. Peak acceleration values ${ }^{1}$ for different media for 1 and $8 \mathrm{kT}$ explosion yield.

\begin{tabular}{lccc}
\hline Medium & $\begin{array}{c}\text { Scale depth of burst } \\
(\mathrm{SDOB})\left(\mathrm{m} / \mathrm{kT}^{1 / 3}\right)\end{array}$ & $\begin{array}{c}\text { Vertical acceleration } \\
\left(\mathrm{m} / \mathrm{s}^{2}\right)\end{array}$ & $\begin{array}{c}\text { Horizontal acceleration } \\
\left(\mathrm{m} / \mathrm{s}^{2}\right)\end{array}$ \\
\hline Paleozoic & 100 & 46 & 8.1 \\
\multirow{2}{*}{ Tuff } & 50 & 69 & 23.5 \\
& 100 & 11 & 10 \\
PLTF & 50 & 32 & 20 \\
& 100 & 50 & 22.4 \\
TFPL & 50 & 60 & 25.5 \\
& 100 & 11 & 17.9 \\
\hline
\end{tabular}

${ }^{1}$ The acceleration values are sensed at a radial distance of $282 \mathrm{~m}$ from source at a depth same as the source.

\subsection{Vertical spectral acceleration $\left(F A_{Y}\right)$}

For SDOB of $100 \mathrm{~m} / \mathrm{kT}^{1 / 3}$, the maximum ratio of Fourier amplitudes of spectral vertical acceleration (FAY) in Paleozoic medium to that in Tuff in the $1-5 \mathrm{~Hz}$ range is 8.5 (sub-interval $1-2 \mathrm{~Hz}$ ) and remains over 5 in other sub-intervals. In the $5-10 \mathrm{~Hz}$ range, for the same case, the maximum ratio is 7.8 (sub-interval $8-9 \mathrm{~Hz}$ ) and the minimum ratio is 3.8 (sub-interval $6-8 \mathrm{~Hz}$ ). In the $10-15 \mathrm{~Hz}$ range, the notable ratios are 15.6 (sub-interval 12-13 Hz) and 16.2 (sub-interval $13-14 \mathrm{~Hz}$ ) and for other sub-intervals the spectral ratios are $\sim 6-7.5$.

For SDOB of $50 \mathrm{~m} / \mathrm{kT}^{1 / 3}$, the maximum ratio of Fourier amplitude of peak vertical acceleration $\left(F_{Y}\right)$ in Paleozoic medium to that in Tuff in the $1-5 \mathrm{~Hz}$ range is 5.9 (sub-interval 2-4 Hz) and remains over 3 in other sub-intervals. In the 5-10 Hz range, for the same case, the notable maximum values are 11.3 (sub-interval 6-7 Hz) and 10.7 (sub-interval 7-8 Hz) and the minimum

Table 7. Fourier amplitudes $(\mathrm{m} / \mathrm{s})$ of computed vertical acceleration time history.

\begin{tabular}{|c|c|c|c|c|c|c|c|c|}
\hline \multirow[b]{2}{*}{$\begin{array}{l}\text { Frequency } \\
\text { range }(\mathrm{Hz})\end{array}$} & \multicolumn{2}{|c|}{ Paleozoic } & \multicolumn{2}{|c|}{ Tuff } & \multicolumn{2}{|c|}{ PLTF } & \multicolumn{2}{|c|}{ TFPL } \\
\hline & $\begin{array}{c}100 \\
\left(\mathrm{~m} / \mathrm{kT}^{1 / 3}\right)\end{array}$ & $\begin{array}{c}50 \\
\left(\mathrm{~m} / \mathrm{kT}^{1 / 3}\right)\end{array}$ & $\begin{array}{c}100 \\
\left(\mathrm{~m} / \mathrm{kT}^{1 / 3}\right)\end{array}$ & $\begin{array}{c}50 \\
\left(\mathrm{~m} / \mathrm{kT}^{1 / 3}\right)\end{array}$ & $\begin{array}{c}100 \\
\left(\mathrm{~m} / \mathrm{kT}^{1 / 3}\right)\end{array}$ & $\begin{array}{c}50 \\
\left(\mathrm{~m} / \mathrm{kT}^{1 / 3}\right)\end{array}$ & $\begin{array}{c}100 \\
\left(\mathrm{~m} / \mathrm{kT}^{1 / 3}\right)\end{array}$ & $\begin{array}{c}50 \\
\left(\mathrm{~m} / \mathrm{kT}^{1 / 3}\right)\end{array}$ \\
\hline $1-2$ & 390 & 419 & 46 & 137 & 438 & 516 & 40 & 134 \\
\hline $2-3$ & 380 & 670 & 78 & 114 & 360 & 516 & 130 & 130 \\
\hline $3-4$ & 520 & 670 & 78 & 114 & 336 & 440 & 130 & 138 \\
\hline $4-5$ & 598 & 642 & 94 & 137 & 312 & 382 & 182 & 157 \\
\hline $5-6$ & 520 & 879 & 94 & 157 & 360 & 573 & 211 & 202 \\
\hline $6-7$ & 260 & 1395 & 68 & 123 & 528 & 611 & 195 & 205 \\
\hline $7-8$ & 390 & 1311 & 102 & 123 & 528 & 573 & 65 & 67 \\
\hline $8-9$ & 530 & 920 & 68 & 176 & 570 & 516 & 97 & 35 \\
\hline $9-10$ & 490 & 338 & 75 & 208 & 600 & 573 & 162 & 138 \\
\hline $10-11$ & 598 & 446 & 102 & 208 & 600 & 669 & 135 & 138 \\
\hline $11-12$ & 598 & 600 & 102 & 268 & 360 & 955 & 195 & 140 \\
\hline $12-13$ & 1090 & 670 & 70 & 235 & 516 & 945 & 289 & 188 \\
\hline $13-14$ & 1100 & 1116 & 68 & 285 & 552 & 487 & 325 & 302 \\
\hline $14-15$ & 1300 & 1256 & 170 & 285 & 552 & 375 & 310 & 335 \\
\hline
\end{tabular}


Table 8. Fourier amplitude (m/s) of computed horizontal acceleration time history.

\begin{tabular}{|c|c|c|c|c|c|c|c|c|}
\hline \multirow[b]{2}{*}{$\begin{array}{l}\text { Frequency } \\
\text { range }(\mathrm{Hz})\end{array}$} & \multicolumn{2}{|c|}{ Paleozoic } & \multicolumn{2}{|c|}{ Tuff } & \multicolumn{2}{|c|}{ PLTF } & \multicolumn{2}{|c|}{ TFPL } \\
\hline & $\begin{array}{c}100 \\
\left(\mathrm{~m} / \mathrm{kT}^{1 / 3}\right)\end{array}$ & $\begin{array}{c}50 \\
\left(\mathrm{~m} / \mathrm{kT}^{1 / 3}\right)\end{array}$ & $\begin{array}{c}100 \\
\left(\mathrm{~m} / \mathrm{kT}^{1 / 3}\right)\end{array}$ & $\begin{array}{c}50 \\
\left(\mathrm{~m} / \mathrm{kT}^{1 / 3}\right)\end{array}$ & $\begin{array}{c}100 \\
\left(\mathrm{~m} / \mathrm{kT}^{1 / 3}\right)\end{array}$ & $\begin{array}{c}50 \\
\left(\mathrm{~m} / \mathrm{kT}^{1 / 3}\right)\end{array}$ & $\begin{array}{c}100 \\
\left(\mathrm{~m} / \mathrm{kT}^{1 / 3}\right)\end{array}$ & $\begin{array}{c}50 \\
\left(\mathrm{~m} / \mathrm{kT}^{1 / 3}\right)\end{array}$ \\
\hline $1-2$ & 223 & 143 & 38 & 79 & 304 & 224 & 160 & 129 \\
\hline $2-3$ & 140 & 257 & 49 & 79 & 322 & 200 & 128 & 84 \\
\hline $3-4$ & 140 & 286 & 42 & 77 & 252 & 150 & 128 & 129 \\
\hline $4-5$ & 122 & 286 & 28 & 59 & 221 & 150 & 130 & 137 \\
\hline $5-6$ & 145 & 215 & 42 & 68 & 223 & 155 & 127 & 140 \\
\hline $6-7$ & 145 & 265 & 42 & 82 & 180 & 238 & 58 & 152 \\
\hline $7-8$ & 145 & 386 & 73 & 90 & 118 & 275 & 73 & 152 \\
\hline $8-9$ & 239 & 472 & 73 & 151 & 118 & 305 & 209 & 251 \\
\hline $9-10$ & 265 & 608 & 84 & 184 & 118 & 410 & 270 & 372 \\
\hline 10-11 & 265 & 307 & 112 & 220 & 162 & 447 & 290 & 471 \\
\hline $11-12$ & 191 & 522 & 140 & 225 & 310 & 745 & 270 & 684 \\
\hline $12-13$ & 223 & 715 & 140 & 180 & 310 & 745 & 133 & 760 \\
\hline $13-14$ & 178 & 486 & 38 & 168 & 345 & 615 & 130 & 684 \\
\hline $14-15$ & 159 & 329 & 56 & 86 & 320 & 417 & 183 & 380 \\
\hline
\end{tabular}

ratio is 1.63 (sub-interval $9-10 \mathrm{~Hz}$ ). In the $10-15 \mathrm{~Hz}$ range the maximum ratio is 4.4 (sub-interval $14-15 \mathrm{~Hz}$ ) while it remains above 2 in other sub-intervals.

In the Paleozoic medium, the ratio of $F A_{Y}$ for $50 \mathrm{~m} / \mathrm{kT}^{1 / 3}$ to that for $100 \mathrm{~m} / \mathrm{kT}^{1 / 3}$ as shown in table 7 , has maximum value of $\sim 5.4$ in $6-7 \mathrm{~Hz}$ range and remains around $2-3$ in other subintervals. In Tuff medium, this ratio has a value $\sim 1.5-3$ throughout the spectrum.

For SDOB of $100 \mathrm{~m} / \mathrm{kT}^{1 / 3}$, the maximum ratio of Fourier amplitude of peak vertical acceleration (FAY) in composite PLTF medium to that in composite TFPL in the $1-5 \mathrm{~Hz}$ range is 10.95 (sub-interval $1-2 \mathrm{~Hz}$ ) and remains between 1.7 and 2.8 in other sub-intervals as shown in

Table 9. Ratio of vertical spectral acceleration $(\mathrm{m} / \mathrm{s})$ in different media.

\begin{tabular}{|c|c|c|c|c|}
\hline $\begin{array}{l}\text { Frequency } \\
\text { range }(\mathrm{Hz})\end{array}$ & $\frac{\mathrm{PL} / \mathrm{TF}}{100\left(\mathrm{~m} / \mathrm{kT}^{1 / 3}\right)}$ & $\frac{\mathrm{PL} / \mathrm{TF}}{50\left(\mathrm{~m} / \mathrm{kT}^{1 / 3}\right)}$ & $\frac{\text { PLTF/TFPL }}{100\left(\mathrm{~m} / \mathrm{kT}^{1 / 3}\right)}$ & $\frac{\text { PLTF/TFPL }}{50\left(\mathrm{~m} / \mathrm{kT}^{1 / 3}\right)}$ \\
\hline $1-2$ & 8.48 & 3.06 & 10.95 & 3.85 \\
\hline $2-3$ & 4.87 & 5.88 & 2.77 & 3.9 \\
\hline $3-4$ & 6.67 & 5.88 & 2.59 & 3.2 \\
\hline $4-5$ & 6.36 & 4.69 & 1.71 & 2.4 \\
\hline $5-6$ & 5.53 & 5.60 & 1.71 & 2.8 \\
\hline $6-7$ & 3.82 & 11.34 & 2.71 & 2.98 \\
\hline $7-8$ & 3.82 & 10.66 & 8.12 & 8.55 \\
\hline 8-9 & 7.79 & 5.23 & 5.88 & 14.74 \\
\hline $9-10$ & 6.53 & 1.63 & 3.70 & 4.15 \\
\hline $10-11$ & 5.86 & 2.14 & 4.44 & 4.84 \\
\hline $11-12$ & 5.86 & 2.24 & 1.85 & 6.8 \\
\hline $12-13$ & 15.57 & 2.85 & 1.79 & 5.0 \\
\hline $13-14$ & 16.18 & 3.92 & 1.70 & 1.6 \\
\hline $14-15$ & 7.65 & 4.41 & 1.78 & 1.1 \\
\hline
\end{tabular}


Table 10. Ratio of horizontal spectral acceleration $(\mathrm{m} / \mathrm{s})$ in different media.

\begin{tabular}{|c|c|c|c|c|}
\hline $\begin{array}{l}\text { Frequency } \\
\text { range }(\mathrm{Hz})\end{array}$ & $\frac{\mathrm{PL} / \mathrm{TF}}{100\left(\mathrm{~m} / \mathrm{kT}^{1 / 3}\right)}$ & $\frac{\mathrm{PL} / \mathrm{TF}}{50\left(\mathrm{~m} / \mathrm{kT}^{1 / 3}\right)}$ & $\frac{\text { PLTF } / \text { TFPL }}{100\left(\mathrm{~m} / \mathrm{kT}^{1 / 3}\right)}$ & $\frac{\text { PLTF } / \text { TFPL }}{50\left(\mathrm{~m} / \mathrm{kT}^{1 / 3}\right)}$ \\
\hline $1-2$ & 5.87 & 1.81 & 1.90 & 1.74 \\
\hline $2-3$ & 2.86 & 3.25 & 2.52 & 2.38 \\
\hline $3-4$ & 3.33 & 3.71 & 1.97 & 1.16 \\
\hline $4-5$ & 4.36 & 4.85 & 1.70 & 1.09 \\
\hline $5-6$ & 3.45 & 3.16 & 1.76 & 1.11 \\
\hline $6-7$ & 3.45 & 3.23 & 2.47 & 1.57 \\
\hline $7-8$ & 1.99 & 4.29 & 1.62 & 1.81 \\
\hline $8-9$ & 3.27 & 3.13 & 0.56 & 1.22 \\
\hline $9-10$ & 3.15 & 3.3 & 0.44 & 1.10 \\
\hline $10-11$ & 2.37 & 1.40 & 0.6 & 1.00 \\
\hline $11-12$ & 1.36 & 2.32 & 0.56 & 1.1 \\
\hline $12-13$ & 1.59 & 3.97 & 2.33 & 1.0 \\
\hline $13-14$ & 4.68 & 2.89 & 2.65 & 1.0 \\
\hline $14-15$ & 2.84 & 3.83 & 1.75 & 1.24 \\
\hline
\end{tabular}

Notes: PL/TF spectral vertical/horizontal acceleration ratio for Paleozoic and Tuff media TF/PL spectral vertical/horizontal acceleration ratio for Tuff and Paleozoic media

PLTF/TFPL spectral vertical/horizontal acceleration ratio for PLTF composite and TFPL composite

table 9 . In the $5-10 \mathrm{~Hz}$ range, for the same case, the notable maximum ratios are 8.1 (sub-interval $7-8 \mathrm{~Hz}$ ) and 5.9 (sub-interval $8-9 \mathrm{~Hz}$ ) and remain between 1.7 and 3.7 in other sub-intervals. In the $10-15 \mathrm{~Hz}$ range, the maximum ratio is 4.44 (sub-interval $10-11 \mathrm{~Hz}$ ).

For SDOB of $50 \mathrm{~m} / \mathrm{kT}^{1 / 3}$, the maximum ratio of Fourier amplitude of peak vertical acceleration $\left(F A_{Y}\right)$ in composite PLTF medium to that in composite TFPL in the $1-5 \mathrm{~Hz}$ range is 3.9 (sub-interval 1-3 Hz) and the minimum is 2.4 (sub-interval 4-5 Hz). In the 5-10 Hz range, for the same case, the notable maximum ratios are 8.6 (sub-interval 7-8 Hz) and 14.7 (sub-interval $8-9 \mathrm{~Hz}$ ) and remains between 2.8 and 4.2 in the other sub-intervals. In the 10-15 Hz range, the maximum ratio is 6.8 (sub-interval $11-12 \mathrm{~Hz}$ ).

\subsection{Horizontal spectral acceleration $\left(F A_{X}\right)$}

For SDOB of $100 \mathrm{~m} / \mathrm{kT}^{1 / 3}$, the maximum ratio of Fourier amplitudes of spectral horizontal acceleration $\left(\mathrm{FA}_{X}\right)$ in Paleozoic medium to that in Tuff, as shown in table 10 , in the $1-5 \mathrm{~Hz}$ range is 5.87 (sub-interval 1-2 Hz) and remains over 3 in other sub-intervals. In the 5-10 $\mathrm{Hz}$ range, for the same case, the maximum ratio is 3.45 (sub-interval $5-7 \mathrm{~Hz}$ ) and the minimum ratio is 2 (sub-interval 7-8 Hz). In the 10-15 Hz range, the notable ratio is 4.7 (sub-interval $13-14 \mathrm{~Hz}$ ) and for other sub-intervals, these ratios are $\sim 2$.

For SDOB of $50 \mathrm{~m} / \mathrm{kT}^{1 / 3}$, the maximum ratio of Fourier amplitude of peak horizontal acceleration $\left(F A_{X}\right)$ in Paleozoic medium to that in Tuff, in the $1-5 \mathrm{~Hz}$ range, is 4.85 (sub-interval 4-5 Hz) and remains over 2 in other sub-intervals. In the 5-10 Hz range, for the same case, the maximum value is 4.3 (sub-interval $7-8 \mathrm{~Hz}$ ) and other ratios are $\sim 3$. In the $10-15 \mathrm{~Hz}$ range, the maximum ratio ranges from 3.97 (sub-interval 12-13 Hz) to 3.83 (sub-interval 14-15 Hz) while for other sub-intervals the range is 1.4-2.9. 
In the Paleozoic medium, the ratio of Fourier amplitudes, $F A_{X}$ for $50 \mathrm{~m} / \mathrm{kT}^{1 / 3}$ to that for $100 \mathrm{~m} / \mathrm{kT}^{1 / 3}$, as shown in table 8 , has the maximum value of $\sim 3.2$ in $12-13 \mathrm{~Hz}$ range and remains around $2-3$ in other sub-intervals. For the Tuff medium, this ratio has a value $\sim 1.5-4$ throughout the spectrum.

For SDOB of $100 \mathrm{~m} / \mathrm{kT}^{1 / 3}$, the maximum ratio of Fourier amplitude of the peak horizontal acceleration $\left(F A_{X}\right)$ in composite PLTF medium to that in composite TFPL, as shown in table 10, in the 1-5 Hz range is 2.52 (sub-interval $2-3 \mathrm{~Hz}$ ) and remains between 1.7 and 2 in the other sub-intervals. In the $5-10 \mathrm{~Hz}$ range, for the same case, the notable maximum ratio is 2.5 (subinterval 6-7 Hz). In the $10-15 \mathrm{~Hz}$ range, the maximum ratio is 2.65 (sub-interval $13-14 \mathrm{~Hz}$ ). Here it is worth noting that there is a shift of the spectral envelope in the composite PLTF towards 12-14 Hz compared to the corresponding envelope position in 8-11 Hz band for TFPL which results in a spectral amplitude ratio (PLTF/TFPL for $100 \mathrm{~m} / \mathrm{kT}^{1 / 3}$ ) of $\sim 0.5$ in the $8-11 \mathrm{~Hz}$ band. But this effect is masked for SDOB of $50 \mathrm{~m} / \mathrm{kT}^{1 / 3}$ due to pronounced reflections from the free surface.

For SDOB of $50 \mathrm{~m} / \mathrm{kT}^{1 / 3}$, the maximum ratio of Fourier amplitude of the peak horizontal acceleration $\left(\mathrm{FA}_{\mathrm{X}}\right)$ in composite PLTF medium to that in composite TFPL medium in the $1-5 \mathrm{~Hz}$ range is 2.38 (sub-interval $2-3 \mathrm{~Hz}$ ) and the minimum is 1.1 (sub-interval $4-5 \mathrm{~Hz}$ ). In the $5-10 \mathrm{~Hz}$ range, for the same case, the maximum ratio is 1.8 (sub-interval 7-8 Hz). In the 10-15 Hz range, the maximum ratio is 1.24 (sub-interval $14-15 \mathrm{~Hz}$ ). It is noted from the table 8 that for both the composite media, at SDOB of $50 \mathrm{~m} / \mathrm{kT}^{1 / 3}$, the spectral amplitudes are not widely different.

\section{Conclusions}

In the present study, transient three-dimensional finite element code SHOCK-3D has been used to study the effects of local nonlinearities and layer patterns of the geological formations on the synthetic seismic signals in different media of Baneberry site. Paleozoic medium with high strength is shown to have good seismic coupling characteristics. In case of homogeneous Tuff medium, the peak signals are significantly lower due to its relatively weaker coupling.

The composite media with source emplaced in hard Paleozoic rock underneath a soft Tuff medium (PLTF) behave similar to homogeneous medium at lower yield of 1 kT. Similarly, the composite TFPL with emplacement in Tuff with close Paleozoic layer underneath also generates near field vertical acceleration signals of similar order as observed for homogeneous Tuff medium at $100 \mathrm{~m} / \mathrm{kT}^{1 / 3}$. In case of horizontal acceleration, though the signals are weak, the influence of reflection from hard Paleozoic layer is visible for both the composite media that behave in nearly identical manner as shown in table 6 . At higher yield level of $8 \mathrm{kT}\left(50 \mathrm{~m} / \mathrm{kT}^{1 / 3}\right)$, the acceleration signals are of larger magnitude compared to $1 \mathrm{kT}$ yield signals. However, the geological layer pattern again strongly influences the acceleration signals. This is evident from table 6 , which shows that for TFPL composite medium higher fraction of energy propagates towards the GZ with the result that the vertical acceleration signals are very weak. Any attempt to estimate the source strength with seismic signals alone, which depend on these near field signals, the propagation path and the local geology near the monitoring stations would thus be misleading. The spectral acceleration in tables 7-10 indicate that even if the instruments are tuned to a particular frequency band, the influence of near source geology and associated inelastic effects along with depth of emplacement would strongly influence the seismic signals that are transmitted and sensed by network of seismic stations for the nuclear event discrimination and yield estimation. 
The mechanisms that influence the seismic signals beyond the elastic radius are the cavity growth, its stability in various media (stable cavity growth or cavity collapse), crushing and spallation of rock layers and lateral growth of the medium due to inelastic strain field and spallinduced slap down. In addition, the mound growth and the crater formation are also important factors that alter the seismic signals. Composite layer pattern of geological strata and the relative location of the source also influence the signals as has been shown in this study. At times these mechanisms are active simultaneously and it would be difficult to detect an event and estimate the yield with requisite confidence with recorded seismic signals alone if the in-depth knowledge on local geology were not available. In addition, the seismic wave propagation through earth media and local geology around the monitoring stations are also important factors, which are inherently known to influence the seismic signals.

\section{Acknowledgements}

The finite element models for different computational studies were provided by Mr. Rajeev Ranjan. His participation in the Baneberry event modelling and parametric simulation studies is thankfully acknowledged.

\section{References}

Bache C T, Day M S and Swanger J H 1982 Rayleigh wave synthetic seismograms from multi-dimensional simulations of under ground explosions. Bull. Seism. Soc. Am. 72: 15-28

Bolt Bruce A 1976 Nuclear Explosions and Earthquakes - The Parted Veil, W H Freeman and Company, San Francisco

Burton D E, Snell C M and Bryan J B 1975 Computer design of high-explosive experiments to simulate subsurface nuclear detonations. Nucl. Tech. 26: 65-87

Butkovich T R 1967 Gas Equation of State for Natural materials, UCRL-14729

Butkovich T R 1973 Techniques for Generating Pressure-Volume Relationships and Failure Envelopes for R ocks, UCRL-51441

Cherry J T and Petersen F L 1970 Numerical Simulation of Stress Wave Propagation from Underground Nuclear Explosions, IAEA-PL-388/15, Peaceful Nuclear Explosions, IAEA, Vienna, pp 241-325

Glenn L A 1984 Verification limits for test-ban treaty. Nature 310: 359-362

Glenn L A, Ladd A J C, Moran B and Wilson K A 1985 Elastic radiation from explosively loaded ellipsoidal cavities in an unbounded medium. Geophys. J. R. Astr. Soc. 81: 231-241

Harkrider D G 1964 Surface waves in multilayered media I. Rayleigh and love waves from burried sources in multilayered half-space. Bull. Seism. Soc. Am. 54(2): 627-679

Haskell N A 1961 A Static theory of the seismic coupling of a contained underground explosion. J. Geophys. Res. 66: 2937-2945

Herbst R F, Werth G C and Springer D L 1961 Use of large cavities to reduce seismic waves from underground explosions. J. Geophys. Res. 66: 959-978

Hoek E and Brown E T 1998 Practical estimates of rock mass strength. Int. J. Rock Mech. Min. Sci. 34: $1165-1186$

Larsen D B 1979 Spherical Wave Propagation in Elastic Media and its Application to Energy Coupling for Tamped and Decoupled Explosions, UCRL-52655

Latter A L, LeLevier R E, Martinelli E A and McMillan W G 1961 A method of concealing underground nuclear explosions. J. Geophys. Res. 66: 943-946

Mueller R A and Murphy J R 1971 Seismic characteristics of underground nuclear detonations, part I. Seismic spectrum scaling. Bull. Seism. Soc. Am. 61: 1675-1692

Patterson D W 1966 Nuclear decoupling, full and partial. J. Geophys. Res. 71: 3427-3436 
Ranjan Rajeev, Singh R K, Sikka S K and Kakodkar A 2005 Cratering and spall simulation of pokhran-1 event with three dimensional transient finite element analysis. Curr. Sci. 88(7): 1133-1141

Ranjan Rajeev, Singh R K, Sikka S K and Kakodkar A 2006 Baneberry event revisited with three dimensional finite element transient simulation. Nucl. Technol. 153(3): 341-359

Rodean R C 1980 Inelastic Processes in Seismic Wave Generation by Underground Explosions. In: Identification of Seismic Sources-Earthquake or Underground Explosion, (eds) Eystein S Husehye and Mykkoltveit S, Proc. NATO, ASI, Oslo, Norway

Schatz J F 1973 Physics of SOC and TENSOR Code, UCRL-51352, 21

Sommerfeld A 1949 Partial Differential equations in Physics, Academic Press

Taylor S R and Randall G E 1989 The effect of spall on regional seismograms. Geophys. Res. Lett. 16: 211-214

Terhune R W, Glenn H D, Burton D E, MeKague and Rambo J T 1977 Calculational Examination of the Baneberry Event, UCRL-52365, Lawrence Livermore Laboratory Report

Terhune R W, Glenn H D, Burton D E, MeKague and Rambo J T 1979 Numerical simulation of the Baneberry event. Nucl. Technol. 46: 159-169

Werth G C and Herbst R F 1963 Comparison of amplitude of seismic waves from nuclear explosions in four mediums. J. Geophys. Res. 68: 1463-1475

Zienkiewicz O C, Kelly D W and Bettess 1977 The Sommerfeld (Radiation) Condition on Infinite Domains and its Modeling in Numerical Procedures, Report C/R/302/77, University College of Swansea, Wales, UK

Zienkiewicz O C and Taylor L 1991 The Finite Element Method, 4th ed., 2, Chapter 11, McGraw-Hill Book Co., London 